\title{
Traveltime and Longitudinal Dispersion in Illinois Streams
}

By JULIA B. GRAF

Prepared in cooperation with the

Illinois Environmental Protection Agency 


\section{DEPARTMENT OF THE INTERIOR \\ DONALD PAUL HODEL, Secretary}

U.S. GEOLOGICAL SURVEY

Dallas L. Peck, Director

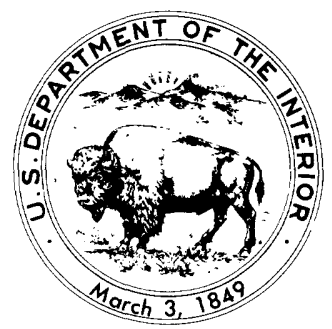

For sale by the Books and Open-File Reports Section, U.S. Geological Survey, Federal Center, Box 25425, Denver, CO 80225

Library of Congress Cataloging-in-Publication Data

Graf, Julia B.

Traveltime and longitudinal dispersion in Illinois streams.

(U.S. Geological Survey water-supply paper ; 2269)

Bibliography: p. 63

Supt. of Docs. no.: I. 19.13:2269

1. Stream measurements-Illinois. 2. Dispersion. 3.

Hydrology. I. Illinois. Environmental Protection

Agency. II. Title. III. Series: U.S. Geological Survey

water-supply paper ; 2269.

QB1225.127G7 $1985 \quad 551.48^{\prime} 3^{\prime} 09773 \quad 85-600037$ 


\title{
CONTENTS
}

\author{
Abstract 1 \\ Introduction 1 \\ Purpose and scope 1 \\ Previous studies 5 \\ Techniques 6 \\ Data collection 6 \\ Data analysis 8 \\ Results for measured streams \\ Apple River 9 \\ Cedar Creek 14 \\ Elkhorn Creek 18 \\ Embarras River 22 \\ Kaskaskia River 26 \\ Mackinaw River $\mathbf{3 0}$ \\ Middle Fork Vermilion River $\mathbf{3 4}$ \\ Sangamon River 38 \\ Shoal Creek $\mathbf{4 2}$ \\ Vermilion River 46 \\ Extension of results to unmeasured streams $\mathbf{5 0}$ \\ Traveltime of peak $\mathbf{5 0}$ \\ Traveltime of leading edge $\mathbf{5 0}$ \\ Unit-peak concentration $\mathbf{5 1}$ \\ Passage time $\mathbf{5 1}$ \\ Application of estimating techniques $\mathbf{5 1}$ \\ Examples $\mathbf{5 1}$ \\ Limits of application $\mathbf{5 4}$ \\ Average reach velocity $\mathbf{5 8}$ \\ Discussion of dispersion characteristics in measured streams \\ 59 \\ Conclusions $\mathbf{6 0}$ \\ References 63 \\ Glossary 64 \\ Metric conversion factors \\ 65
}

\section{FIGURES}

1. Map showing the location of Illinois streams measured and index gages used in the study 2

2-4. Map and graphs for Apple River showing:

2. Location of injection and sampling sites $\mathbf{1 0}$

3. Relation of traveltime of peak concentration to discharge, distance from injection, and flow-duration frequency 12

4. Relation of unit-peak concentration $(A)$ and passage time $(B)$ to traveltime of peak concentration 13

5-7. Map and graphs for Cedar Creek showing:

5. Location of injection and sampling sites 14

6. Relation of traveltime of peak concentration to discharge, distance from injection, and flow-duration frequency 16

7. Relation of unit-peak concentration $(A)$ and passage time $(B)$ to traveltime of peak concentration $\mathbf{1 7}$ 
8-10. Map and graphs for Elkhorn Creek showing:

8. Location of injection and sampling sites 18

9. Relation of traveltime of peak concentration to discharge, distance from injection, and flow-duration frequency 20

10. Relation of unit-peak concentration $(A)$ and passage time $(B)$ to traveltime of peak concentration 21

11-13. Map and graphs for Embarras River showing:

11. Location of injection and sampling sites 22

12. Relation of traveltime of peak concentration to discharge, distance from injection, and flow-duration frequency 24

13. Relation of unit-peak concentration $(A)$ and passage time $(B)$ to traveltime of peak concentration and flow-duration frequency 25

14-16. Map and graphs for Kaskaskia River showing:

14. Location of injection and sampling sites 26

15. Relation of traveltime of peak concentration to discharge, distance from injection, and flow-duration frequency $\mathbf{2 8}$

16. Relation of unit-peak concentration $(A)$ and passage time $(B)$ to traveltime of peak concentration 29

17-19. Map and graphs for Mackinaw River showing:

17. Location of injection and sampling sites $\mathbf{3 0}$

18. Relation of traveltime of peak concentration to discharge, distance from injection, and flow-duration frequency $\mathbf{3 2}$

19. Relation of unit-peak concentration $(A)$ and passage time $(B)$ to traveltime of peak concentration and flow-duration frequency 33

20-22. Map and graphs for Middle Fork Vermilion River showing:

20. Location of injection and sampling sites 34

21. Relation of traveltime of peak concentration to discharge, distance from injection, and flow-duration frequency $\mathbf{3 6}$

22. Relation of unit-peak concentration $(A)$ and passage time $(B)$ to traveltime of peak concentration and flow-duration frequency 37

23-25. Map and graphs for Sangamon River showing:

23. Location of injection and sampling sites $\mathbf{3 8}$

24. Relation of traveltime of peak concentration to discharge, distance from injection, and flow-duration frequency $\mathbf{4 0}$

25. Relation of unit-peak concentration $(A)$ and passage time $(B)$ to traveltime of peak concentration and flow-duration frequency 41

26-28. Map and graphs for Shoal Creek showing:

26. Location of injection and sampling sites $\mathbf{4 2}$

27. Relation of traveltime of peak concentration to discharge, distance from injection, and flow-duration frequency $\mathbf{4 4}$

28. Relation of unit-peak concentration $(A)$ and passage time $(B)$ to traveltime of peak concentration $\mathbf{4 5}$

29-31. Map and graphs for Vermilion River showing:

29. Location of injection and sampling sites $\mathbf{4 6}$

30. Relation of traveltime of peak concentration to discharge, distance from injection, and flow-duration frequency $\mathbf{4 8}$

31. Relation of unit-peak concentration $(A)$ and passage time $(B)$ to traveltime of peak concentration and flow-duration frequency 49

32-36. Graphs showing:

32. Relation between measured and estimated traveltime of peak concentration $\mathbf{5 0}$

33. Relation of unit-peak concentration $(A)$ and passage time $(B)$ to traveltime of peak concentration and flow-duration frequency, for all measured streams $\mathbf{5 2}$ 
34-36. Graphs showing:

34. Relation between measured and estimated average reach velocity for measured streams $\mathbf{5 9}$

35. Relation between measured average reach velocity and reach velocity computed with hydraulic-geometry relations $\mathbf{6 1}$

36. Relation between flow-duration frequency and the difference between measured and computed average reach velocity $\mathbf{6 2}$

\section{TABLES}

1. Sampling sites and index gages for traveltime measurements 3

2. Estimated distance for complete transverse mixing for each traveltime measurement, and data required for estimates 7

3-12. Traveltime and dispersion data for:

3. Apple River 11

4. Cedar Creek 15

5. Elkhorn Creek 19

6. Embarras River 23

7. Kaskaskia River 27

8. Mackinaw River 31

9. Middle Fork Vermilion River $\mathbf{3 5}$

10. Sangamon River 39

11. Shoal Creek 43

12. Vermilion River $\mathbf{4 7}$

13. Standard error of estimate for equations for traveltime of the peak concentration, traveltime of the leading edge of the dye cloud, unit-peak concentration, and passage time for individual streams $\mathbf{5 5}$

14. Hydraulic-geometry relations used to compute reach velocity for nine streams

15. Dispersion efficiency of measured streams

62 


\section{LIST OF SYMBOLS}

A Cross-sectional area of flow at a site on a stream reach, in square feet.

c Constant which is a measure of the influence of channel geometry and degree of mixing on the transverse mixing coefficient, dimensionless.

C Concentration of dye at a given site on a stream at a given time, in micrograms per liter.

$C_{u} \quad$ Unit-peak concentration of dye at a site on a stream, in micrograms per liter per pound times cubic feet per second.

$d \quad$ Mean depth of flow in a stream reach, in feet.

$D$ Area of the drainage basin of a stream, in square miles.

$E_{z} \quad$ Transverse mixing coefficient, equal to $c d u_{*}$, in square feet per second.

$F \quad$ Flow-duration frequency, expressed as a decimal, dimensionless.

$L \quad$ Transverse mixing length, or the distance along a stream required for transverse mixing, in miles.

$P \quad$ Passage time of dye cloud past a site on the stream, in hours.

$Q \quad$ Discharge at a given site on a stream, in cubic feet per second.
$R \quad$ Recovery ratio, or the fraction of injected dye that passes a site on the stream downstream of injection, dimensionless.

$T$ Cumulative traveltime of the peak dye concentration through a stream reach, in hours.

$T_{L} \quad$ Cumulative traveltime of the leading edge of the dye cloud through a stream reach, in hours.

$t$ Time, in hours.

$t_{0.01}$ Time on the receding limb of the time-concentration curve at which the dye concentration has decreased to 1 percent of its peak concentration, in hours.

$\bar{t}$ Mean time, or centroid, of the time-concentration curve, in hours.

$u_{*} \quad$ Mean shear velocity of flow in a reach, in feet per second.

$U$ Stream order, dimensionless.

$V \quad$ Mean velocity of flow through a stream reach, in miles per hour.

w Weight of dye observed at a sampling site, in micrograms.

$W$ Average width of flow in a stream reach, in feet.

$X \quad$ Distance of a site downstream of the point of injection of dye, in miles. 


\title{
Traveltime and Longitudinal Dispersion in Illinois Streams
}

\author{
By Julia B. Graf
}

\section{Abstract}

Twenty-seven measurements of traveltime and longitudinal dispersion in 10 Illinois streams made from 1975 to 1982 provide data needed for estimating traveltime of peak concentration of a conservative solute, traveltime of the leading edge of a solute cloud, peak concentration resulting from injection of a given quantity of solute, and passage time of solute past a given point on a stream. These four variables can be estimated graphically for each stream from distance of travel and either discharge at the downstream end of the reach or flow-duration frequency. From equations developed from field measurements, the traveltime and dispersion characteristics also can be estimated for other unregulated streams in Illinois that have drainage areas less than about 1,500 square miles. For unmeasured streams, traveltime of peak concentration and of the leading edge of the cloud are related to discharge at the downstream end of the reach and to distance of travel. For both measured and unmeasured streams, peak concentration and passage time are best estimated from the relation of each to traveltime. In measured streams, dispersion efficiency is greater than that predicted by Fickian diffusion theory. The rate of decrease in peak concentration with traveltime is about equal to the rate of increase in passage time. Average velocity in a stream reach, given by the velocity of the center of solute mass in that reach, can be estimated from an equation developed from measured values. The equation relates average reach velocity to discharge at the downstream end of the reach. Average reach velocities computed for 9 of the 10 streams from available equations that are based on hydraulic-geometry relations are high relative to measured values. The estimating equation developed from measured velocities provides estimates of average reach velocity that are closer to measured velocities than are those computed using equations developed from hydraulic-geometry relations.

\section{INTRODUCTION}

Traveltime and mixing of water within a stream reach are basic streamflow characteristics that water-resources managers and planners must know to predict the rate of movement and dilution of contaminants that may be introduced into streams. They also are necessary for most water- quality models used in water-resources planning. A study designed to measure traveltime and longitudinal mixing in selected reaches of Illinois streams under a range of steady flow conditions was carried out from 1975 through 1982 in cooperation with the Illinois Environmental Protection Agency.

\section{Purpose and Scope}

The purposes of this report are to summarize the results of measurements that were used to develop relations for estimating traveltime and mixing characteristics for unregulated streams in Illinois and to present the estimating techniques.

Ten streams were selected for measurement of traveltime and mixing characteristics (fig. 1). They include a range in drainage area and conditions expected to govern velocity and mixing. Measured reaches range from 5.2 to $40.3 \mathrm{mi}$ in length, average channel slopes range from 0.98 to $7.97 \mathrm{ft} / \mathrm{mi}$, and drainage areas above sampling sites range from 12.4 to $1,516 \mathrm{mi}^{2}$. Most of the studied streams, like the majority of streams in Illinois, have sand beds with sand and gravel riffles. Beds of the Apple and Vermilion Rivers are coarser than those of the other eight streams and are composed primarily of gravel and bedrock. Although nine of the streams have predominantly naturally formed meandering channels, the Kaskaskia River has a straightened, dredged channel in the reach measured. Flow is unregulated in all reaches measured, but some artificial structures or modifications are present. Riffle-pool sequences are apparent on the streambed at low flow, and these sequences cause local variations in channel geometry, velocity, and slope. Stream gages are located on each stream (fig. 1, table 1), and the gaging records provided the data base used to relate measured variables to the long-term streamflow regime.

Details of the measurements and graphical relations for estimation of traveltime and mixing characteristics are presented for each measured stream. Equations for estimating traveltime and mixing for unmeasured streams are derived, and examples of the application of techniques to 


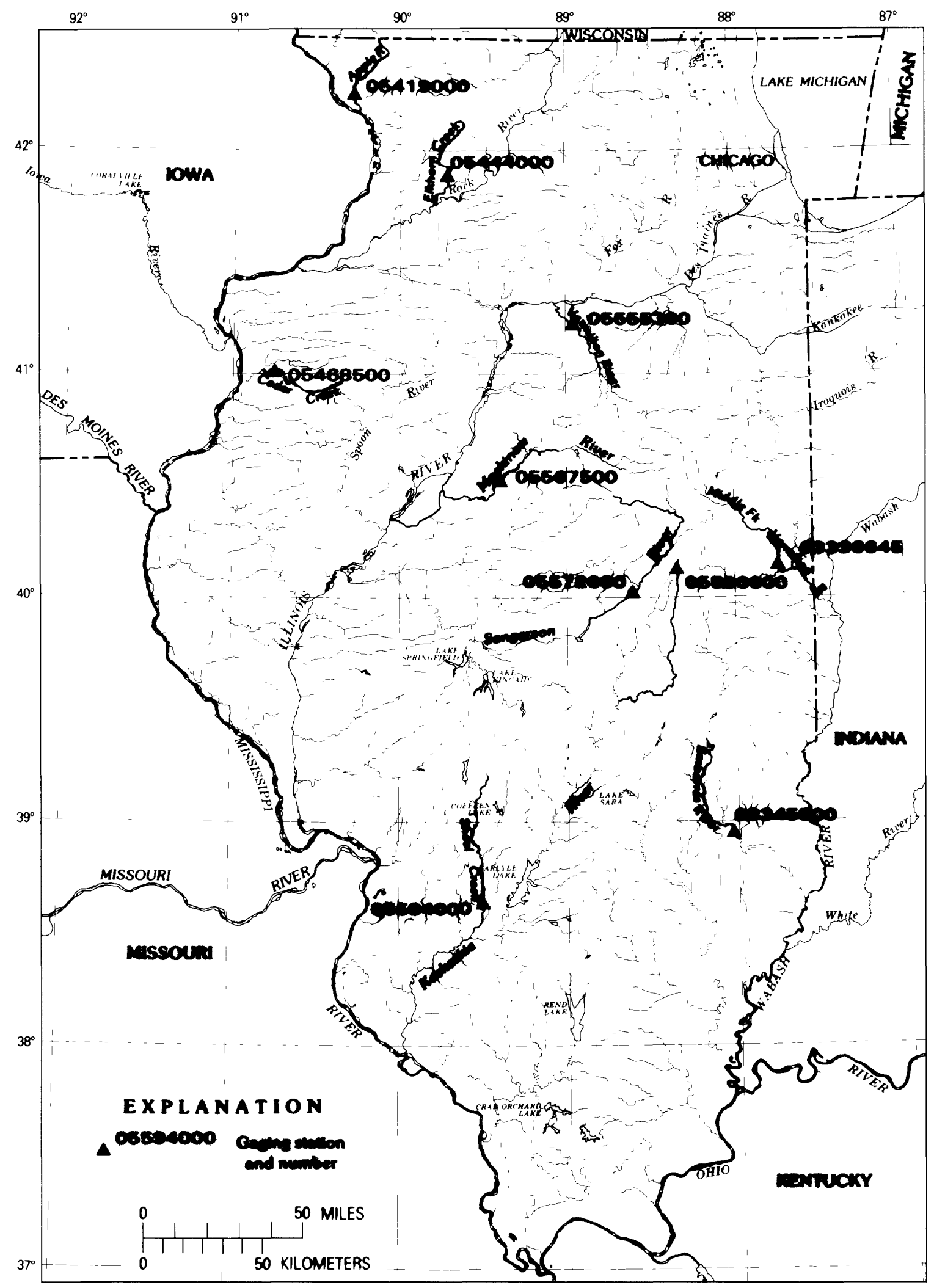

Figure 1. Location of Ilinois streams measured and index gages used in the study. 
Table 1. Sampling sites and index gages for traveltime measurements

[River miles obtained from Healy (1979a, 1979b), except for Cedar Creek mileages, which were measured on maps revised since that report was prepared. Drainage areas for some locations were available from Healy (1979a, 1979b), and the others were measured during the study. Dye injection locations are given in the summary table that accompanies the discussion of each stream. All sites are shown on figures that accompany the discussion of each stream]

\begin{tabular}{|c|c|c|c|c|}
\hline $\begin{array}{l}\text { Station } \\
\text { number }\end{array}$ & Station name & $\begin{array}{l}\text { Period of } \\
\text { continuous } \\
\text { stage record } \\
\text { at index gage } \\
\text { (water years) }\end{array}$ & $\begin{array}{l}\text { River } \\
\text { mile }\end{array}$ & $\begin{array}{c}\text { Drainage } \\
\text { area } \\
\left(m i^{2}\right)\end{array}$ \\
\hline \multicolumn{5}{|c|}{ APPLE RIVER } \\
\hline 05418725 & near Apple River & -- & 45.0 & 36.1 \\
\hline 05418945 & at Elizabeth & -- & 23.9 & 188 \\
\hline 05419000 & near Hanover & 1935-present & 13.9 & 247 \\
\hline 05419080 & near Whitton & -- & 9.9 & 249 \\
\hline \multicolumn{5}{|c|}{ CEDAR CREEK } \\
\hline 05468300 & near Galesburg & -- & 35.5 & 33.2 \\
\hline 05468400 & near Monmouth & -- & 19.2 & 76.7 \\
\hline 05468500 & at Little York & $1941-1971$ & 5.5 & 130 \\
\hline 05468700 & near Bald Bluff & -- & 0.0 & 165 \\
\hline \multicolumn{5}{|c|}{ ELKHORN CREEK } \\
\hline 05443560 & near Haldane & -- & 45.6 & 20.9 \\
\hline 05443650 & near Milledgeville & -- & 33.6 & 69.2 \\
\hline 05444000 & near Penrose & 1940-present & 17.5 & 146 \\
\hline 05444025 & near Emerson & -- & 6.3 & 215 \\
\hline \multicolumn{5}{|c|}{ EMBARRAS RIVER } \\
\hline 03344200 & near Greenup & -- & 88.5 & 1,022 \\
\hline 03344600 & near Rose Hill & -- & 73.6 & 1,327 \\
\hline 03344680 & near Falmouth & -- & 66.8 & 1,365 \\
\hline 03345000 & at Newton & -- & 59.7 & 1,392 \\
\hline 03345500 & at ste. Marie & 1914-present & 48.2 & 1,516 \\
\hline
\end{tabular}


Table 1. Sampling sites and index gages for traveltime measurements-Continued

\begin{tabular}{|c|c|c|c|c|}
\hline $\begin{array}{l}\text { Station } \\
\text { number }\end{array}$ & station name & $\begin{array}{l}\text { Period of } \\
\text { continuous } \\
\text { stage record } \\
\text { at index gage } \\
\text { (water years) }\end{array}$ & $\begin{array}{l}\text { River } \\
\text { mile }\end{array}$ & $\begin{array}{c}\text { Drainage } \\
\text { area } \\
\left(m i^{2}\right)\end{array}$ \\
\hline \multicolumn{5}{|c|}{ KASKASKIA RIVER } \\
\hline 05590000 & $\begin{array}{c}\text { Kaskaskia Ditch } \\
\text { at Bondville }\end{array}$ & 1949-present & 289.6 & 12.4 \\
\hline 05590280 & near Grange & -- & 275.0 & 67.2 \\
\hline 05590400 & near Pesotum & -- & 271.4 & 109 \\
\hline 05590460 & near Hayes & -- & 267.8 & 120 \\
\hline 05590480 & above Ficklin & -- & 265.1 & 125 \\
\hline 05590950 & at Chesterville & -- & 254.0 & 360 \\
\hline \multicolumn{5}{|c|}{ MACKINAW RIVER } \\
\hline 05567500 & near Congervillel & 1945-present & 58.7 & 767 \\
\hline 05567600 & near Mackinaw & -- & 39.9 & 855 \\
\hline 05567650 & near Tremont & -- & 34.7 & 911 \\
\hline 05568005 & below Green Valley & -- & 10.1 & 1,092 \\
\hline \multicolumn{5}{|c|}{ MIDDLE FORK VERMILION RIVER } \\
\hline 03336280 & near Armstrong & -- & 60.2 & 279 \\
\hline 03336645 & above Oakwood & 1979-present & 31.7 & 432 \\
\hline \multicolumn{5}{|c|}{ SANGAMON RIVER } \\
\hline 05571000 & at Mahomet & -- & 185.7 & 362 \\
\hline 05571100 & near Mahomet & -- & 184.4 & 364 \\
\hline 05572000 & at Monticello & 1914-present & 162.2 & 550 \\
\hline 05572125 & $\begin{array}{l}\text { at Allerton Park } \\
\text { near Monticello }\end{array}$ & - & 158.0 & 573 \\
\hline 05572300 & near Cisco & -- & 150.0 & 625 \\
\hline
\end{tabular}

1 The index gage near congerville is above the measured reach and is not a sampling site.

4 Traveltime and Longitudinal Dispersion in Illinois Streams 
Table 1. Sampling sites and index gages for traveltime measurements-Continued

\begin{tabular}{|c|c|c|c|c|}
\hline $\begin{array}{l}\text { Station } \\
\text { number }\end{array}$ & station name & $\begin{array}{l}\text { Period of } \\
\text { continuous } \\
\text { stage record } \\
\text { at index gage } \\
\text { (water years) }\end{array}$ & $\begin{array}{l}\text { River } \\
\text { mile }\end{array}$ & $\begin{array}{c}\text { Drainage } \\
\text { area } \\
\left(m i^{2}\right)\end{array}$ \\
\hline \multicolumn{5}{|c|}{ SHOAL CREEK } \\
\hline 05593880 & near old Ripley & -- & 55.0 & 464 \\
\hline 05593950 & at Jamestown & -- & 38.2 & 700 \\
\hline 05593975 & at Frogtown & -- & 26.4 & 727 \\
\hline 05594000 & near Breese & 1946-present & 21.3 & 735 \\
\hline \multicolumn{5}{|c|}{ VERMILION RIVER } \\
\hline 05555300 & near Leonore & 1931-present & 17.2 & 1,251 \\
\hline 05555500 & at Iowell & -- & 10.5 & 1,278 \\
\hline 05555600 & at oglesby & -- & 2.7 & 1,329 \\
\hline
\end{tabular}

both measured and unmeasured streams are presented. An estimating equation for average reach velocity, developed from measurements of velocity of the center of mass of the dye cloud, is presented. Measured reach velocities are compared with velocities computed from the hydraulicgeometry relations (Stall and Fok, 1968, p. 20) available for 9 of the 10 measured streams. Velocity and mixing characteristics of Illinois streams are discussed in the final section.

\section{Previous Studies}

Although techniques for estimating velocity are available, conditions in natural stream channels are often very different from those for which the techniques have been derived, and the applicability of these relations to realistic situations is limited. Relations such as the Manning equation and hydraulic-geometry equations (Leopold and Maddock, 1953, p. 25) that relate reach velocity to channel geometry, slope, or roughness can be used to estimate velocity in some situations. However, the nonuniformity of natural channels and the difficulty in defining values of roughness parameters for reaches prevent these equations from being useful for a large range of conditions. Equations for velocity of peak concentration of a conservative solute (which in many cases is close to the average reach velocity) developed from measurements on 300 streams throughout the United States (Boning, 1974) have standard errors of 30 to 50 percent. Other studies (Eikenberry and Davis, 1976) have shown that the standard error can be reduced signifi- cantly when a more geographically limited data base is used for developing the estimating equations.

Traveltimes have been computed for many Illinois streams (Stall and Hiestand, 1969) from velocities computed from hydraulic-geometry relations at gaged sites (Stall and Fok, 1968, p. 20). Stall and Hiestand (1969, p. 6) believed that actual velocities would be close to computed velocities for relatively high flows but could be much lower than computed for low flows. Prior to the present study, very few measurements were available to determine the accuracy of these computed velocities.

Longitudinal mixing in open channels is commonly described as a one-dimensional Fickian-type diffusion process (Fischer, 1973, eq. 11, p. 63). Dye injected into a stream at steady flow will move with the mean flow of the stream and mix with surrounding water, forming a cloud of increasing size. This mixing, called dispersion, is caused by molecular diffusion, by turbulent diffusion, and by velocity gradients (Fischer, 1973, p. 59). For turbulent flows in natural channels, molecular diffusion generally is neglected and velocity gradients are assumed to be the primary cause of dispersion (Fischer, 1973, p. 59).

The one-dimensional approach is used to describe spreading of the dye cloud and change in dye concentration after the dye has become mixed or nearly mixed throughout the width and depth of flow. According to the theory, dye concentrations are normally distributed and the variance of the concentration distribution increases linearly with travel distance and time (Nordin and Sabol, 1974, p. 6-7). A 
number of studies have shown that the mixing process is not adequately described by the one-dimensional Fickian approach. Godfrey and Frederick (1970, p. K9) measured diffusion coefficients as being 4 to 35 times those predicted by the theory. Day (1975, p. 913) found that dye-cloud variance did not increase linearly with distance in mountain streams in New Zealand. Nordin and Sabol (1974, p. 55) and Day (1975, p. 916) observed that measured dyeconcentration curves are often skewed rather than, as predicted by theory, symmetrical. More complex models have been proposed to account for characteristics in streams that may be causing these deviations from the one-dimensional theory (for example, Nordin and Troutman, 1980). However, no technique has been developed that can be used to reliably estimate concentrations of a dispersing substance or the size of the cloud the substance forms.

\section{TECHNIQUES}

\section{Data Collection}

For this study, a known quantity of fluorescent dye was traced through 5- to 40-mile reaches of 10 streams at two or three flow conditions each. Water samples collected at two to four sites in each reach were analyzed for dye concentration. Criteria for sampling-site selection were (1) feasibility of measuring discharge over a range of flow conditions, (2) accessibility, and (3) security for unattended automatic sampling equipment. All sampling sites were located at bridge crossings where the three requirements could be met (table 1). When possible, the same sampling sites were used for all measurements on a given stream. Time constraints, equipment malfunction, and other problems caused some sampling sites to be changed.

Flow-duration curves provide a common base for comparison of streams having different-sized drainage areas. Flow-duration curves developed from daily mean discharge over the period of record at the index gages (table 1) were used to select the discharges at each index gage corresponding to certain flow-duration frequencies. For the measured streams, flows that occur with low flow-duration frequencies are relatively high discharges that occur during floods, whereas flows that occur with high flow-duration frequencies are low discharges that approach steady, basebase-flow conditions. In this report, flow-duration frequency $(F)$ is expressed as a decimal fraction. Discharges corresponding to flow-duration frequencies of $0.20,0.50$, and 0.80 were initially selected, but because of the unpredictable nature of streamflow, measurements at discharges other than the preselected discharges were somtimes made. Measurements were made at discharges corresponding to flow-duration frequencies ranging from 0.04 to 0.90 . Although measurements at steady flows were planned, some change in discharge with time was observed during most traveltime measurements. The greatest rate of change in discharge occurred during the traveltime measurement at the highest flow rate (lowest flow-duration frequency) for a given stream, because many of these measurements were made as discharge was decreasing from a peak. Measurements were begun after the initial rapid recession had ceased but when the change in discharge with time was still significant.

Rhodamine WT, a red fluorescent dye developed for tracer work, was used in this study. This dye is detectable at very low concentrations, mixes readily with water, and is relatively inexpensive. Although some dye is lost during a measurement owing to sorption by aquatic plants or sediment and by chemical and photochemical decay, recovery is high compared with other available substances (Smart and Laidlaw, 1977).

The amount of dye needed was estimated before each injection from an empirical relation between volume of dye and discharge, reach length, reach velocity, and dye concentration (Hubbard and others, 1982, p. 18-19).

An analytical expression for transverse mixing of a dye slug injected into the center of flow presented by Yotsukura and Cobb (1972, p. C17) and by Fischer and others (1979, p. 114) was used to estimate transverse mixing lengths for reaches below injection points at the measured flow conditions. The relation is

$$
L=\frac{0.1 V W^{2}}{E_{z}},
$$

where $V$ is mean reach velocity, $W$ is stream width, and $E_{z}$ is a transverse mixing coefficient, equal to a constant times the product of depth, $d$, and shear velocity, $u_{*}$. (Symbois are defined in a list of symbols and a glossary at the front of the report.) For complete mixing in straight rectangular channels, the value of the constant, $c$, is about 0.2 , whereas in channels with curves and irregular banks the value is higher (0.4 to 0.6) (Fischer and others, 1979, p. 109-112). In this study, a value of 0.2 was used for $c$, as recommended by Hubbard and others (1982). This lower value yields estimated transverse-mixing lengths that are long compared with those that may be expected in many natural channels.

Mean flow width and depth in the reach and mean reach velocity were estimated from field observations for the initial mixing-length estimates. Channel slope in the reach, determined from topographic maps, was used to approximate water-surface slope. Transverse mixing lengths, $L$, were estimated again from equation 1 after measurements were completed, using reach velocities measured by the dye movement rather than estimated velocity. Comparison of these estimated mixing lengths with distances between injection and the first sampling site for measured flows (table 2) shows that mixing should have been approximately complete at the first sampling site for most of the measurements. Estimated mixing lengths are greater than the distance between the point of injection and the first 
Table 2. Estimated distance for complete transverse mixing for each traveltime measurement, and data required for estimates

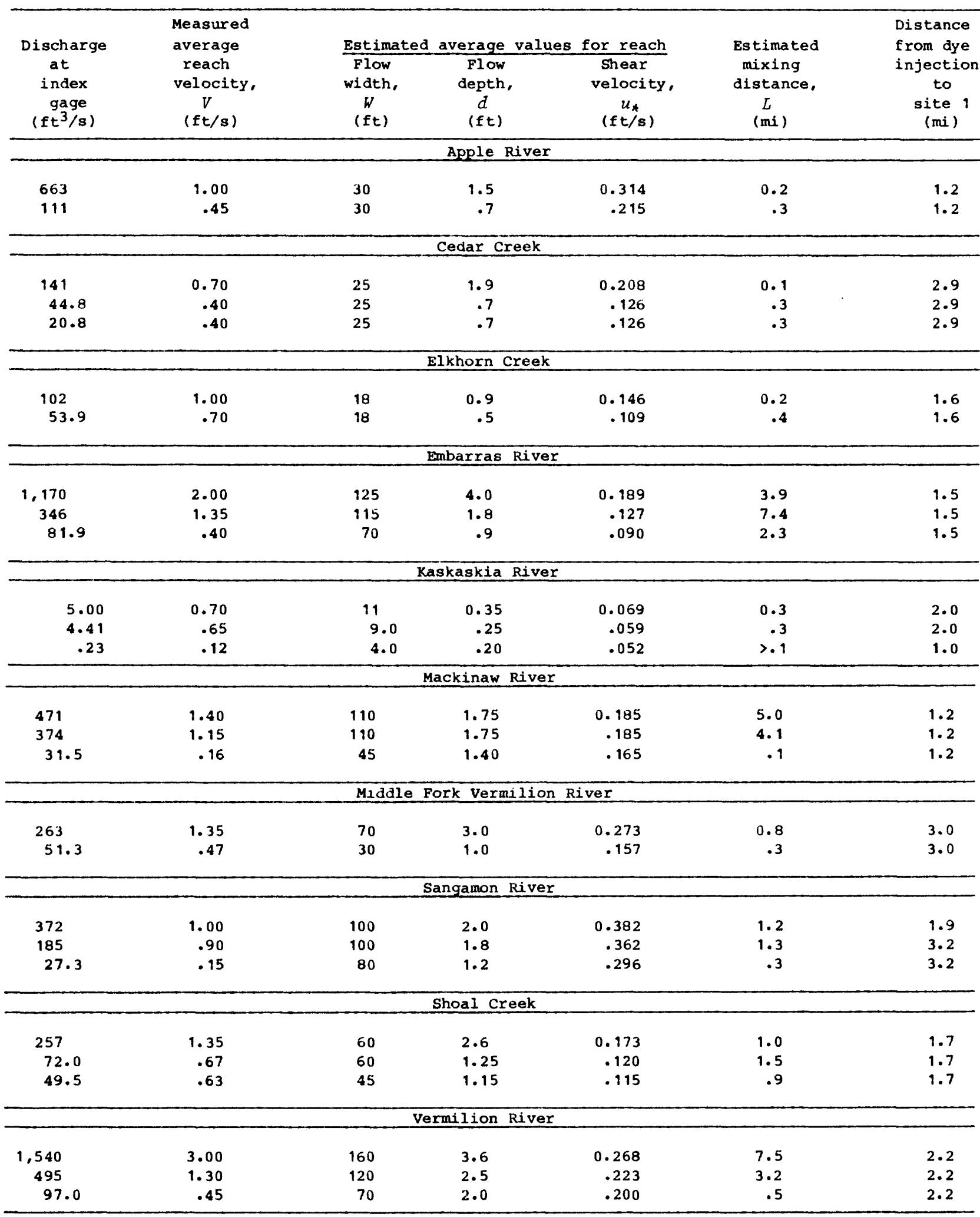


sampling site for some flows in the Embarras, Mackinaw, and Vermilion Rivers.

For each traveltime measurement, the dye was measured into buckets, diluted with stream water to aid in mixing, and poured into the stream from a bridge or, conditions permitting, from a point in the stream. In most cases, dye was injected as a single slug near the center of flow. Dye was injected in a line across the central two-thirds of flow or as two slugs separated by about one-third the channel width where mixing lengths were estimated to be close to the distance between injection and the first sampling site. These injection methods decrease the downstream distance required for transverse mixing (Hubbard and others, 1982).

At each sampling site, samples were collected periodically by hand in a small glass bottle or with a batteryoperated automatic sampler. The automatic sampler was designed specifically for dye-tracing work and is described by Kilpatrick (1972). Both methods sample only water near the surface. Sampling interval varied with passage time of the dye cloud and ranged from 1 to 2 minutes to 1 to 2 hours. Samples of stream water were collected before arrival of the dye for measurement of backgound fluorescence. The dye cloud was sampled from its first appearance at each site to at least a time when the concentration had decreased to 10 percent of peak concentration. At most sampling sites, samples were collected at one point in the cross section. For a few measurements, samples were collected at two or three points at the first sampling site to assess the degree of transverse mixing. The results are discussed in the sections for the rivers to which they apply.

Relative dye concentrations were measured at the site with a filter fluorometer to determine arrival time of the dye, approximate peak concentration, and time at which an approximate concentration of 10 percent of the peak was reached. Samples were reanalyzed in the laboratory for accurate concentrations using methods described by Wilson (1968). For the final measurements, the fluorometer was calibrated with solutions of known concentration of dye of the same dye lot used for the measurement. Samples and standard solutions were allowed to equilibrate to the laboratory temperature for measurement.

Discharge, $Q$, was measured at least once at each site during dye cloud passage. Additional measurements were made if changes in stage indicated significant discharge changes during dye passage. Discharge was measured at the index gaging station to determine if adjustments to the existing stage-discharge relation were needed for the period of the traveltime measurements. If discharge at the index gage changed significantly during the measurement, the timeweighted average discharge was computed, and that discharge and the corresponding flow-duration frequency were used in the analysis.

Photographs were taken, and visual observations made, of the character of bed materials and of the channel configuration during each measurement at locations along the stream where access was possible. These observations aided in description of measured reaches and qualitative evaluation of traveltime results. Because access was limited to bridge crossings, stream descriptions given in the following sections apply to only a small fraction of the measured reach.

\section{Data Analysis}

Once accurate concentrations for each sample had been measured in the laboratory, background concentration of stream water was subtracted from each sample concentration to give dye concentration. Curves of elapsed time versus dye concentration, $C$, (time-concentration curves) were plotted from these data. Although some of the dye clouds were sampled until concentrations had decreased to background concentration, for many traveltime measurements, especially those at sites near the end of a reach, sampling was terminated before background concentrations had been reached. Curves were either truncated at or extrapolated to a time corresponding to a concentration of 1 percent of peak concentration, and that time was taken as the trailing edge of the dye cloud. For extrapolation, a linear decrease of the logarithm of dye concentration with time was assumed.

The fraction of injected dye that was recovered at each sampling site (the recovery ratio, $R$ ) was computed by dividing the weight of dye observed at a cross section by the weight of dye injected. The weight of dye observed was found from

$$
w=1.02 \times 10^{5} Q \int_{0}^{t_{0.01}} C d t,
$$

where $w$ is weight of dye in micrograms, $Q$ is discharge through the cross section in cubic feet per second, $C$ is dye concentration in micrograms per liter $(\mu \mathrm{g} / \mathrm{L}), t$ is time in hours, $t_{0.01}$ is the time on the time-concentration curve at which the dye concentration has decreased to 1 percent of its peak value, and $1.02 \times 10^{5}$ is a constant used to convert cubic feet per second to liters per hour. Weight of injected dye was computed using a dye concentration of stock solution of $2.38 \times 10^{8} \mu \mathrm{g} / \mathrm{L}$, computed for a 20 -percent solution with a specific gravity of 1.19 (Hubbard and others, 1982, p. 33). The quantity $\int_{0}{ }^{t_{0.01}} C d t$ is the area under the timeconcentration curve and was computed by numerical integration using the trapezoid method. It is assumed that the mass of dye recovered at the sampled points is representative of the entire cross section (that the dye is mixed across the section) and that the discharge did not change during passage of the dye cloud past the sampling site. Some of the computed recovery ratios are unrealistic (greater than one, or greater at downstream sites than at upstream sites), and these values are probably the result of failure to meet these assumptions. Although some error is involved in measuring dye concentration and in determining the area under the time-concentration curve, these errors are usually small 
compared with errors caused by discharge changes or by incomplete mixing.

Dye concentrations that would have been observed if no dye had been lost during the measurement (conservative concentrations) were computed by dividing measured concentration by the recovery ratio. Conservative-peak concentrations reflect variations in discharge along the reach and differences in the amount of dye injected. To reduce the effect of these factors, each conservative-peak concentration was divided by the weight of dye injected and multiplied by the discharge at the sampling site. The result is a quantity, $C_{u}$, known as unit-peak concentration (Hubbard and others, 1982 , p. 34), that reflects only variations in dispersion.

The times of the leading edge, the peak concentration, and the trailing edge of the dye cloud at each site were found from the time-concentration curves. Passage time, $P$, was computed as the time of the leading edge minus the time of the trailing edge. The time corresponding to the center of mass of dye concentration, the mean time or centroid of the time-concentration curve, was found from the equation

$$
\bar{t}=\frac{\int_{0}^{t_{0.01}} C t d t}{\int_{0}^{t_{0.01}} C d t},
$$

and integrals were computed numerically using the trapezoid method.

In this report, traveltime is expressed as both the traveltime of the leading edge of the dye cloud and traveltime of the peak concentration, and dispersion as changes in unit-peak concentration and passage time. Data are presented in both tabular and graph form. For each stream, the time from injection to the arrival of the peak at a specific sampling site, the cumulative traveltime of the peak concentration, $T$, is plotted against discharge, $Q$, at the sampling site on a double logarithmic scale (for example, see fig. 6). Each point on these plots represents a measurement at one sampling site at one flow condition (flow-duration frequency, $F$ ). Traveltimes for equal distances of travel, $X$, plot along nearly straight lines, for example, line M62-M15 in figure 6 . These lines can be extrapolated to show the relation between traveltime and discharge at that site for all flow conditions. Traveltimes measured at the same flowduration frequency, $F$, also plot along nearly straight lines, for example, line G15-B15 in figure 6. These flow-duration frequency lines cross the equal-distance lines at a high angle and illustrate the relation between traveltime and discharge at the site for the same flow condition for all distances of travel. To aid in use of these plots for estimation of traveltime at flow conditions and distances other than those measured, lines of equal distance of travel and of equal flowduration frequency have been drawn on each plot. Positions of lines were determined by solution of equations computed by least squares linear regression using logarithms of the measured variables. The equations used differ for each stream and are presented on their respective plots.

Traveltime of the leading edge of the dye cloud relates to flow-duration frequency, discharge at the sampling site, and distance of travel in much the same way as does traveltime of the peak concentration. For each stream, equations are presented for estimating traveltime of the leading edge from flow-duration frequency and distance of travel and from discharge at the sampling site and distance of travel.

Unit-peak concentration and passage-time data for each stream are each plotted against cumulative traveltime from injection, also on double logarithmic scale. For some streams, the points define a single straight line and unit-peak concentration or passage time can be estimated directly from the plot of that line or from its equation. Equations were computed using simple linear regression techniques with the logarithm of cumulative-peak traveltime as the independent variable and the logarithm of unit-peak concentration or the logarithm of passage time as the dependent variable. For other streams, a variation in unit-peak concentration, passage time, or both, with flow-duration frequency is shown on these plots. For those streams, flow-duration frequency was added as an independent variable in the regression and the resulting multiple regression equations were used to plot lines of equal flow-duration frequency. The slope of lines computed by the regression equations or of lines drawn through the data points on these graphs is a measure of dispersion efficiency of the stream. Steeper slopes indicate more efficient dispersion, or more rapid reduction of peak concentration and increase in dye-cloud length with time. Standard errors for these equations are given in table 13 and are discussed in the section on limits of application.

Data from all streams were used to develop equations for estimating traveltime of peak concentration, traveltime of the leading edge, unit-peak concentration, and passage time for unmeasured streams having channel and watershed characteristics similar to measured streams. Step-backward regression was used to find the most significant set of independent variables from among drainage area, channel slope, discharge at the index gage, average discharge at the index gage, discharge at the sampling site, and flow-duration frequency. Logarithmic transformations of the variables as well as untransformed values were examined. In the backward-elimination procedure, a variable was retained in the regression model if the coefficient for that term was significantly different from zero when tested at the 95 percent confidence level.

\section{RESULTS FOR MEASURED STREAMS}

\section{Apple River}

The Apple River (figs. 1, 2) drains an area of northwestern Illinois that is partially forested and serves as pasture for dairy cattle. Gravel and bedrock make up the river- 


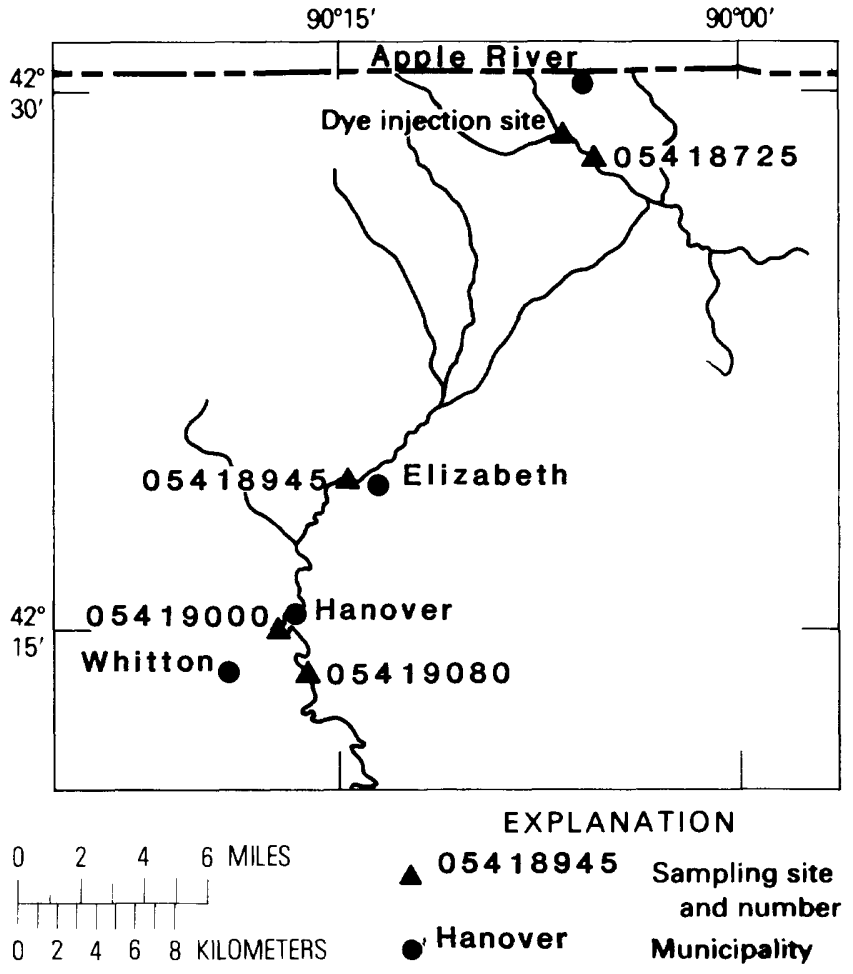

Figure 2. Location of injection and sampling sites, Apple River.

bed at most observed locations, and in places the meandering channel flows along rock cliffs. Bed materials consist of silty sand at the sampling site near Whitton. Channel slope is high compared with most Illinois streams and averages $7.97 \mathrm{ft} / \mathrm{mi}$ from the injection site near Apple River to the gaging station near Hanover (table 1, fig. 2). Channel slope decreases from $10.85 \mathrm{ft} / \mathrm{mi}$ near Apple River to $2.93 \mathrm{ft} / \mathrm{mi}$ in the vicinity of the gaging station near Hanover. At the Whitton site (fig. 2), flow was much more sluggish than at upstream sites, and backwater from the Mississippi River occasionally affects stream velocity. A dam 8- to 10-feet high extends across the river above the index gage near Hanover.

Traveltime measurements were made in the Apple River at discharges at the index gage of 663 and $111 \mathrm{ft}^{3} / \mathrm{s}$, corresponding to 0.04 and 0.34 flow-duration frequencies, respectively (table 3 ). Riffles and pools were observed along the channel at both flow conditions. However, the difference in depth and velocity of flow between the riffles and pools was not great. Eddies at bends were larger at the lower discharge but were observed during both measurements. Gravel bars, many grass-covered, exposed at the lower flow were submerged at the higher flow.

Both measurements were made as discharge at the index gage (at the lower end of the reach) was decreasing. The higher flow measurement was begun after a discharge peak had passed the gage; discharge at the gage decreased 33 percent during the measurement. The lower flow measurement was made during a slower recession, with discharge at the index gage decreasing 16 percent.

All estimated lengths for transverse mixing (table 2) are well within the 1.2-mile distance from injection to the first sampling site.

Six data points from the two traveltime measurements served as the basis for development of figure 3 , which shows the relation of traveltime of peak concentration to discharge at the sampling site, flow-duration frequency, and distance of travel. The lines of equal flow-duration frequency and distance of travel, computed using the equations shown in the figure, permit estimation of traveltime of peak for flow-duration frequencies from 0.02 to 0.40 and for travel distances up to $40 \mathrm{mi}$. Traveltime is estimated equally well by the two equations (table 13). The longer than expected traveltime observed at the Whitton site may have been caused by backwater from the Mississippi River or by the reduced channel slope in that reach.

Equations developed for traveltime of the leading edge are

$$
T_{L}=12.2 X^{1.33} Q^{-0.60}
$$

and

$$
T_{L}=3.48 X^{1.02} F^{0.44},
$$

where $X$ is distance of travel in miles, $Q$ is discharge in cubic feet per second, and $F$ is flow-duration frequency. As for traveltime of the peak concentration, the two equations have equal standard errors of estimate (table 13). As expected, these equations are very similar to those computed for traveltime of the peak (fig. 3).

The relation of unit-peak concentration to traveltime of peak is shown in figure $4 A$; some indication that the relation between these variables varies with flow condition can be seen in the figure. Values measured at the higher flow appear to lie on a line that is approximately parallel to, but above, a line through the values measured at the lower flow. However, flow-duration frequency was not retained in the regression relation because the dependence was judged to be too weak to justify its inclusion. The computed equation and the regression line are shown in figure $4 A$.

Flow-duration frequency, within the range studied, does not appear to be significant in determining passage time, and simple linear regression of the logarithm of passage time against the logarithm of traveltime gives a line that best fits the data. The line or its equation (fig. $4 B$ ) can be used to estimate passage time for any flow-duration frequency less than about 0.40 .

Examples of the use of these graphs to estimate traveltime, peak concentration, and passage time are given in a later section. 


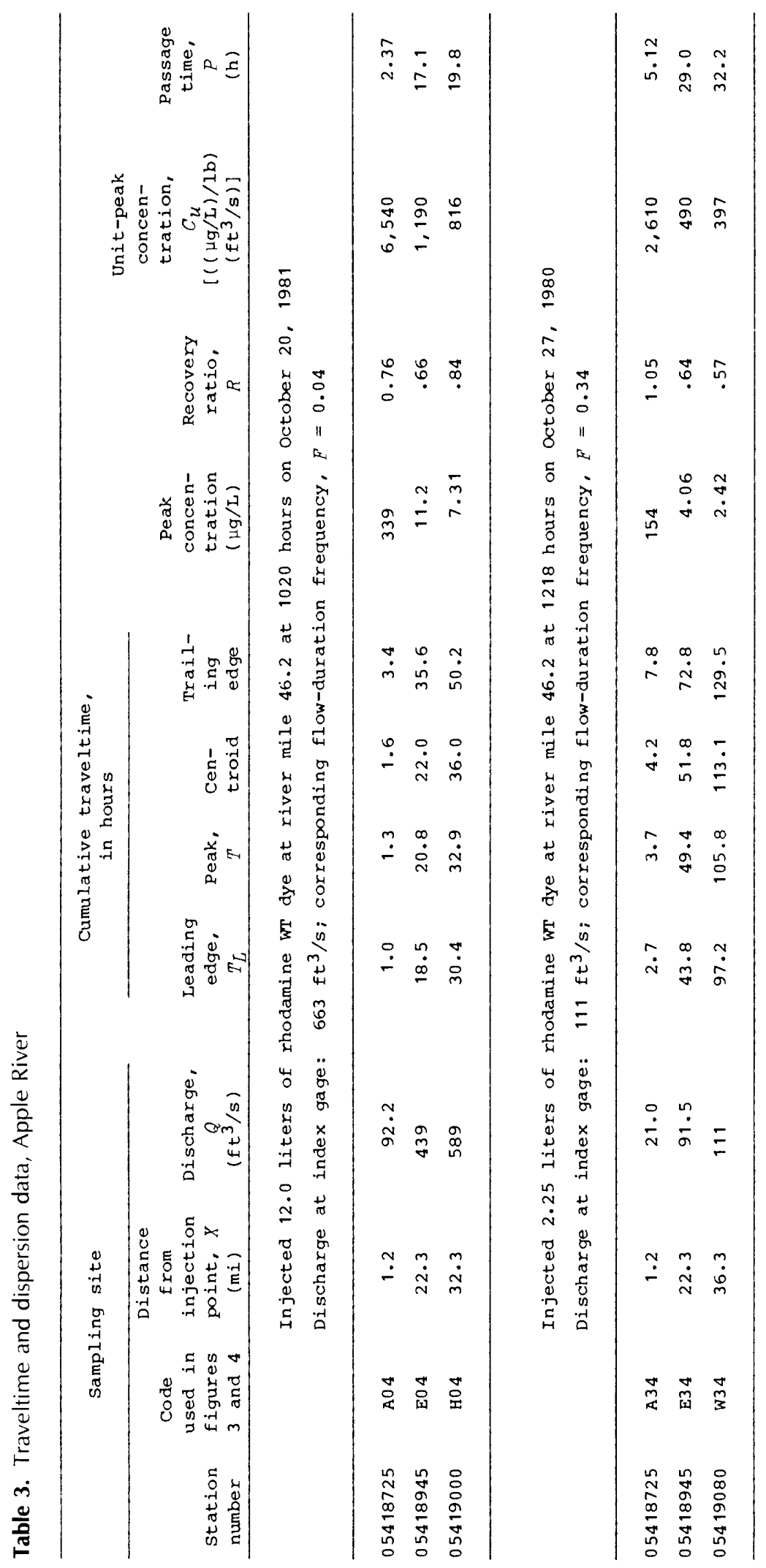




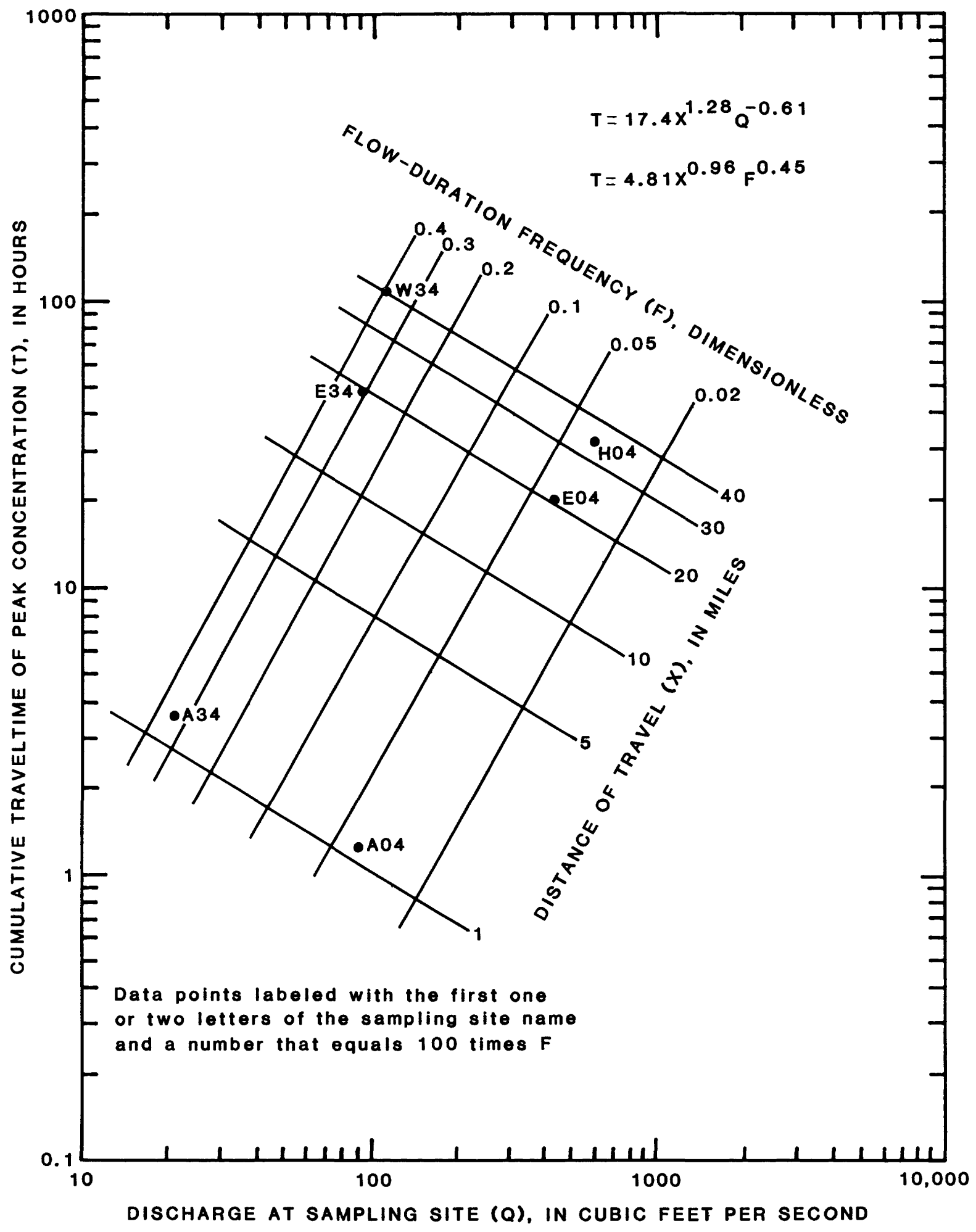

Figure 3. Relation of traveltime of peak concentration to discharge, distance from injection, and flow-duration frequency, Apple River. 


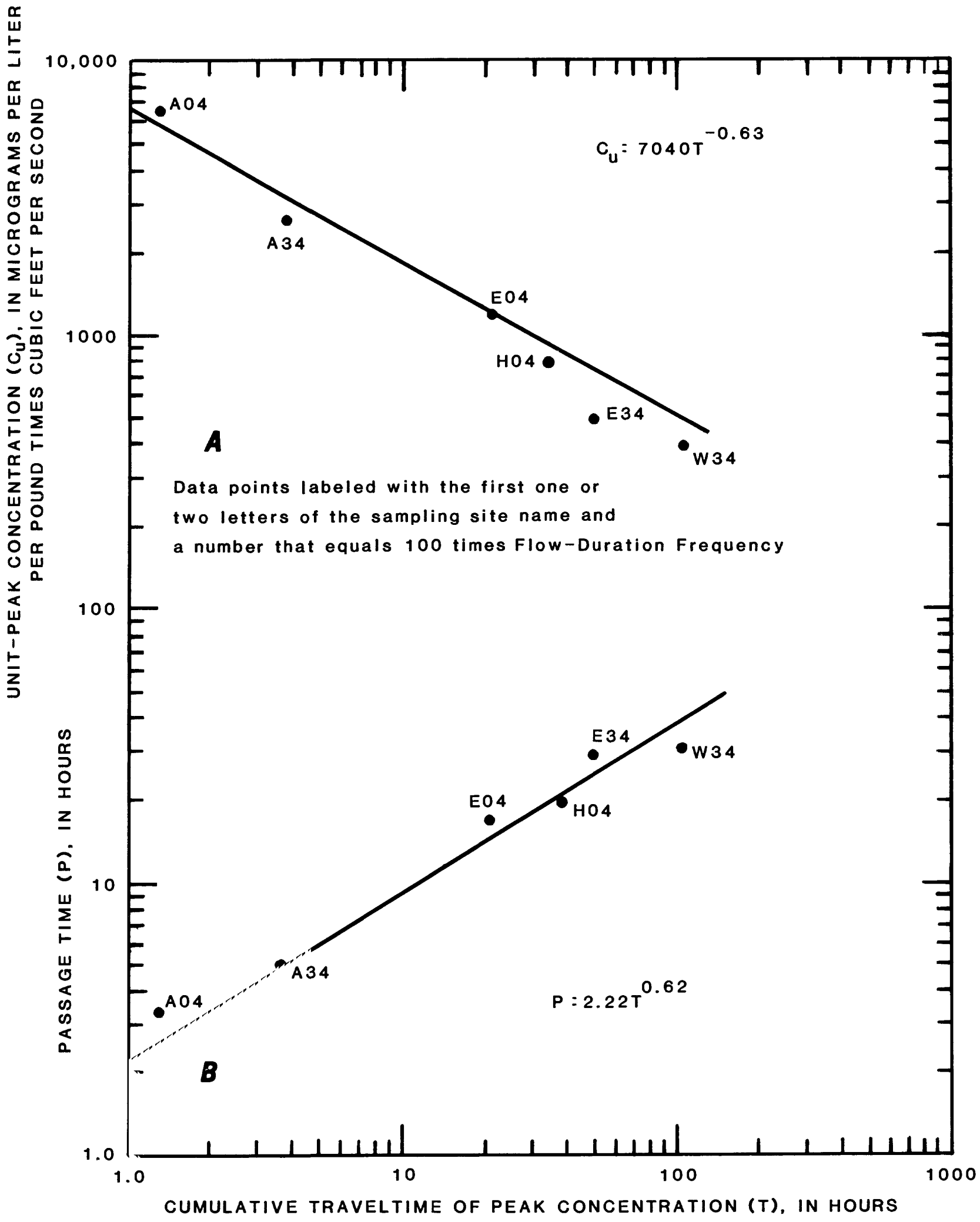

Figure 4. Relation of unit-peak concentration $(A)$ and passage time $(B)$ to traveltime of peak concentration, Apple River. 


\section{Cedar Creek}

Cedar Creek (figs. 1, 5) drains rolling countryside of cropland and pastureland. The creekbed is mostly sand, having some gravel in the thalweg and in riffles. The channel is tightly meandering in the upper reaches, but below the index gage at Little York some artificial straightening has taken place. Bedrock outcrops can be found in places along the upper reaches. The streambanks are wooded along much of the channel, and trees and brush affect streamflow locally. Aquatic vegetation observed in the channel was particularly thick at the sampling site near Galesburg. Average channel slope from the site near Galesburg to that near Bald Bluff (fig. 5) is $4.11 \mathrm{ft} / \mathrm{mi}$, and slope varies insignificantly in the reach measured.

Measurements were made at discharges at the index gage of $141,44.8$, and $20.8 \mathrm{ft}^{3} / \mathrm{s}$, corresponding to 0.15 , 0.46 , and 0.62 flow-duration frequencies, respectively (table 4). Riffles and pools were observed at all three flow conditions. Pools were shallow, and velocity of water through them was not much different from that across fles. Point and midchannel bars were exposed at the lowest flow. At the highest discharge, bars were submerged and boils were observed on the water surface, suggesting dune movement.

All three traveltime measurements were made during periods when the discharge at the index gage was decreasing. Discharge decreased 29 percent during the highest measured flow, 11 percent during the measurement at a discharge of $44.8 \mathrm{ft}^{3} / \mathrm{s}$, and 2 percent during the measurement at the lowest flow. The leading edge of the dye cloud was not sampled at the site near Bald Bluff during the high flow measurement and was extrapolated from the measured samples.

Estimated mixing lengths (table 2) are much less than the 2.9-mile distance between injection and the first measuring site. Similar masses of dye sampled at two points across the channel at the first site in the measurement at highest flow showed that the dye was mixed across the channel.

Eight data points are available to define traveltime in Cedar Creek (fig. 6). Estimation of traveltime for flowduration frequencies from 0.10 to 0.70 and for travel distances up to $40 \mathrm{mi}$ are possible from the data. Equal flowduration frequency and distance of travel lines were drawn, as described previously, using the equations shown in the figure. The regression lines fit the data points very well for both flow-duration frequency and distance (table 13).

The equations for traveltime of the leading edge of the dye cloud in Cedar Creek are

$$
T_{L}=9.97 X^{1.05} Q^{-0.44}
$$

and

$$
T_{L}=4.70 X^{0.89} F^{0.46} \text {. }
$$

Standard errors of estimate are about equal for the two equations (table 13).

Unit-peak concentrations and passage time appear not to vary systematically with flow-duration frequency (fig. 7); each can be estimated from its relation to traveltime.

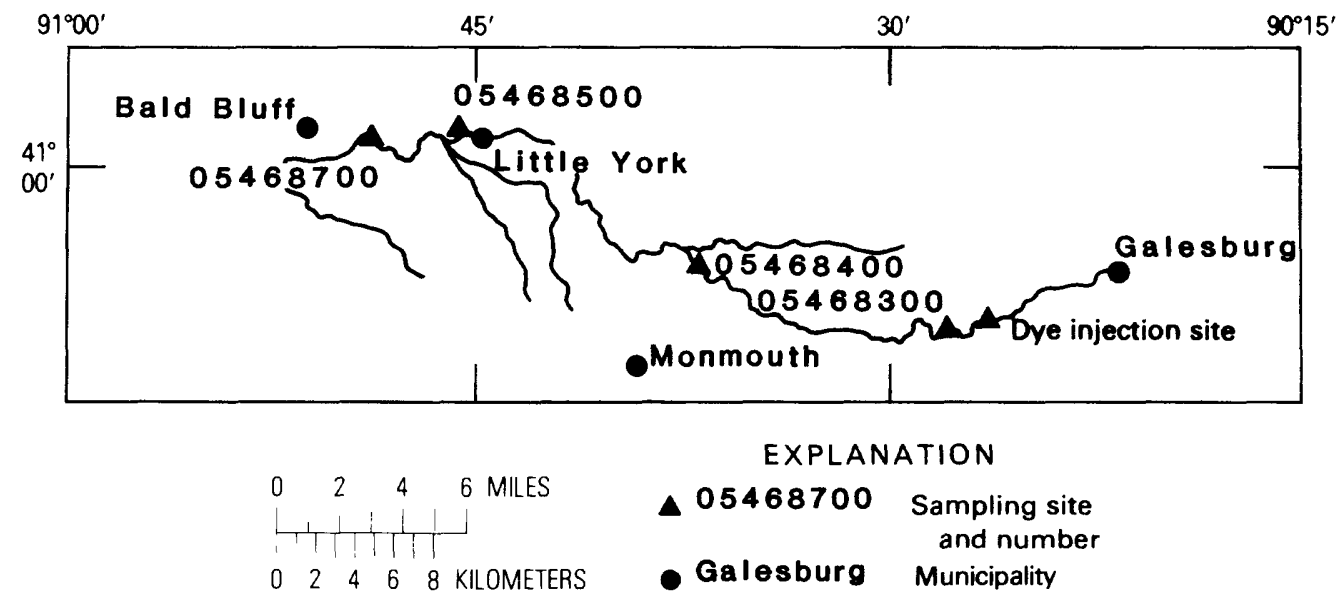

Figure 5. Location of injection and sampling sites, Cedar Creek. 


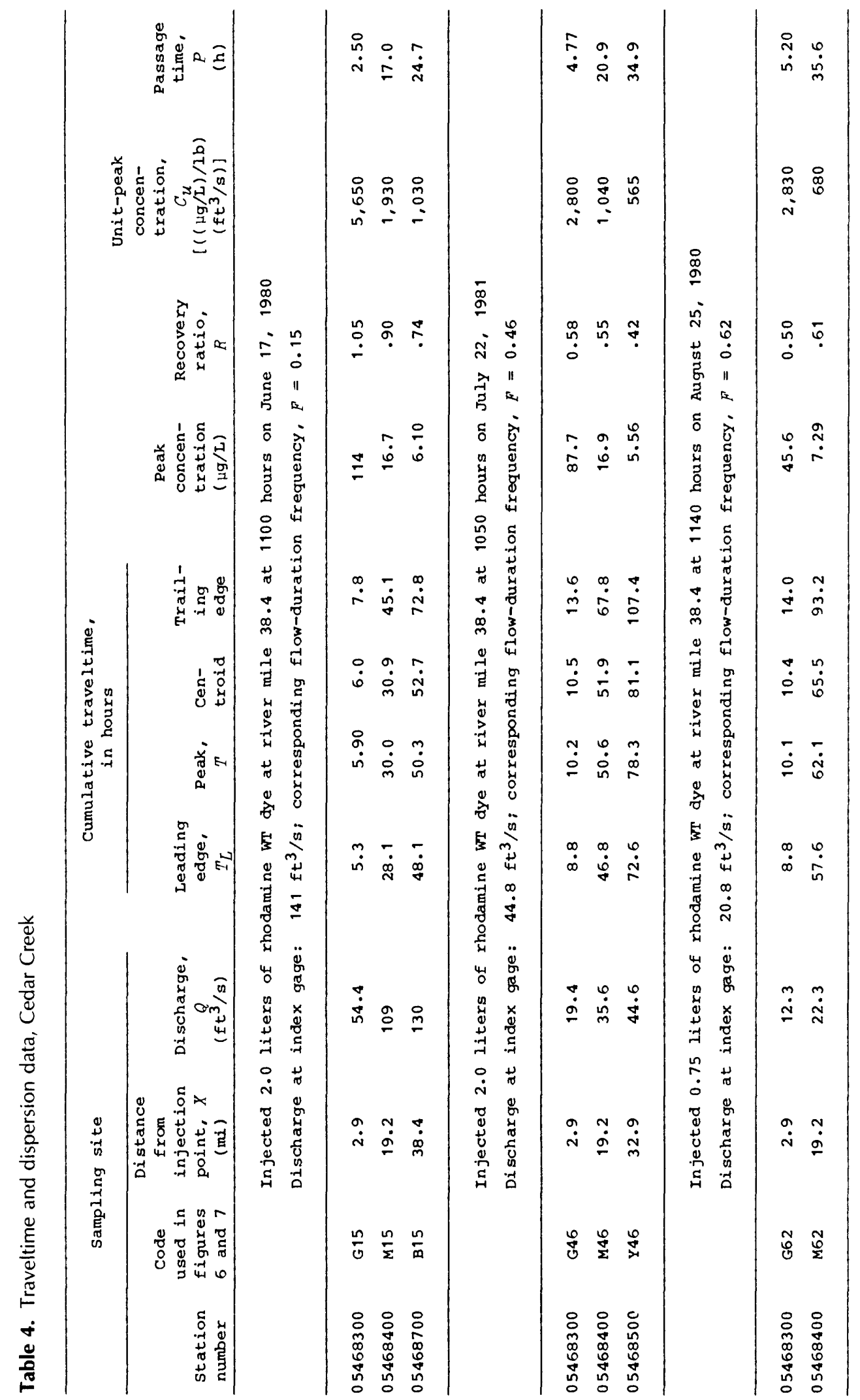




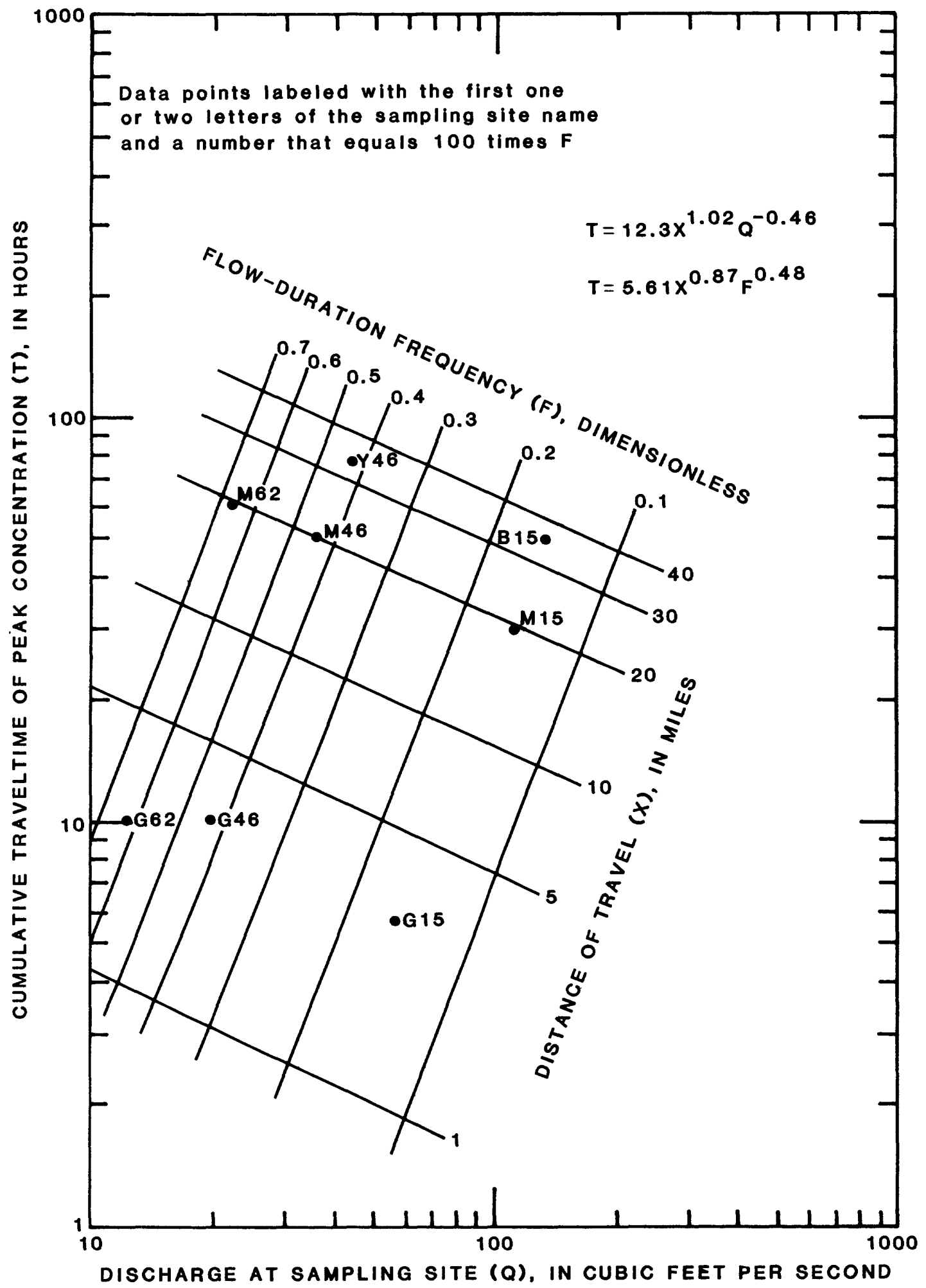

Figure 6. Relation of traveltime of peak concentration to discharge, distance from injection, and flowduration frequency, Cedar Creek. 


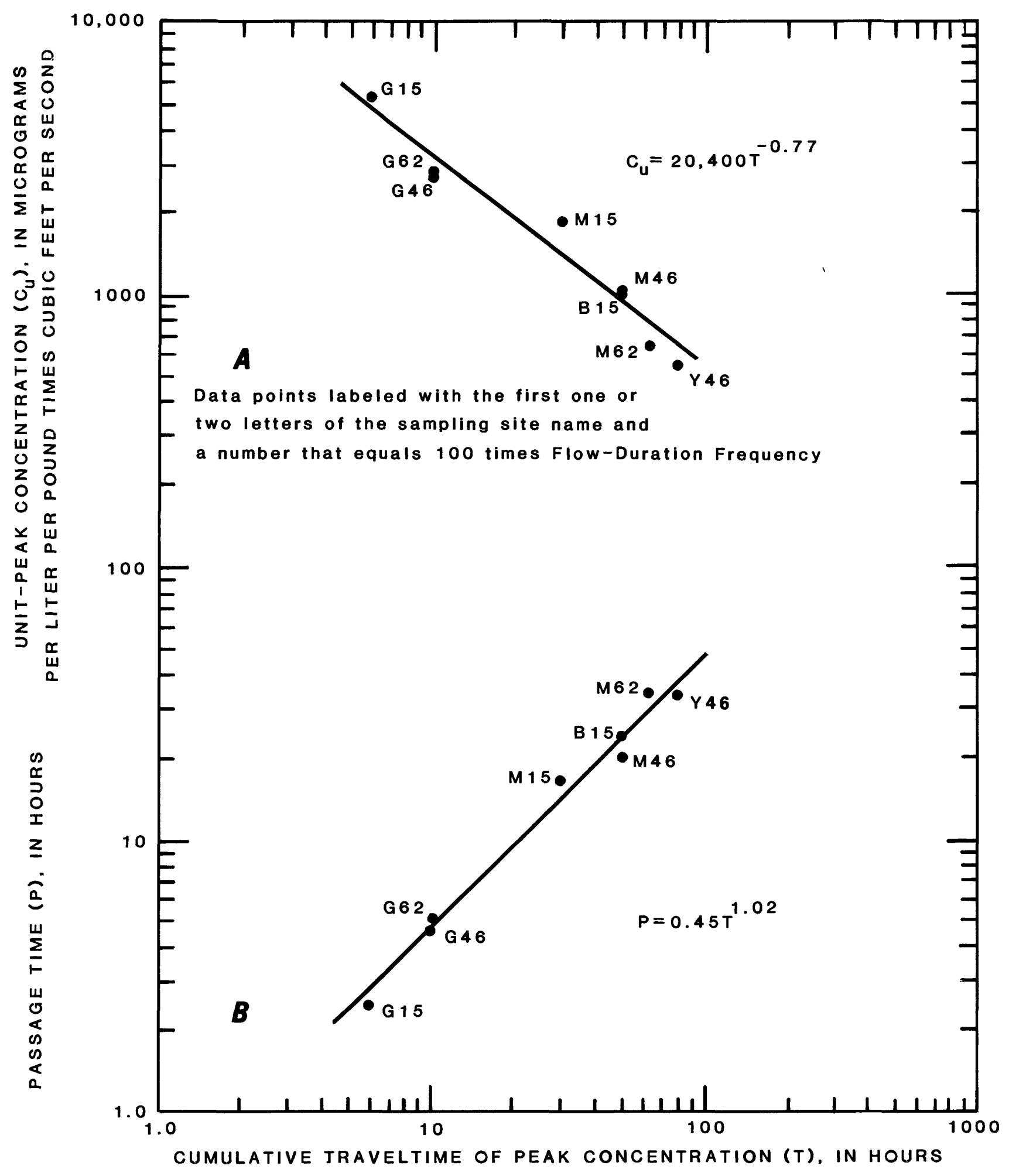

Figure 7. Relation of unit-peak concentration $(A)$ and passage time $(B)$ to traveltime of peak concentration, Cedar Creek. 


\section{Elkhorn Creek}

Elkhorn Creek (figs. 1,8) is a small stream that drains gently rolling terrain covered with row crops and pastures. It has a sand bed and a meandering channel with low grassy banks. Average channel slope is $3.72 \mathrm{ft} / \mathrm{mi}$ in the reach from injection point to the site near Emerson (fig. 8). Channel slope decreases slightly downstream, from $3.88 \mathrm{ft} / \mathrm{mi}$ above Penrose to $3.30 \mathrm{ft} / \mathrm{mi}$ near Emerson. Meanders are tight in the upper reaches but become gentler downstream. At the index gage near Penrose (figs. 1, 8), the channel bed is bedrock and gravel and banks are high. The index gaging station is in the middle of the measured reach.

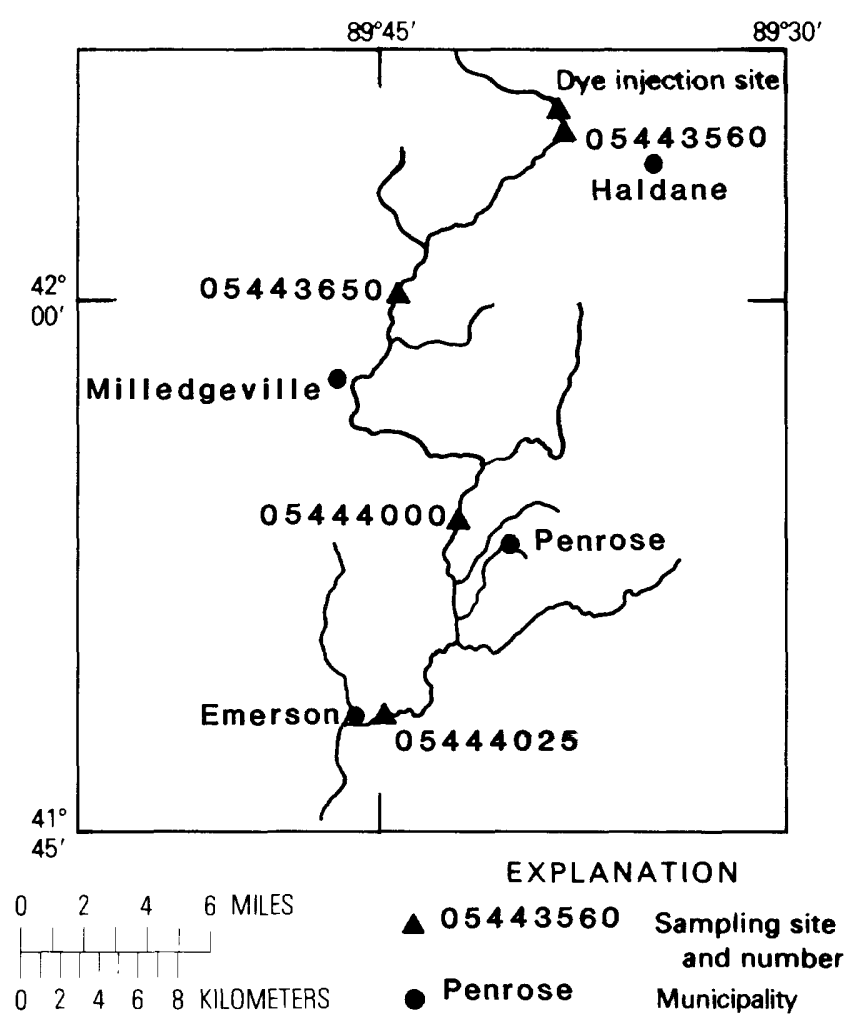

Figure 8. Location of injection and sampling sites, Elkhorn Creek.
Traveltime measurements were made at two flow conditions (table 5), the higher flow $\left(102 \mathrm{ft}^{3} / \mathrm{s}\right)$ at a flowduration frequency of 0.15 and a lower flow $\left(53.9 \mathrm{ft}^{3} / \mathrm{s}\right)$ at a flow-duration frequency of 0.40 . Sand-bed pools and gravel riffles were observed during both measurements. Point and midchannel bars were also visible at both flow conditions but exerted more influence on flow during the lower discharge measurement. Although riffles were observed, they appear not to have influenced flow substantially. This was especially true during the higher flow ( 0.15 flow-duration frequency) measurement.

Discharge at the index gage decreased 16 percent during the higher flow traveltime measurement and 5 percent during the lower flow measurement. The distance between injection and the first sampling site was much greater than estimated mixing lengths for both flow conditions (table 2 ). No multiple samples were collected.

Traveltime of peak is defined by seven data points (fig. 9) from the two measurements. These allow estimation of traveltime for flow-duration frequencies of 0.10 to 0.40 and for travel distances up to $50 \mathrm{mi}$. Traveltime to the site at Milledgeville (fig. 8) is longer than expected from the values for other sites, and no reason for this difference was apparent. Standard errors of estimate for the two equations are about equal and are lower than those for the two streams already discussed (table 13). edge are

The relations developed for traveltime of the leading

$$
T_{L}=5.83 X^{1.20} Q^{-0.44}
$$

and

$$
T_{L}=3.66 X^{0.93} F^{0.35}
$$

The standard errors of estimate of the two equations are about equal and are the same as those for the traveltime of peak relations (table 13).

As in Cedar Creek, flow condition does not affect the relation between either unit-peak concentration or passage time and traveltime (fig. 10). A single line computed from the regression of the logarithms of the variables can be used to estimate both unit-peak concentration and passage time. 


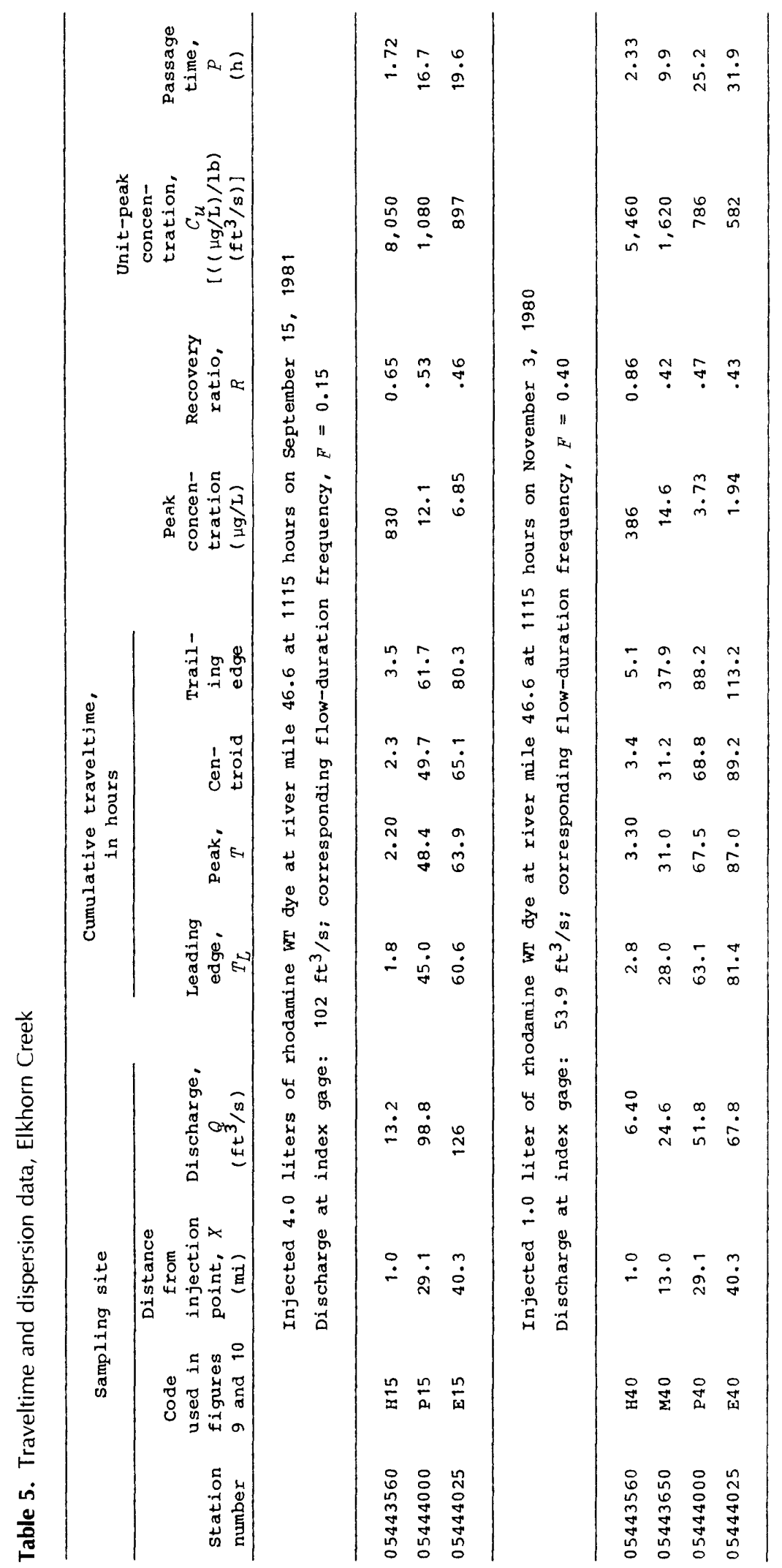




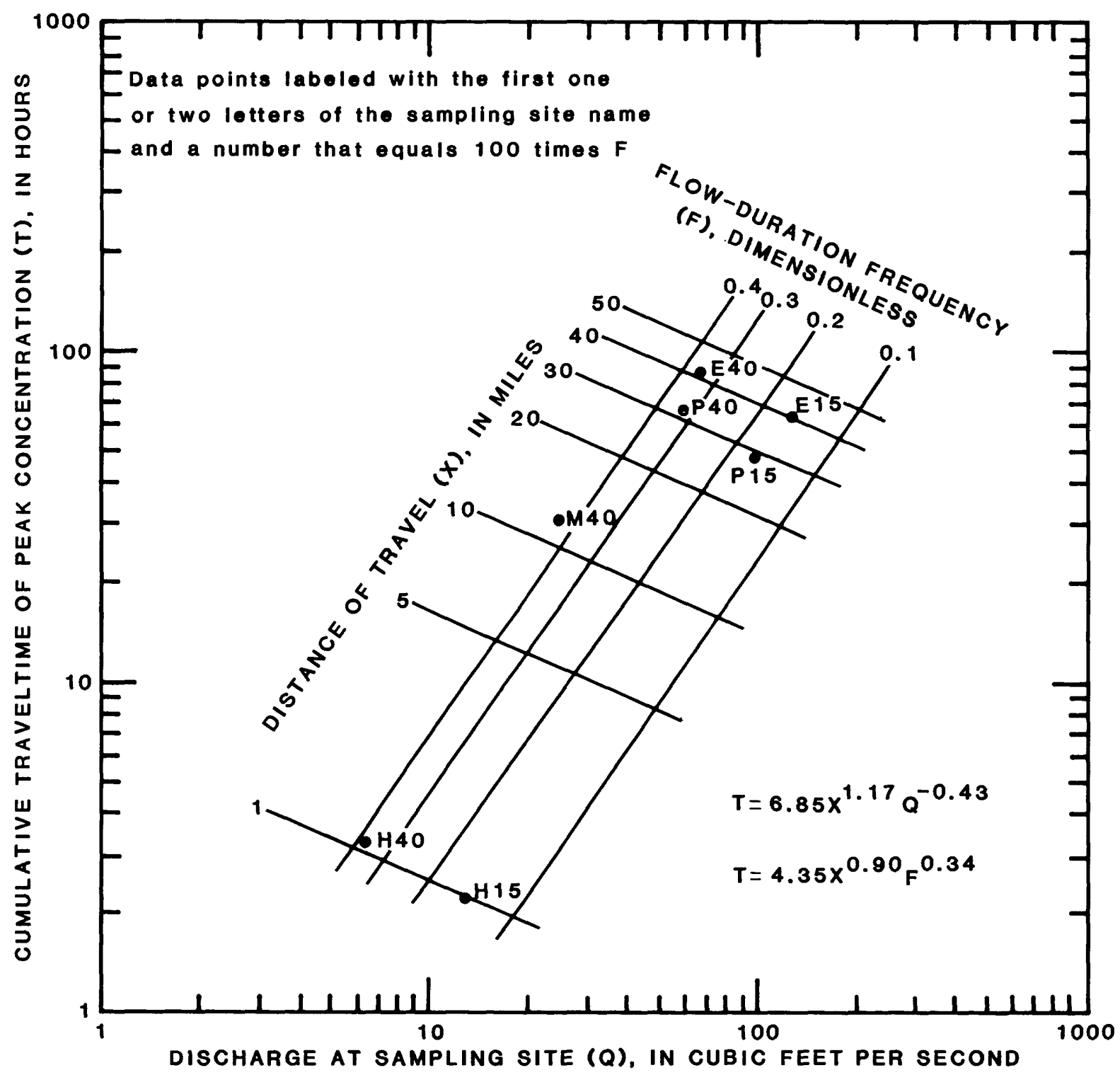

Figure 9. Relation of traveltime of peak concentration to discharge, distance from injection, and flow-duration frequency, Elkhorn Creek. 


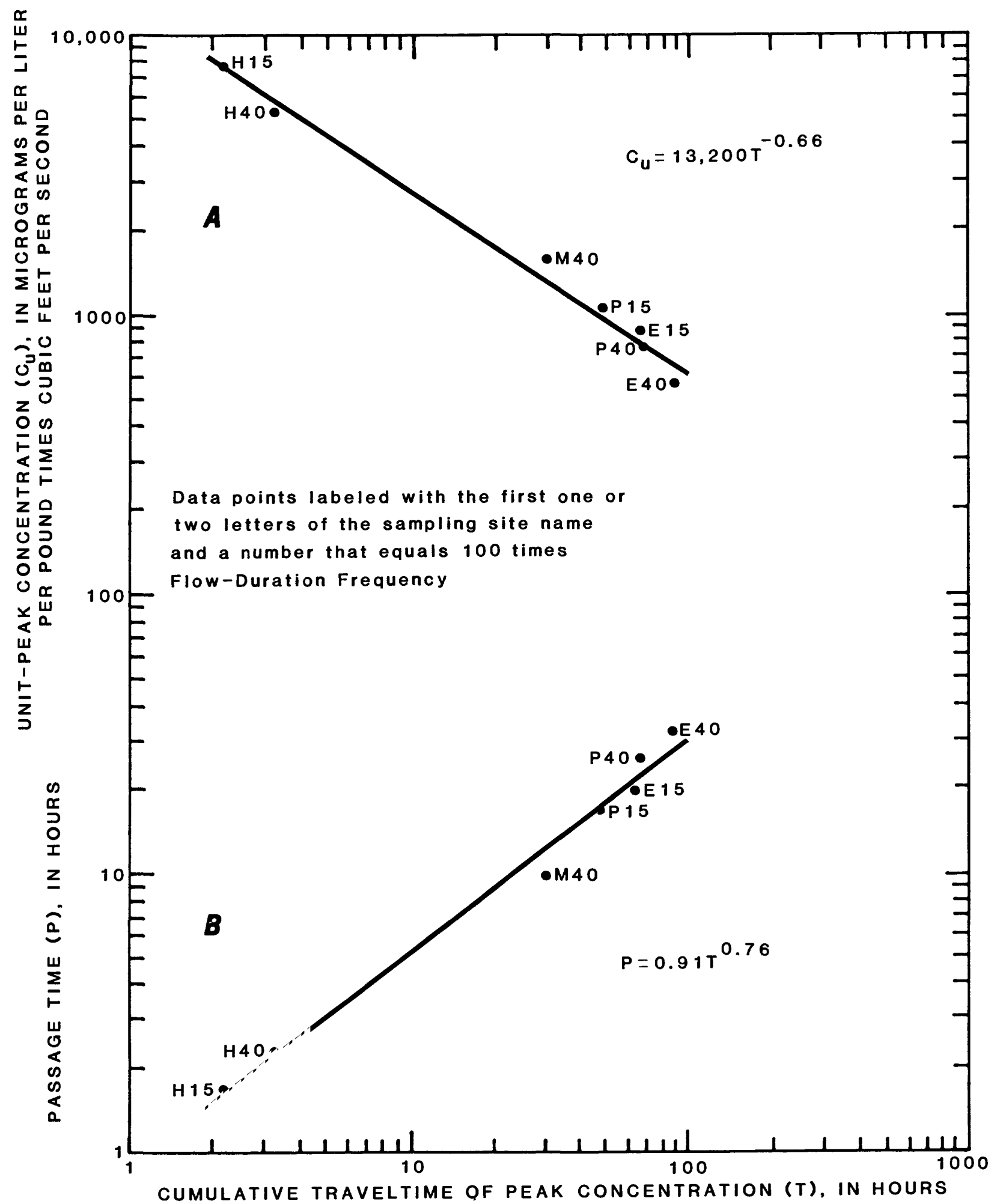

Figure 10. Relation of unit-peak concentration $(A)$ and passage time $(B)$ to traveltime of peak concentration, Elkhorn Creek. 


\section{Embarras River}

The Embarras River (figs. 1, 11) drains slightly undulating countryside that is used largely for growing row crops. The channel is meandering, with low wooded banks and a few bedrock outcrops. Bed materials are sand and gravel, and some bedrock is exposed in the measured reach. A large logjam was present during all measurements at the measuring site near Falmouth (fig. 11). Channel slope from the injection point near Greenup to the index gage at Ste. Marie (fig. 11) averages $1.51 \mathrm{ft} / \mathrm{mi}$ and does not vary significantly along the reach. A low dam across the river at Newton, above the sampling site, acted as a small riffle at low flow but was submerged at higher flows.

Three traveltime measurements were made at flowduration frequencies $(0.26,0.54$, and 0.79$)$ close to those desired (table 6). Discharges at Ste. Marie were 1,170, 346, and $81.9 \mathrm{ft}^{3} / \mathrm{s}$, respectively. At the lowest flow, the thalweg meandered around large sand and gravel bars, and eddies and areas of very slow flow were observed on the downstream side of these bars. Sandbed pools and gravel riffles were also observed. Bars were submerged and flow was fast and turbulent in all observed locations during the highest

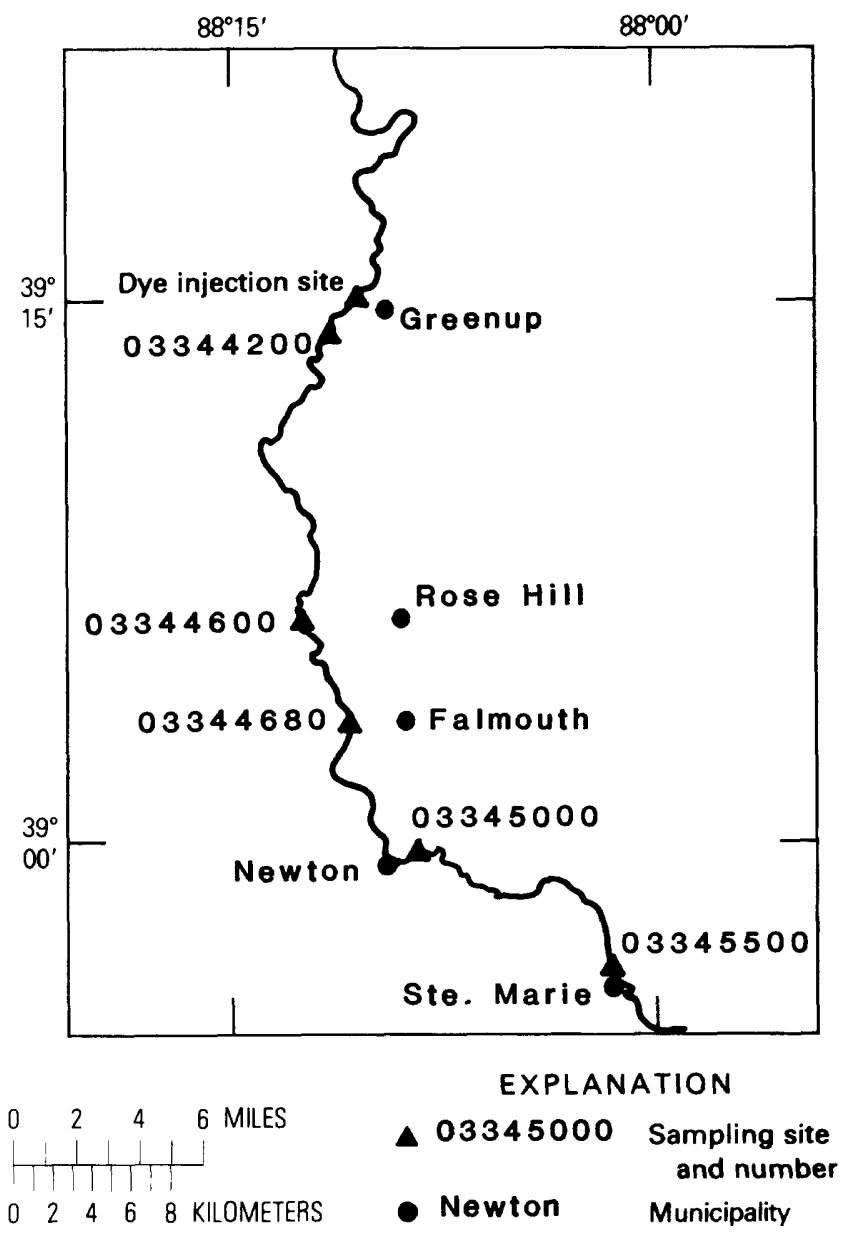

Figure 11. Location of injection and sampling sites, Einbarras River. discharge measurement. Boils on the water surface suggested the presence of sand dunes.

Estimated mixing distances are longer than the distance from injection to the first sampling site for all measurements (table 2). For the highest flow measurement (flow-duration frequency 0.26 ), injection was made along a line across the central part of the flow, and sampling at two points across the section at the first sampling site suggested that mixing was complete. Single-slug injections were made for the two measurements at lower discharges, and samples from three points at the first site taken during the $346 \mathrm{ft}^{3} / \mathrm{s}$ measurement suggested that mixing was not yet complete across the channel. An average time-concentration curve was used for the site.

The traveltime measurement at highest discharge was begun after a large discharge peak had passed the Ste. Marie gaging station, which is at the downstream end of the reach, and discharge at the gage decreased 47 percent during the measurement. Discharge at the index gage also decreased 16 percent during the measurement at a flow-duration frequency of 0.54. An 11-percent decrease in discharge was observed at the gaging station during the lowest flow measurement.

The three traveltime measurements yield nine data points which were used to define traveltime (fig. 12). Traveltime can be estimated for flow-duration frequencies from 0.20 to 0.80 and for distances up to $40 \mathrm{mi}$. The regression relation used to compute the lines of equal flow-duration frequency does not fit these data points as well as streams discussed previously (table 13). Lines of equal distance computed from the regression relations fit the data well, except for the measurement at Ste. Marie.

Traveltime of the leading edge can be estimated from either

$$
T_{L}=17.8 X^{1.14} Q^{-0.53}
$$

or

$$
T_{L}=2.62 X^{1.12} F^{1.34} \text {. }
$$

However, equation 11 has a significantly higher standard error of estimate (table 13). As in the case of traveltime of the peak concentration, the equation using discharge at the sampling site would probably provide better estimates than that using flow-duration frequency. A possible source of error in both cases is in the assignment of a single flowduration frequency to flows that changed with time.

Plots of unit-peak concentration and passage time as a function of traveltime of peak (fig. 13) show that, for the Embarras River, flow-duration frequency is a significant factor. Multiple linear regression was used to relate unitpeak concentration to traveltime, and the resulting equation was used to compute lines of equal flow-duration frequency (fig. 13A). The relation to flow-duration frequency is less well defined for passage time (fig. 13B), but it is significant. Flow-duration frequency was included in the regression for passage time as well as for unit-peak concentration. 


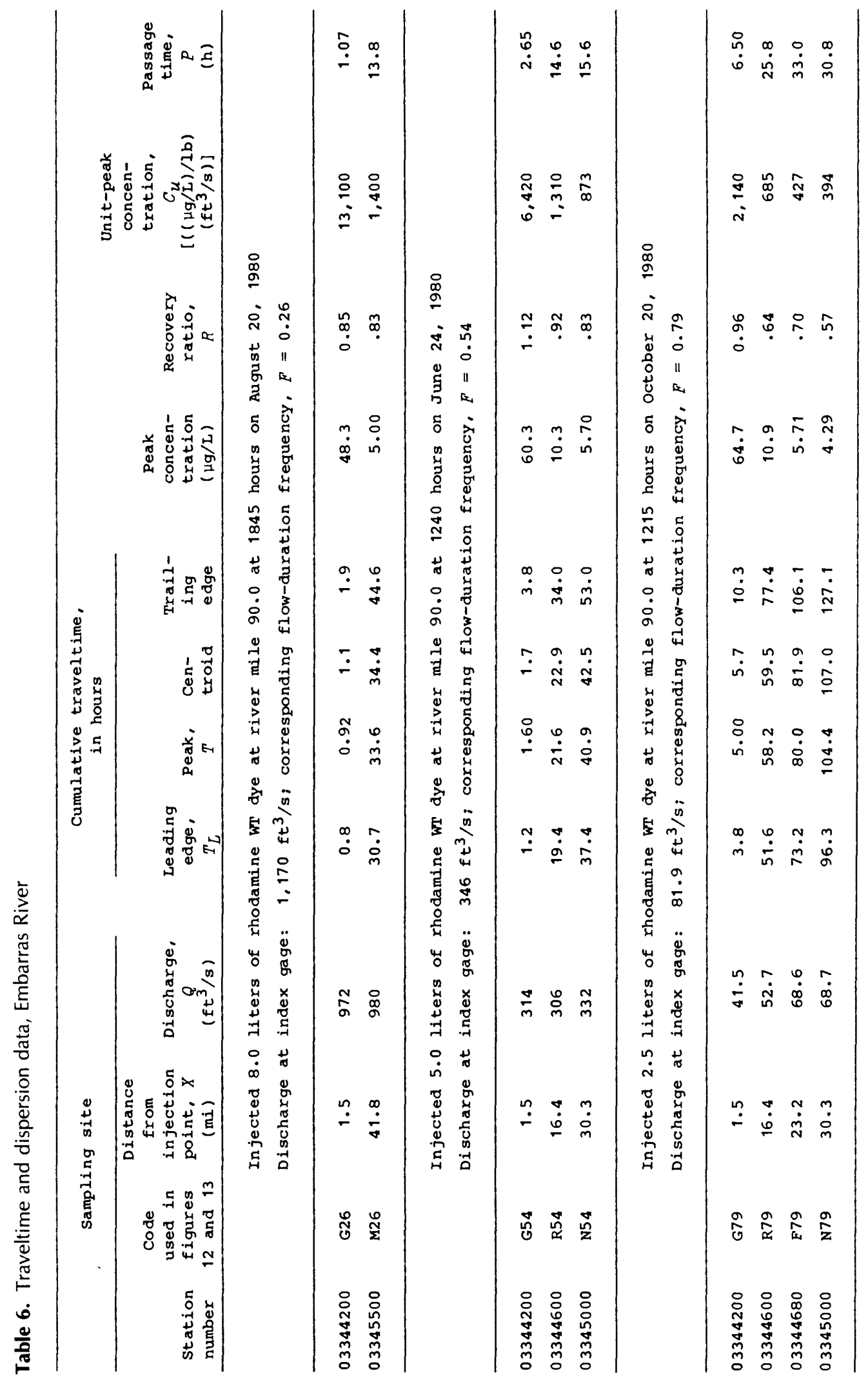




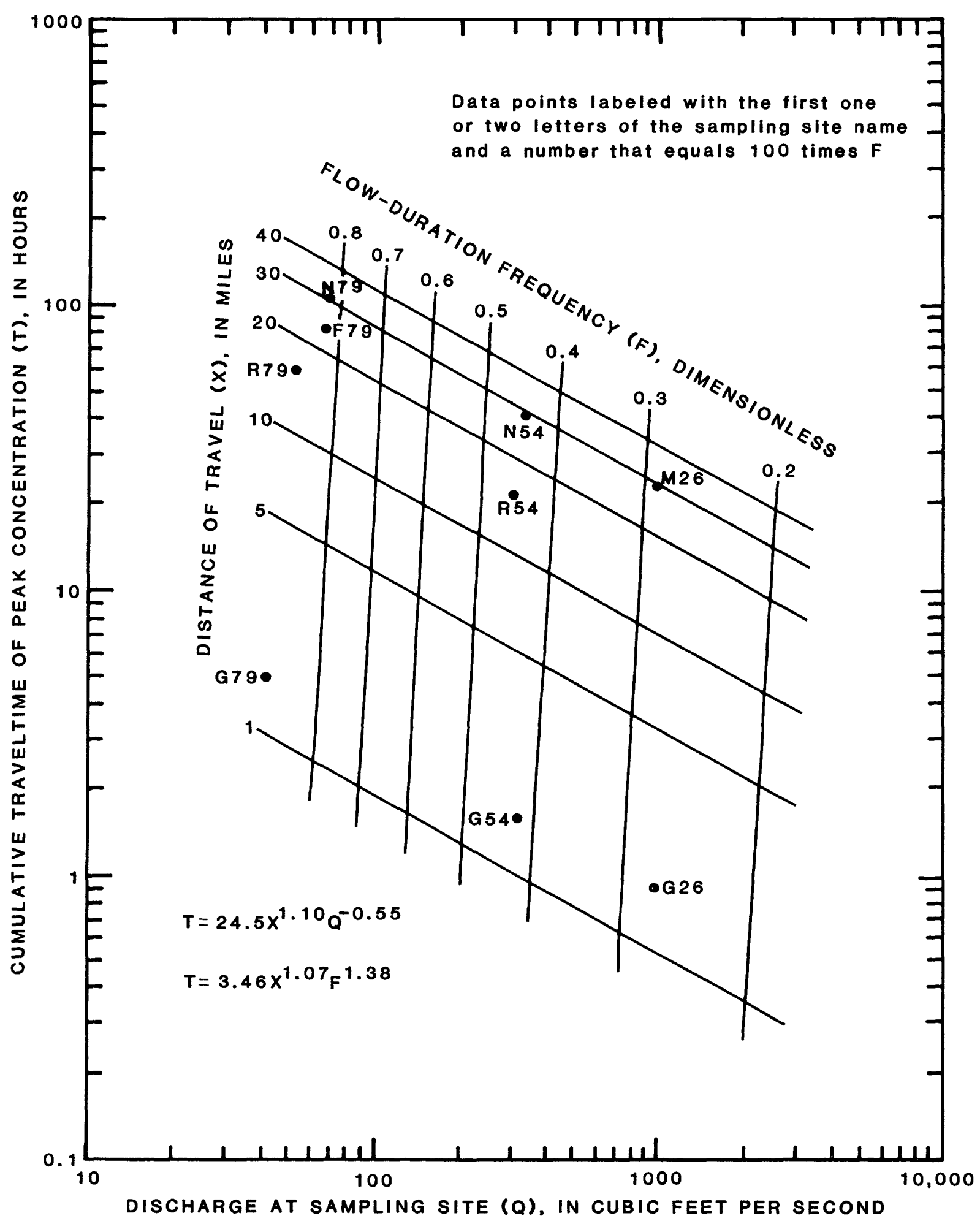

Figure 12. Relation of traveltime of peak concentration to discharge, distance from injection, and flow-duration frequency, Embarras River. 


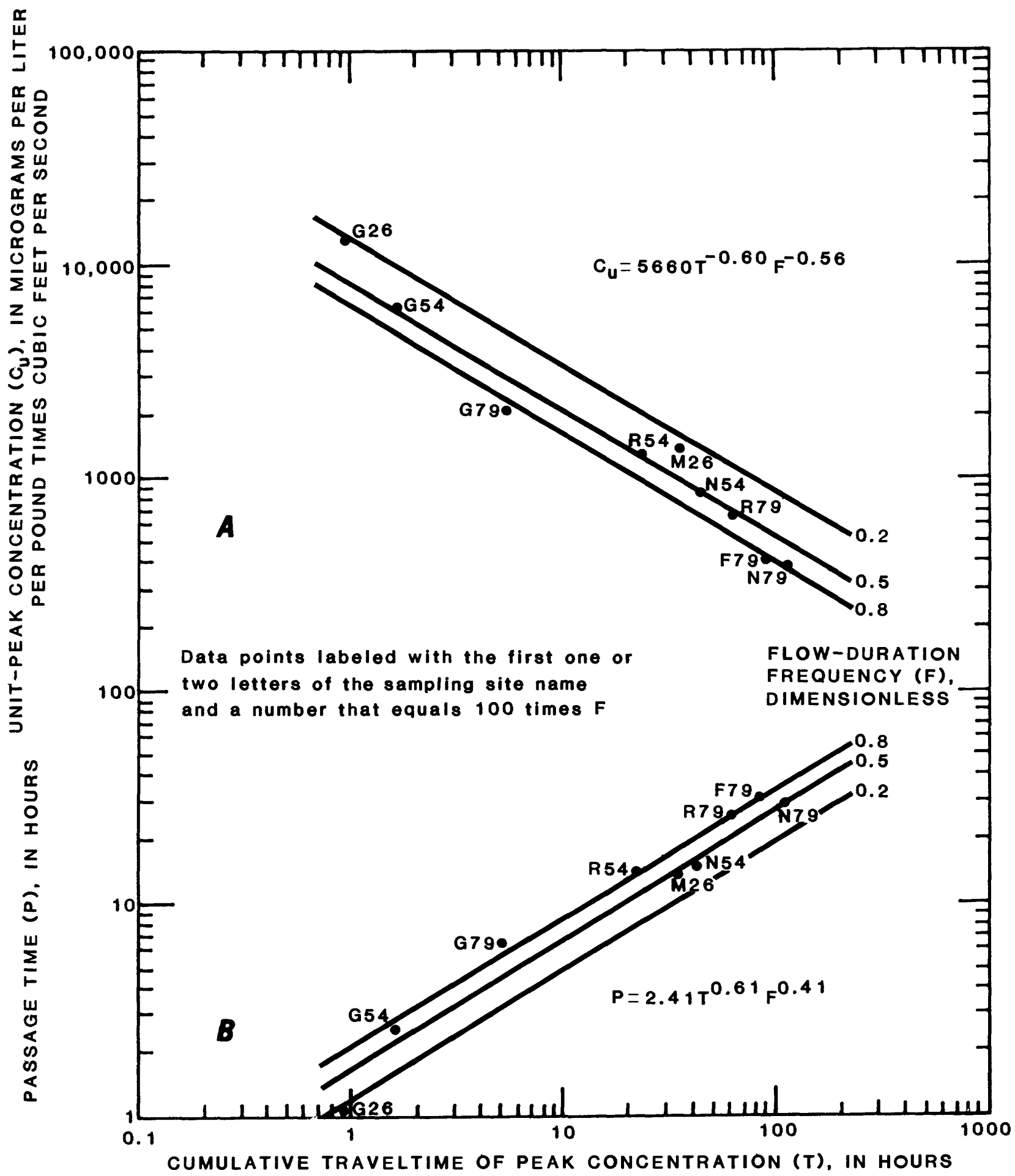

Figure 13. Relation of unit-peak concentration $(A)$ and passage time $(B)$ to traveltime of peak concentration and flowduration frequency, Embarras River. 


\section{Kaskaskia River}

The Kaskaskia River (figs. 1, 14) has a dredged channel for much of the measured length and drains nearly flat farmland devoted to row crops. The channel is meandering and wooded at the sampling site at Chesterville (table 1, fig. 14), but at sites above Ficklin it is straight or very gently curving, flat-bedded, and steep-walled. The bed is composed of sand that is finer near the site above Ficklin than at sites upstream. Above Ficklin, very few trees or large shrubs grow near the channel. Channel slope decreases from about $2.3 \mathrm{ft} / \mathrm{mi}$ near the gaging station to about $0.7 \mathrm{ft} / \mathrm{mi}$ near the sampling site at Chesterville. Average slope for the

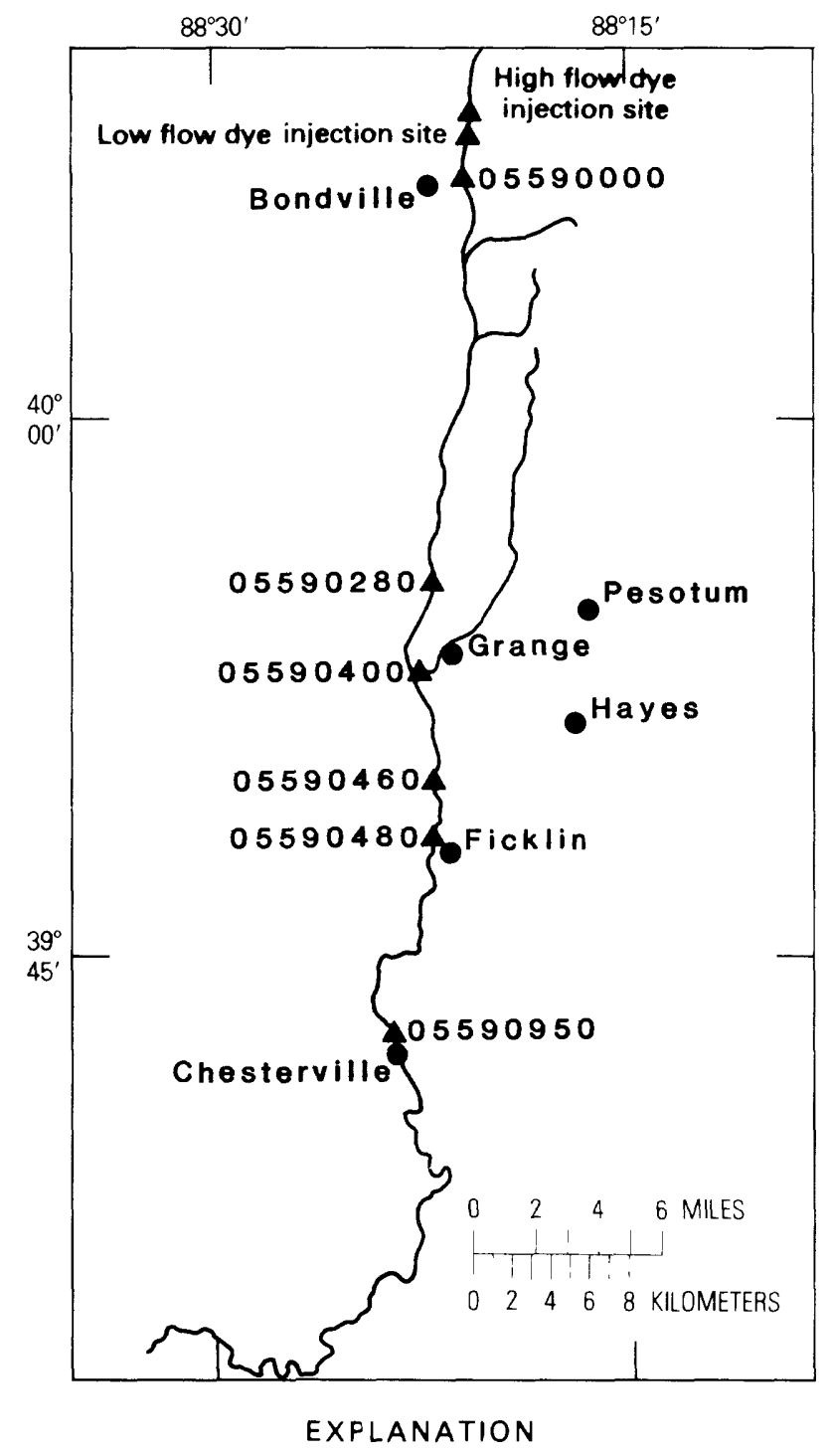

$\begin{array}{ll}\triangle 05590280 & \text { Sampling site and number } \\ \text { - Pesotum } & \text { Municipality }\end{array}$

Figure 14. Location of injection and sampling sites, Kaskaskia River. entire reach is $1.48 \mathrm{ft} / \mathrm{mi}$. The index gage at Bondville (fig. 14) is at the upper end of the measured reach.

Three traveltime measurements were made on the Kaskaskia River, one of these in 1975 (table 7). The lowest flow (discharge at Bondville $=0.23 \mathrm{ft}^{3} / \mathrm{s}$ ) was very shallow and even over the rippled sand bed, with no riffles observed. Flow was deeper and slower near the sampling site above Ficklin than at other sites. At the medium flow condition $\left(\right.$ discharge $\left.=4.41 \mathrm{ft}^{3} / \mathrm{s}\right)$, no difference between the flow near Ficklin and at other sites was noticeable.

Relatively little change in discharge with time was observed at the index gage during the three traveltime measurements. No change was observed during the measurement at the highest discharge $(F=0.38)$. An increase of 8 percent during the measurement at a flow-duration frequency of 0.41 reflected the passage of a small discharge peak on May 30. A rainstorm in the drainage area during the measurement at the lowest discharge $(F=0.90)$ resulted in a small discharge peak which passed the downstream sampling site (near Hayes, table 1, fig. 14) as the dye was passing that site. The peak discharge at that site was about $50 \mathrm{ft}^{3} / \mathrm{s}$, whereas the prestorm discharge had been $23 \mathrm{ft}^{3} / \mathrm{s}$.

Estimated mixing lengths (table 2 ) are all short compared with the distances between injection and the first sampling site. Multiple samples taken across the channel at the first and second sites of the highest discharge measurement showed that the dye was mixed across the stream at those sites.

The traveltime relations developed for the Kaskaskia River are given in figures 15 and 16. The eight data points used to define the relations do not define a set of intersecting lines corresponding to equal flow-duration frequency and distance of travel as clearly as do the data points for streams discussed previously. Further, standard errors of estimates for the two equations presented in figure 15 are an order of magnitude higher than streams already discussed (table 13). Lines passing through the data points at the same flowduration frequency are not parallel as they are for other streams. The traveltime measurement made at the highest discharge $(F=0.38)$ defines a line that is steeper than that through the data points measured at the 0.41 flow-duration frequency, and the reason for that difference is not known. The increase in discharge downstream during the measurement at 0.41 flow-duration frequency is greater than that during the measurement at 0.38 flow-duration frequency; this may be an indication that discharge increases caused by the rainstorm influenced both discharge and traveltime in the lower reaches. The steeper slope of the line representing the traveltime measurement at lowesi flow may be caused by discharge changes during the measurement.

The equations for traveltime of the leading edge are

$$
T_{L}=3.14 X^{1.38} Q^{-0.44}
$$

and

$$
T_{L}=5.43 X^{0.84} F^{0.95}
$$




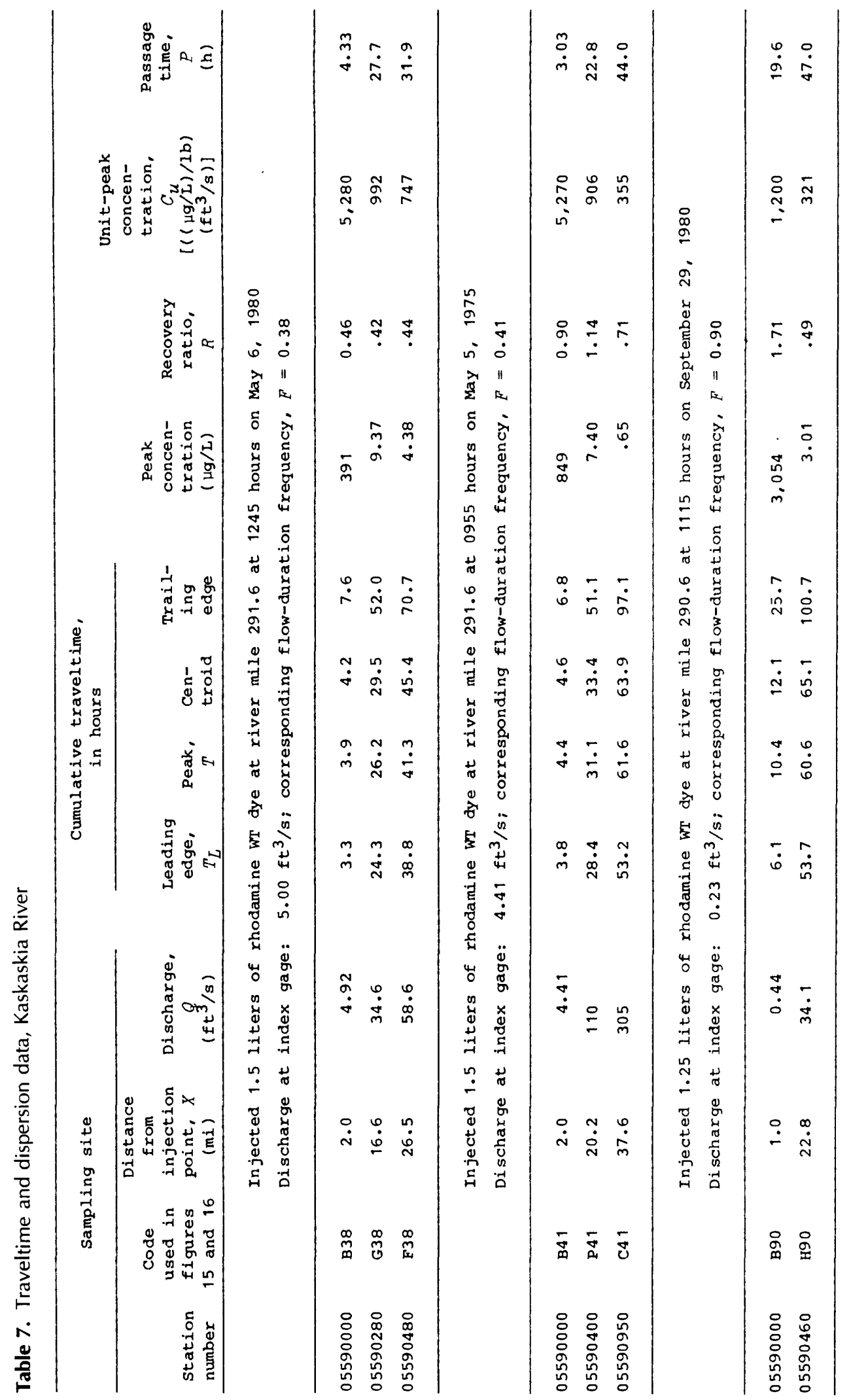


The standard error of estimate for equation 12 is close to those of the equations for traveltime of the peak, but that for equation 13 is lower (table 13).

Some variation with flow condition can be seen on the graphs of unit-peak concentration and passage time versus traveltime (fig. 16), but here, too, the variation with flowduration frequency is not systematic. For this reason, flowduration frequency was found not to be statistically significant and the relation between each of those two variables and traveltime is represented by a single straight line (fig. 16).

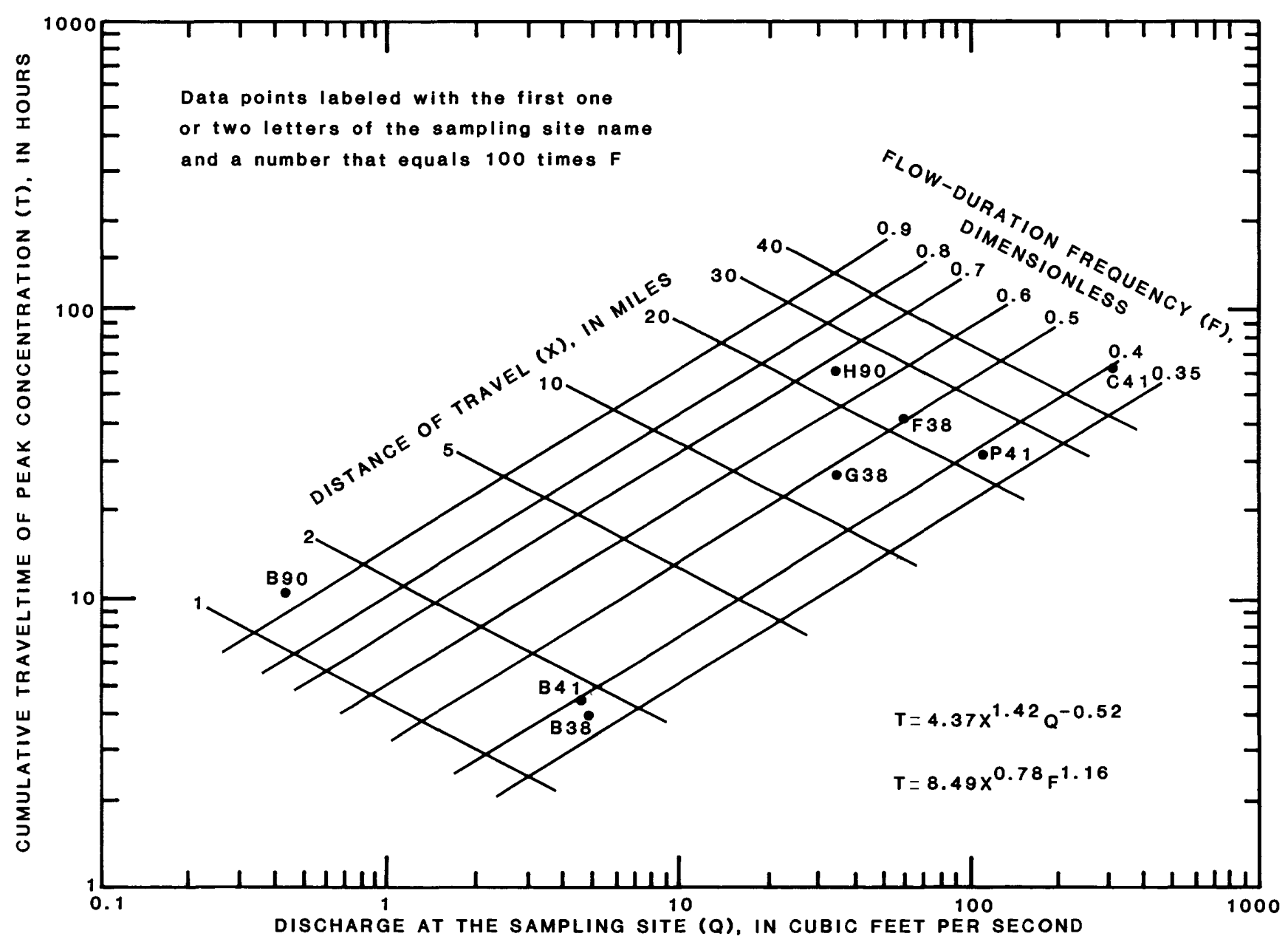

Figure 15. Relation of traveltime of peak concentration to discharge, distance from injection, and flow-duration frequency, Kaskaskia River. 


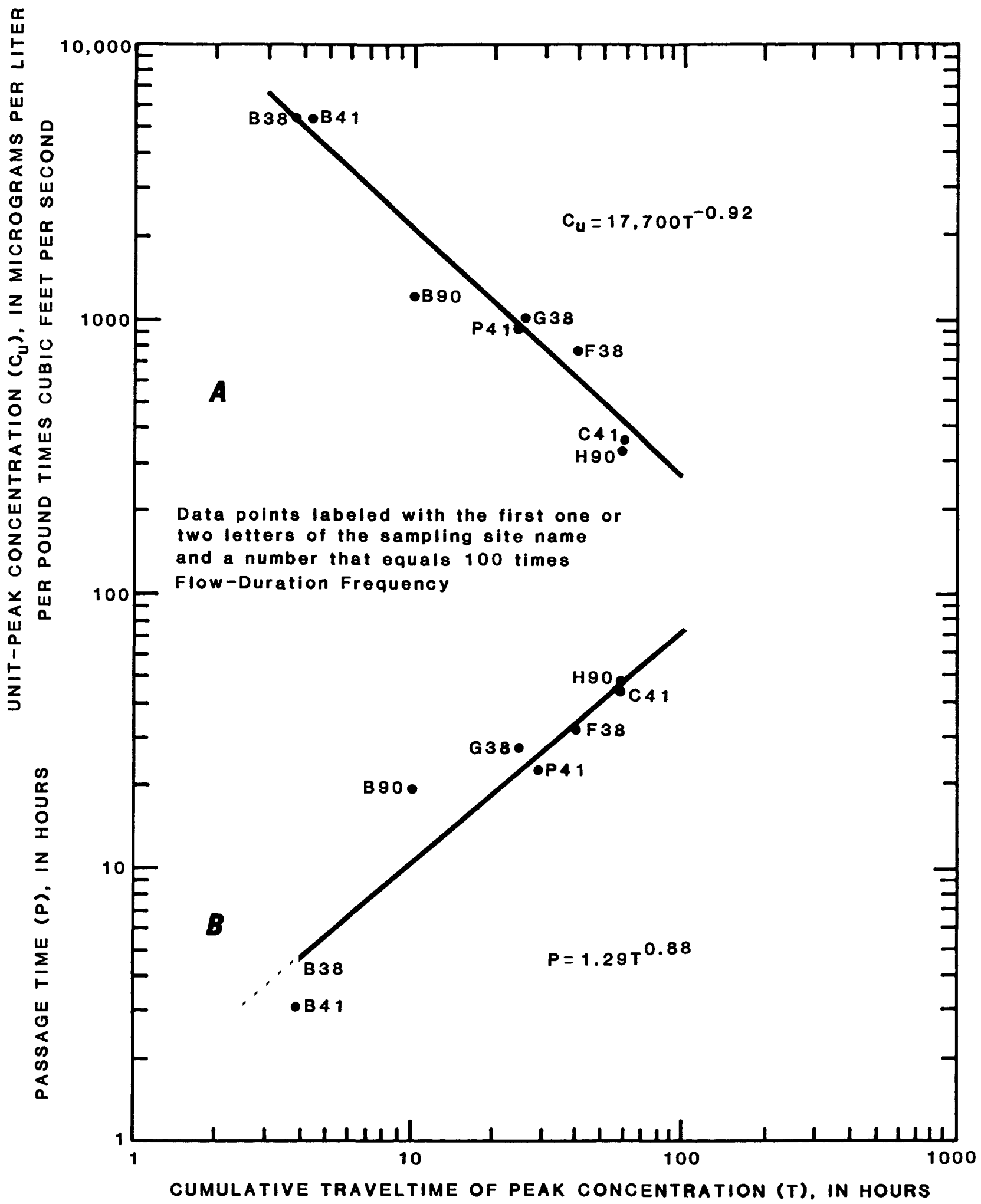

Figure 16. Relation of unit-peak concentration $(A)$ and passage time $(B)$ to traveltime of peak concentration, Kaskaskia River. 


\section{Mackinaw River}

In the reach measured, the Mackinaw River (figs. 1, 17) has a wide meandering channel with low banks. The bed is composed of sand with some gravel that forms large sandbars at bends. Debris and logjams were observed at several places along the channel. The drainage basin is rural and partially wooded. The index gage, near Congerville (table 1; fig. 1), is $17.6 \mathrm{mi}$ above the site used for injection for all measurements. Channel slope from injection to the sampling site below Green Valley is $3.22 \mathrm{ft} / \mathrm{mi}$. Slope is slightly lower upstream and is $2.69 \mathrm{ft} / \mathrm{mi}$ in the reach between injection and the sampling site near Tremont.

Traveltime measurements were made at discharges at the index gage of 471,374 , and $31.5 \mathrm{ft}^{3} / \mathrm{s}$, corresponding to flow-duration frequencies of $0.29,0.34$, and 0.75 , respectively (table 8 ). A very great difference was observed in flow characteristics between the measurement made at low flow and the two measurements at higher flow (table 8). During the measurement at lowest flow, short riffle sections were separated by long, deep pools in which flow was barely detectable. Flow was turbulent and uniform along the channel during the other two measurements. At the flow corresponding to a flow-duration frequency of 0.34 , eddies and areas of lower velocity were present on the downstream sides of point bars. Some of these bars were exposed during the highest flow measurement, but areas of eddies and lower velocity flow were reduced from those at the lower flow. Considerable shifting of the channel bed and debris jams took place between measurements. Because of the compar- atively long traveltime during the measurement at 0.75 flow-duration frequency, the reach measured is very short $(5.2 \mathrm{mi})$.

A rainstorm during the measurement at the highest flow caused a discharge peak which passed through the channel as the dye moved through the measured reach. Peak discharge was 20 percent above the prestorm discharge at the downstream measuring site. The discharge peak passed that site at about the same time as the peak dye concentration. Discharge decreased with time in the measured reach during the measurement begun on September 9, 1981 (table 8 ). The change in discharge at the index gage during the traveltime measurement was about 14 percent. Discharge decreased during much of the measurement at lowest flow, but a small rainstorm caused a rise in stage toward the end of the measurement. A difference of 26 percent was found between the highest and lowest discharges.

Estimated mixing distances for measurements at the two higher flow conditions (table 2) are longer than the distance between the injection and the first sampling site. For those measurements, dye was injected as two slugs to shorten the distance for transverse mixing.

The traveltime of the peak relations developed from the measurements are given in figure 18. Computed lines of equal flow-duration frequency and distance of travel fit the data points fairly well (table 13) except for the measurements at Green Valley. The unsteadiness of flow during both those measurements may be the cause of the lack of agreement of those points. Regression relations developed from the measured values allow estimation of traveltime for

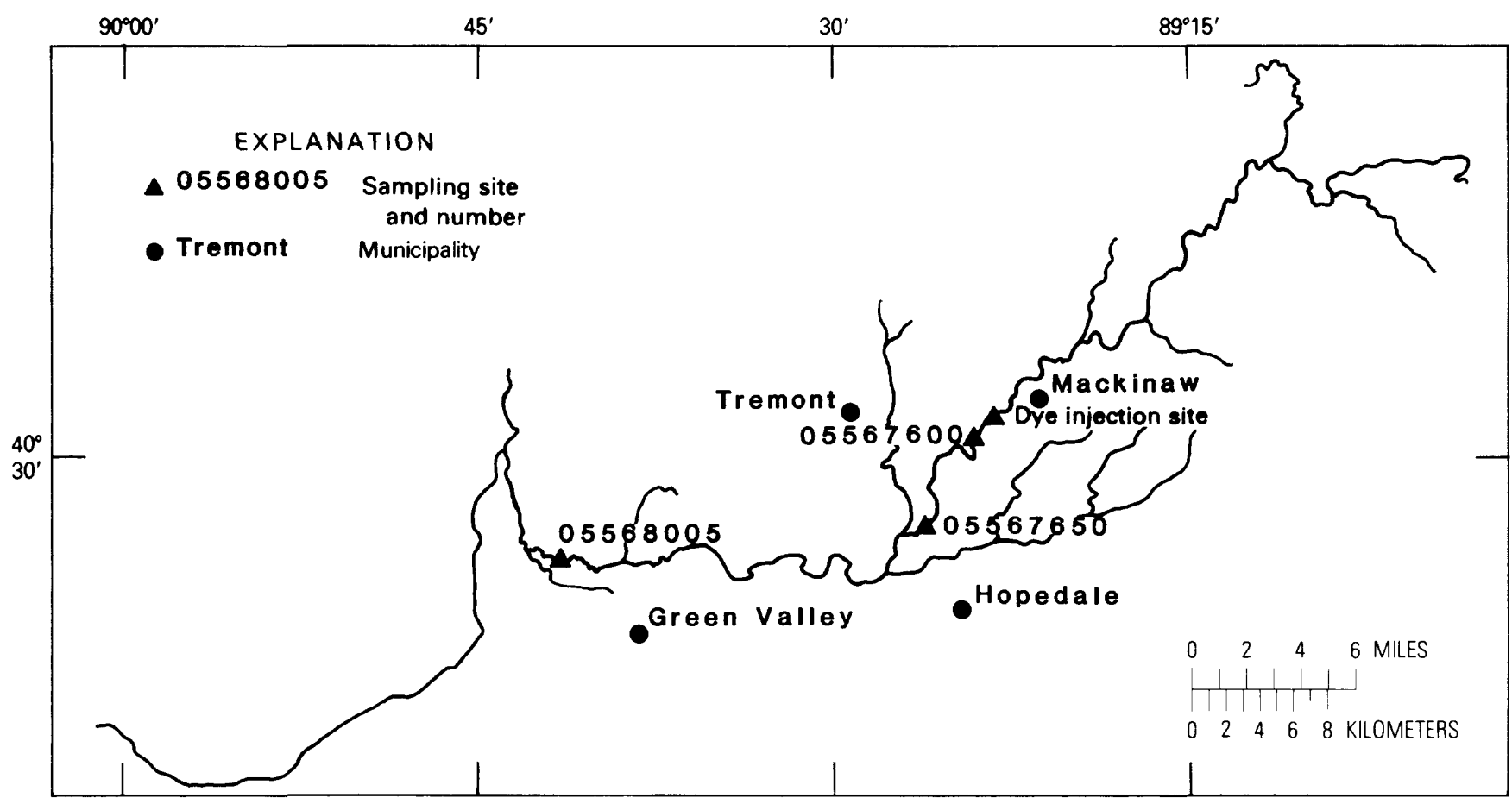

Figure 17. Location of injection and sampling sites, Mackinaw River. 


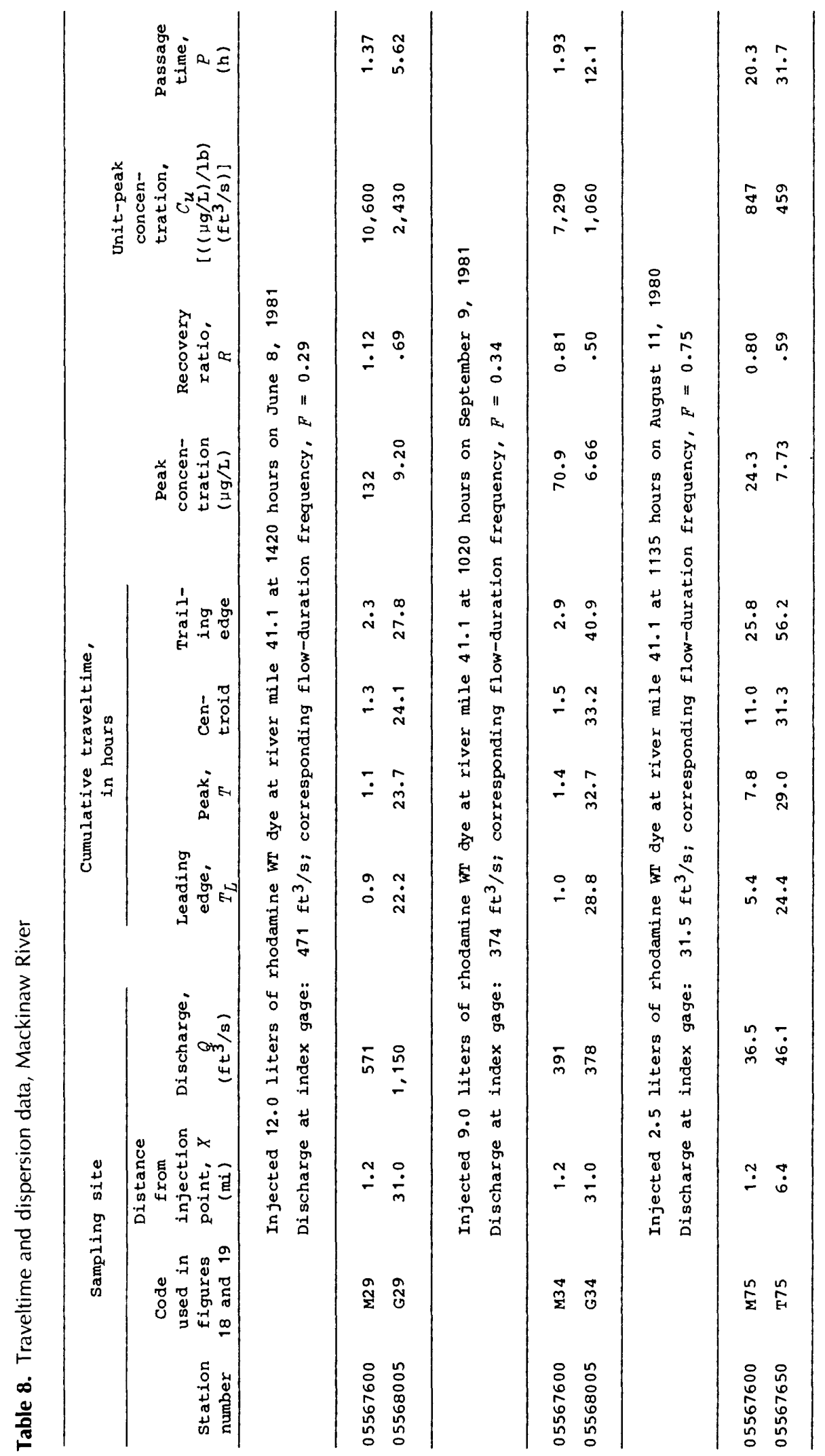


flow-duration frequencies from 0.30 to 0.80 and for distances up to 30 miles.

The equations developed for traveltime of the leading edge are

$$
T_{L}=36.7 X^{1.06} Q^{-0.62}
$$

and

$$
T_{L}=7.03 X^{1.00} F^{1.85} .
$$

For both traveltime of the peak and traveltime of the leading edge, the equations that use flow-duration frequency have lower standard errors than those that use discharge at the sampling site (table 13).

Both unit-peak concentration and passage time are strongly dependent on flow condition in the Mackinaw River (fig. 19). Because of that dependence, regression relations based on both flow-duration frequency and cumulative traveltime of peak concentration were developed, and those equations used to compute the lines of equal flowduration frequency shown in figure 19.

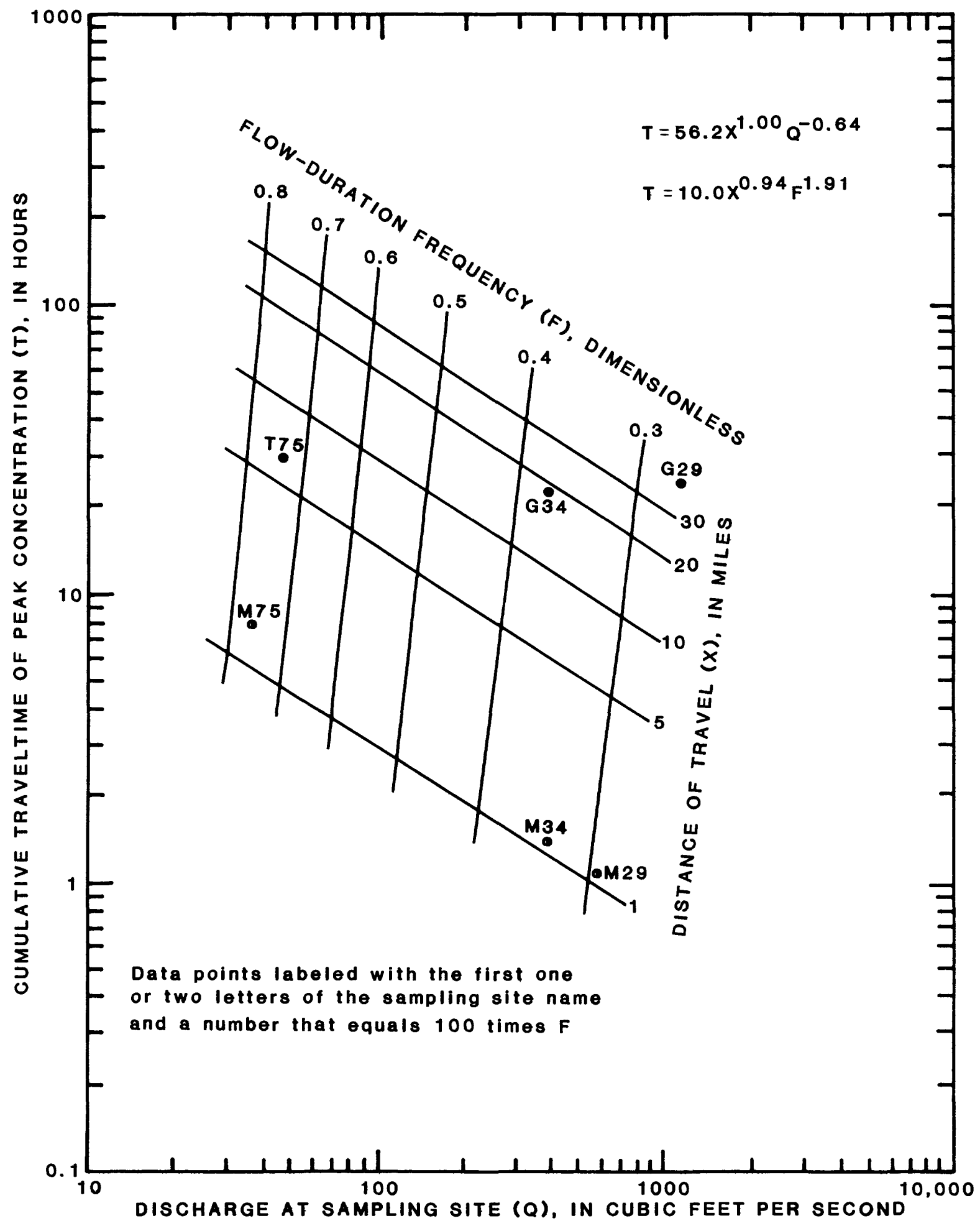




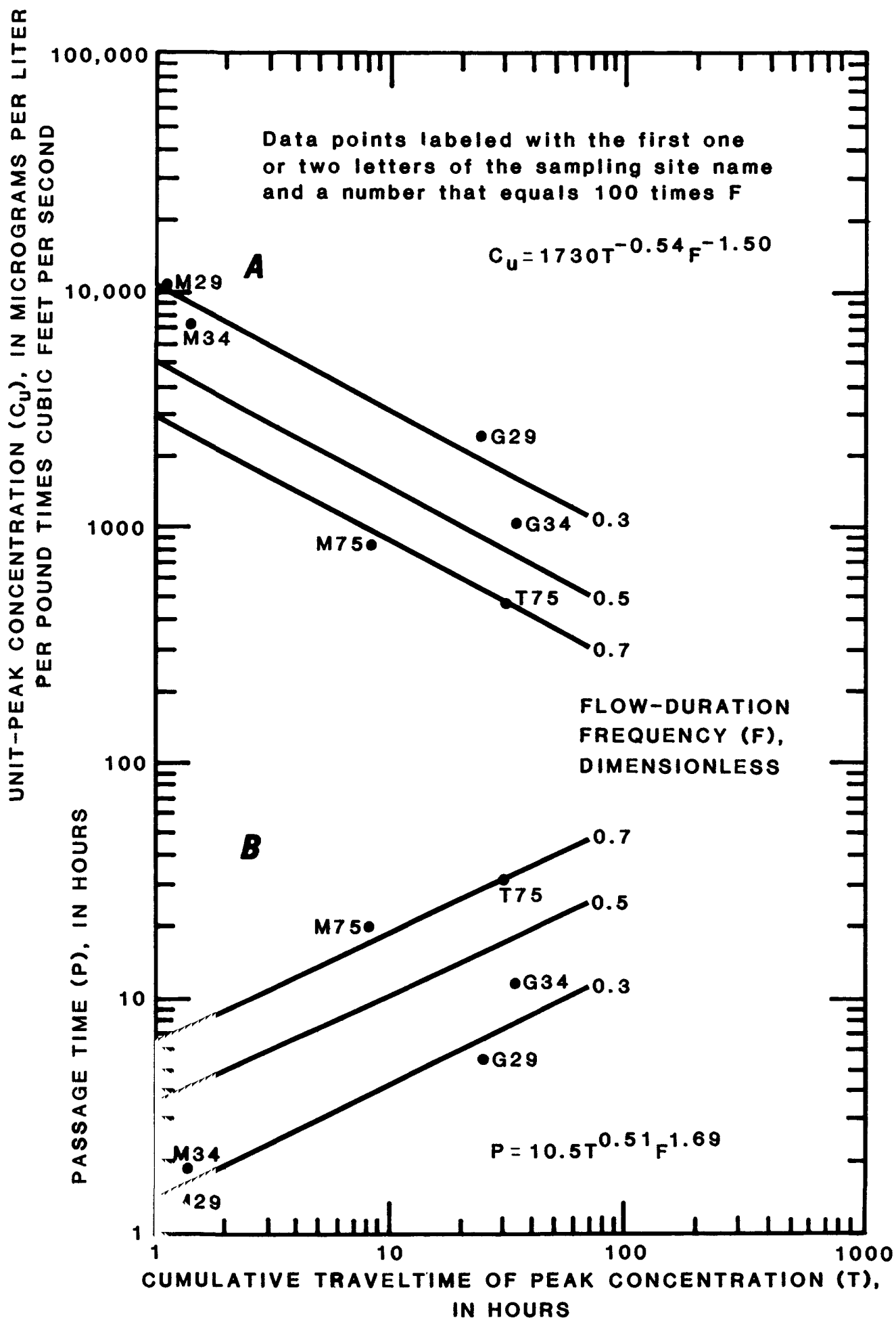

Figure 19. Relation of unit-peak concentration $(A)$ and passage time $(B)$ to traveltime of peak concentration and flow-duration frequency, Mackinaw River. 


\section{Middle Fork Vermilion River}

The meandering channel of the Middle Fork Vermilion River (figs. 1, 20) is composed of sand, gravel, and bedrock. Banks are wooded, and the surrounding counside is agricultural. Extensive gravel bars and riffles were observed at low flow. The average channel slope in the measured reach is $4.07 \mathrm{ft} / \mathrm{mi}$. Channel slope increases from $3.13 \mathrm{ft} / \mathrm{mi}$ near Armstrong to $5.56 \mathrm{ft} / \mathrm{mi}$ near Oakwood (fig. 20). The index gage is at the downstream end of the measured reach.

Only two traveltime measurements were made on this stream, at discharges of 263 and $51.3 \mathrm{ft}^{3} / \mathrm{s}$, corresponding to flow-duration frequencies of 0.34 and 0.65 , respectively (table 9). A distinct difference in flow characteristics was observed between these two measurements. At the lower flow, long gravel riffles over which flow moved at relatively high velocity separated long pools in which flow was much slower. Large gravel bars were exposed and caused the thalweg to meander strongly within the channel. Large areas of eddies and very slow flow were observed on the downstream side of these bars. During the measurement at higher flow, bars were almost submerged and flow velocities were more even, both across and along the channel than at the lower flow. Flow at all observation points was turbulent, with boils visible on the surface.

Both traveltime measurements were made as discharge was decreasing with time. The measurement at the higher discharge was begun after the discharge peak had passed the index gage, and discharge decreased 53 percent at the gage during the measurement. Discharge changed more slowly during the measurement at the lower flow, decreasing 39 percent during the 5 days of measurement.

All estimated mixing lengths were much shorter than the 3.0-mile distance between injection and the first sampling site (table 2). No multiple samples were collected.

The two measurements provide only four data points for definition of traveltime (fig. 21). The measurements were used to develop equations to compute lines of equal flow-duration frequency from 0.30 to 0.70 and of equal distances to $30 \mathrm{mi}$. The relation between traveltime of peak and flow-duration frequency is better defined than that between traveltime of peak and discharge at the sampling site (table 13).

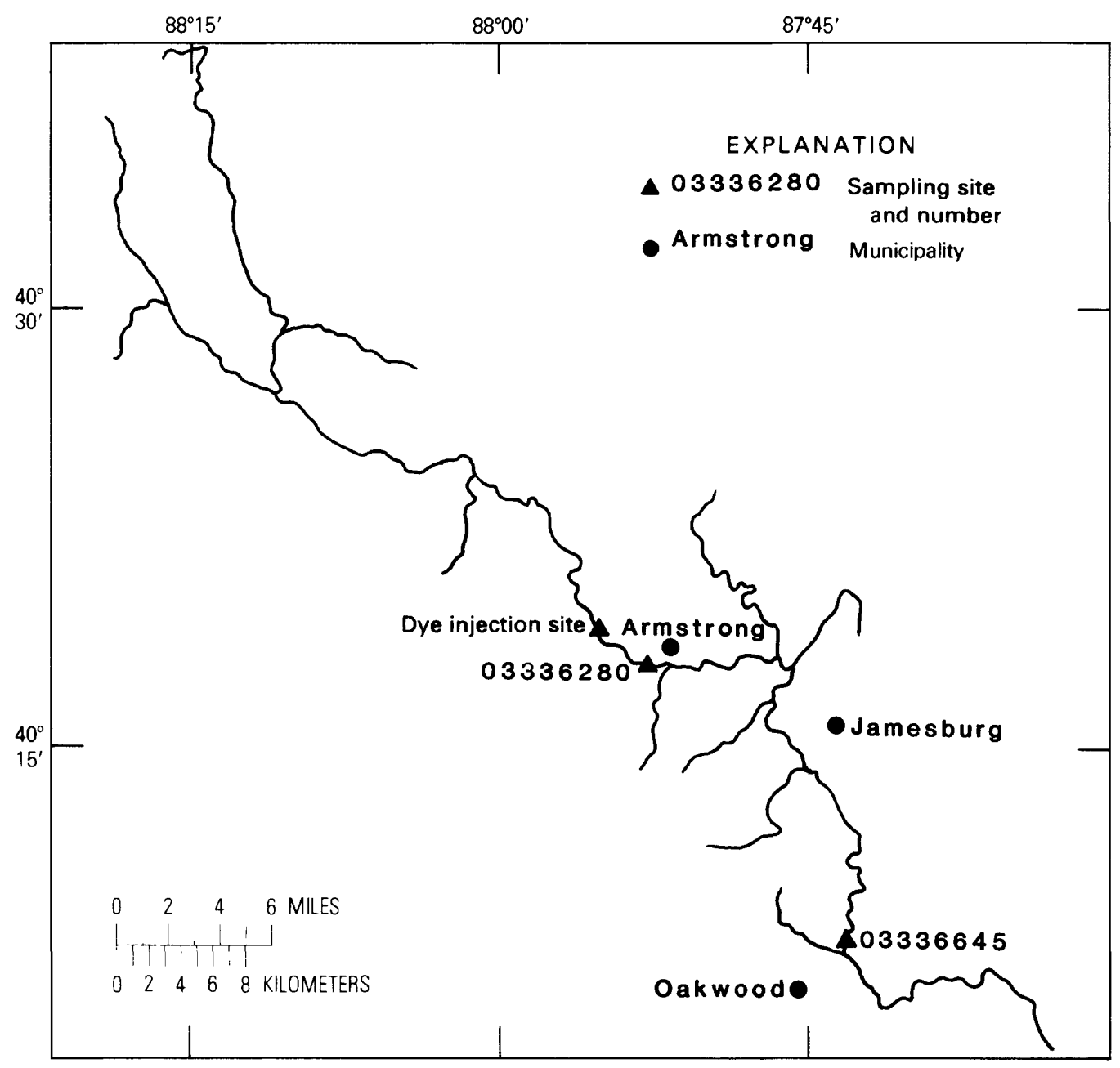

Figure 20. Location of injection and sampling sites, Middle Fork Vermilion River. 


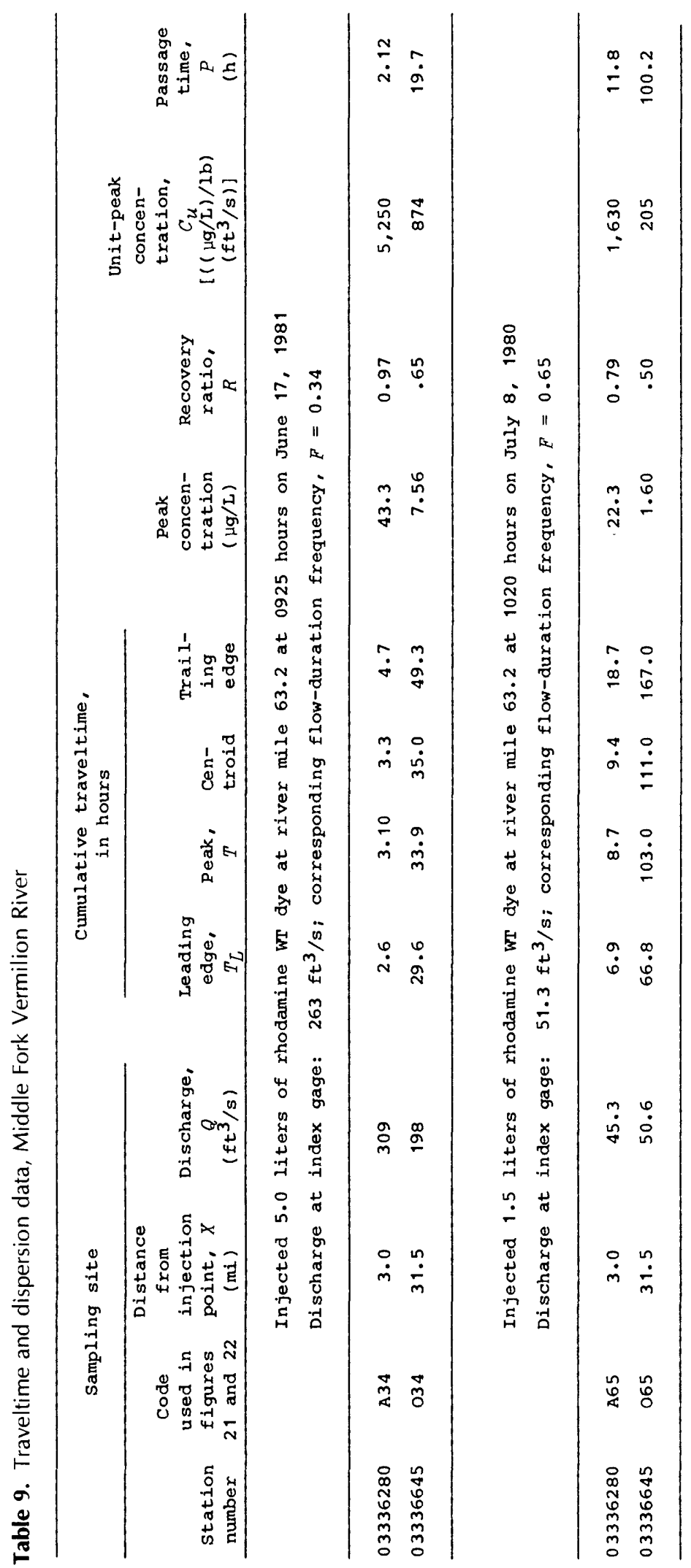


The equations for traveltime of the leading edge are

$$
T_{L}=19.2 X^{0.96} Q^{-0.54}
$$

and

$$
T_{L}=4.03 X^{1.00} F^{1.39}
$$

The standard errors of estimate of these two equations are nearly equal and relatively low (table 13).
The graphs of unit-peak concentration and passage time versus traveltime (fig. 22) suggest that flow condition is significant for this stream. An equation developed with linear regression techniques using flow-duration frequency and traveltime as independent variables was used to compute flow-duration frequency lines shown in the figure.

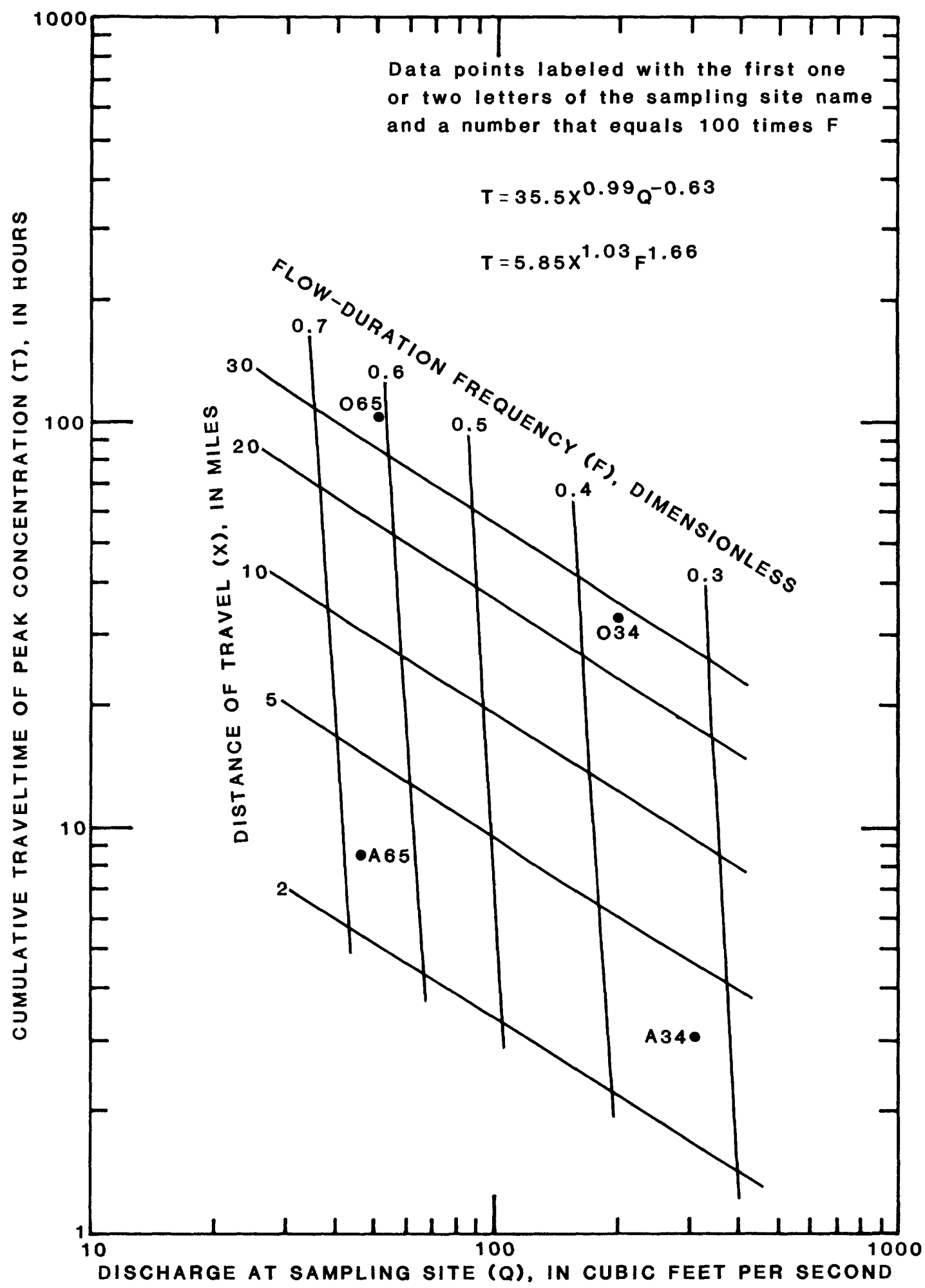




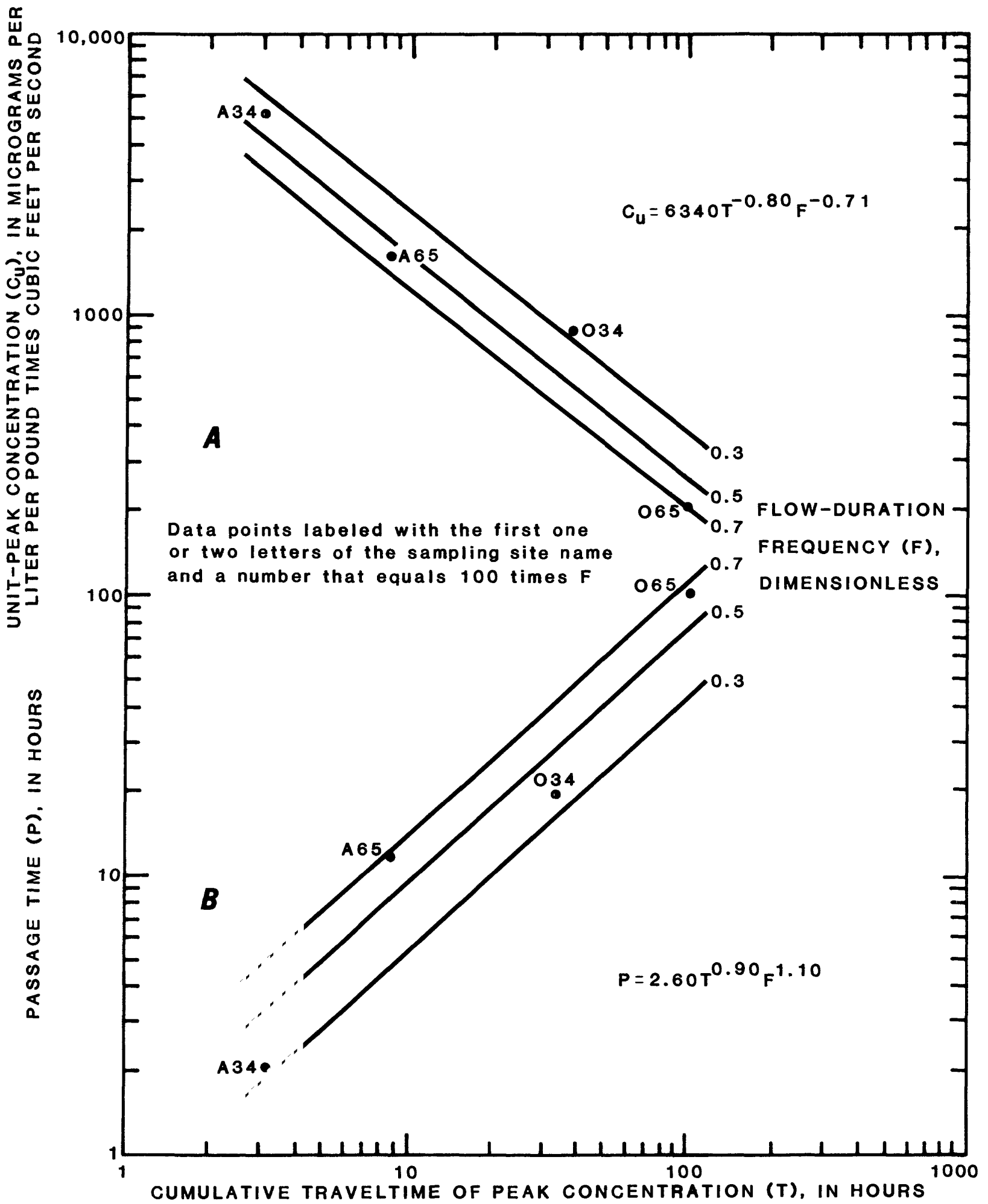

Figure 22. Relation of unit-peak concentration $(A)$ and passage time $(B)$ to traveltime of peak concentration and flow-duration frequency, Middle Fork Vermilion River.

$\leftarrow$ Figure 21. Relation of traveltime of peak concentration to discharge, distance from injection, and flow-duration frequency, Middle Fork Vermilion River. 


\section{Sangamon River}

The Sangamon River (figs. 1, 23) meanders through gently rolling farmland. Its bed is sand, which is clayey and silty in pools and is gravelly at riffles. The channel is lined with trees in most areas, and fallen trees and logs are common in the channel. The index gage station at Monticello (fig. 23) is in the middle of the measured reach. Channel slope is uniform in the reach and averages about $1.40 \mathrm{ft} / \mathrm{mi}$.

Traveltime was measured at flow-duration frequencies of $0.28,0.43$, and 0.76 , corresponding to discharges at the index gage of 372,185 , and $27.3 \mathrm{ft}^{3} / \mathrm{s}$, respectively (table 10). During the measurement at the highest flow, made in 1975 , heavy rains caused a large discharge peak to pass through the channel. The change in discharge probably influenced the measurement in the reach between the sampling sites at Monticello and near Cisco (table 10, fig. 23). Discharge at the index gage varied from +125 percent to -43 percent of the time-weighted average discharge for the measurement. During the measurement at $185 \mathrm{ft}^{3} / \mathrm{s}$, a slight rise and fall in stage reflected a discharge change of 16 percent at the gage. A small discharge peak also passed through the channel during the measurement at the lowest discharge. Maximum discharge at the gage during the measurement was $41.5 \mathrm{ft}^{3} / \mathrm{s}$ and minimum was $16.5 \mathrm{ft}^{3} / \mathrm{s}$.

Estimated lengths for transverse mixing are all less than the distance between injection and the first sampling site (table 2), and dye was injected as a single slug into the center of flow for all measurements. Samples from three points across the channel at the first site of the medium flow measurement suggest that transverse mixing was complete at that point.

Traveltime is defined by eight data points (fig. 24). The regression equations permit estimation of traveltime for flow-duration frequencies of 0.30 to 0.80 and for distances up to $40 \mathrm{mi}$. The logarithmic transformation of all variables used results in fit of computed equations to data that is not as good as that for other streams. Computed distances fit the data reasonably well, but the computed flow-duration frequency lines do not (table 13). The cause of this difference is not known.

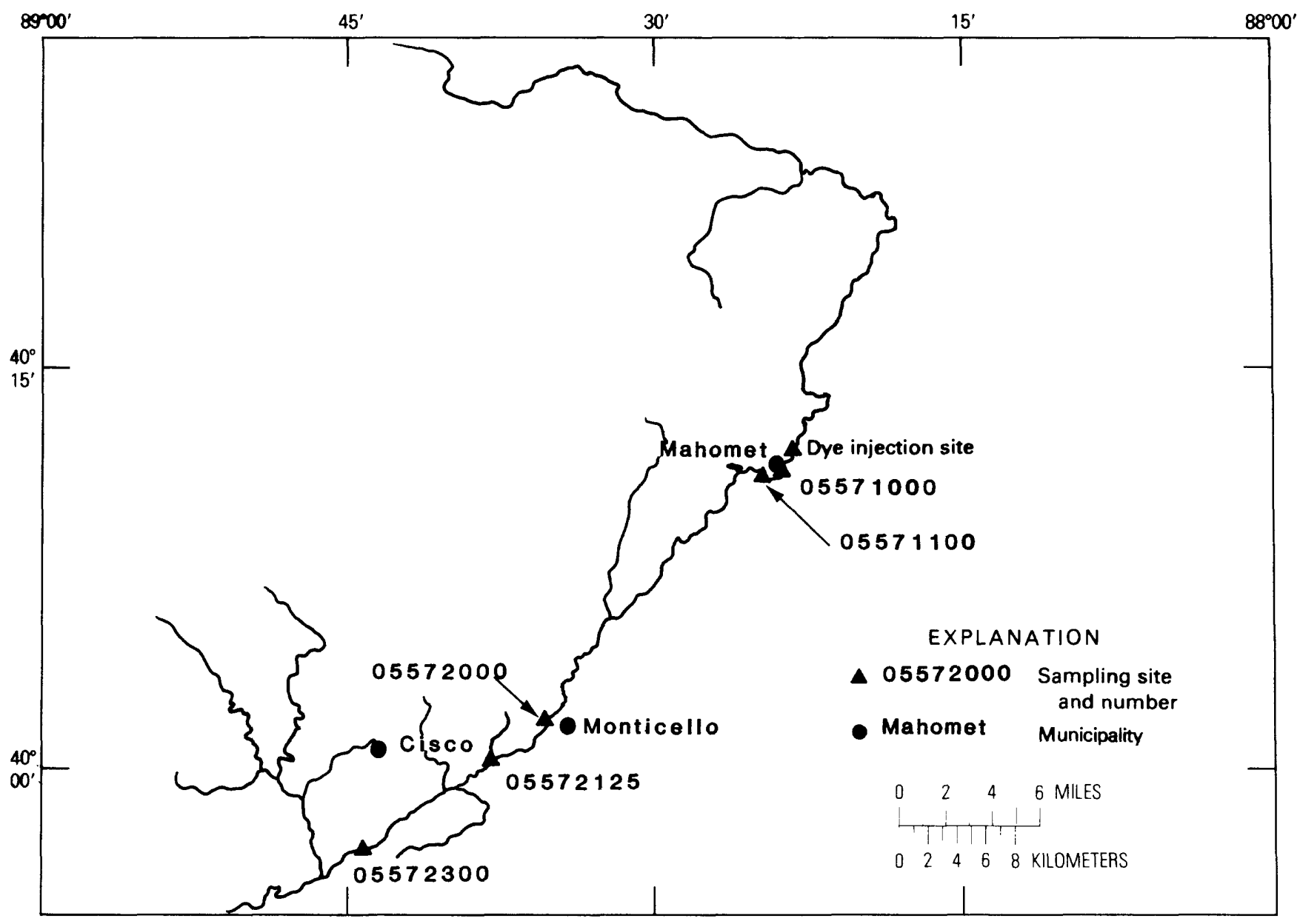

Figure 23. Location of injection and sampling sites, Sangamon River. 


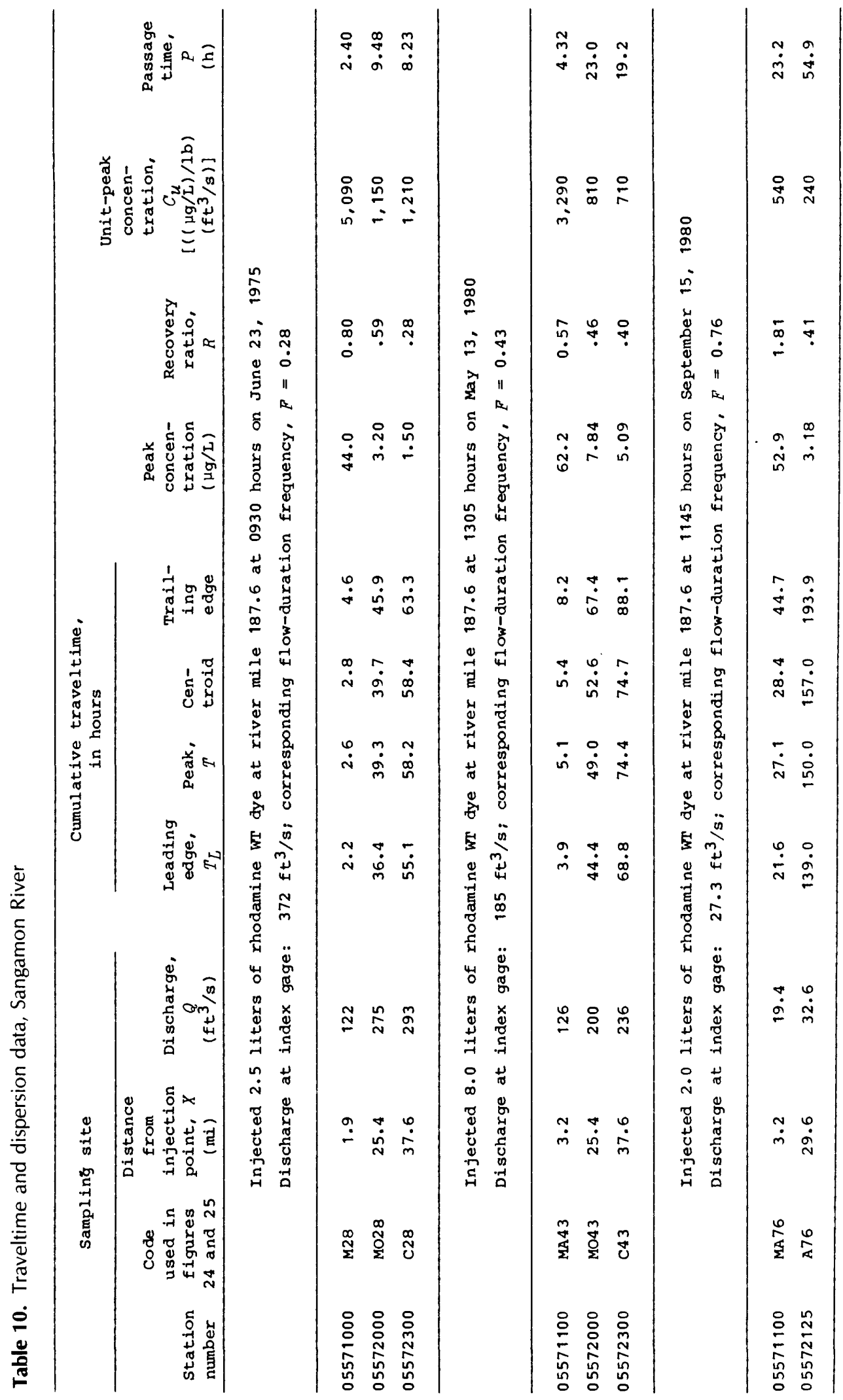


The equations for traveltime of the leading edge are

and

$$
T_{L}=30.1 X^{1.24} Q^{-0.69}
$$

$$
T_{L}=6.37 X^{1.03} F^{1.41}
$$

As in the case of traveltime of peak concentration, the equation that uses flow-duration frequency has a higher standard error of estimate than does that using discharge at the sampling site.
The relation of both unit-peak concentration and passage time to traveltime for the Sangamon River (fig. 25) is strongly dependent on flow condition, and lines of equal flow-duration frequency are shown in the figure to aid in interpolation.

Dashed lines labeled "example in text" are used in the section "Application of Estimating Techniques" to illustrate the use of the graphs presented.

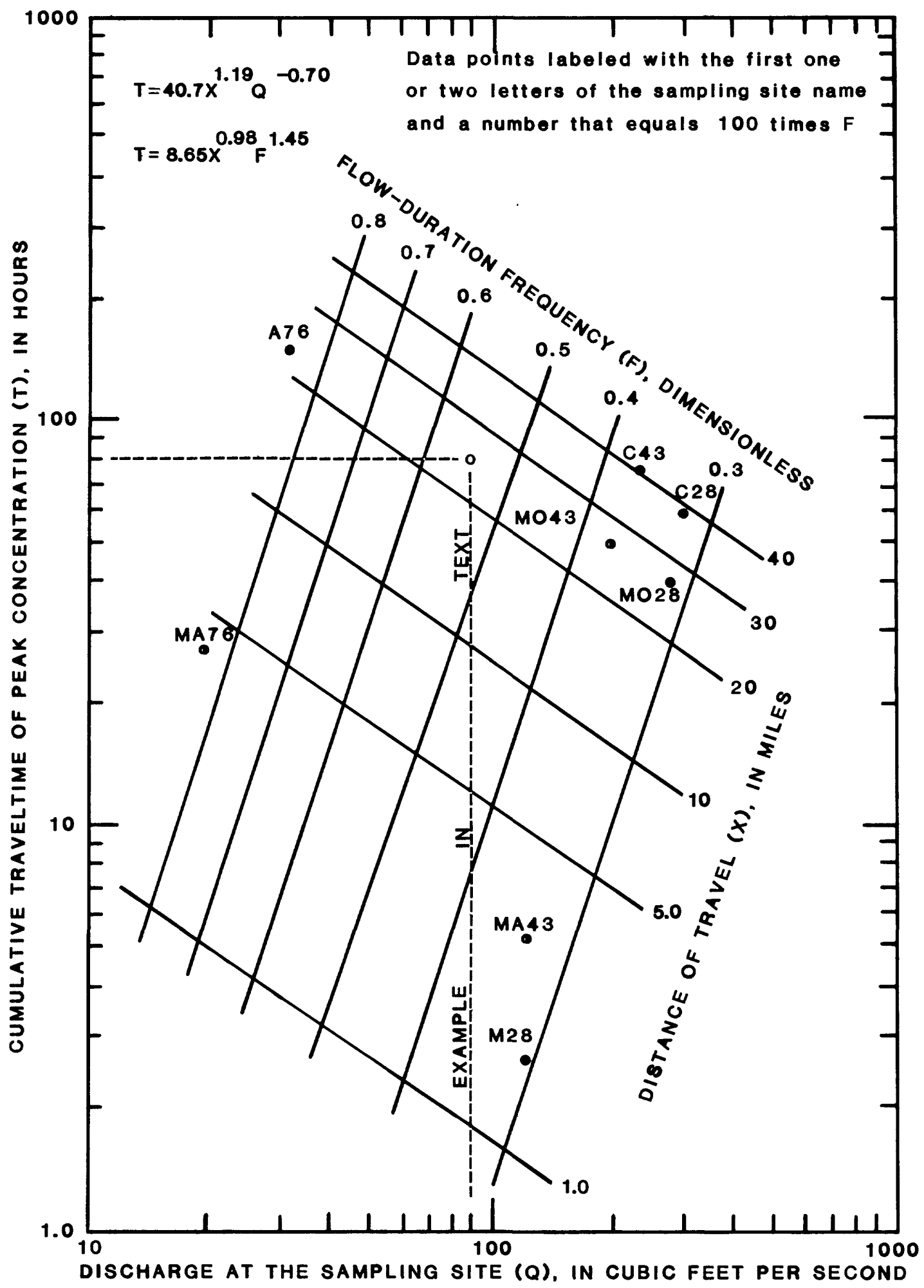




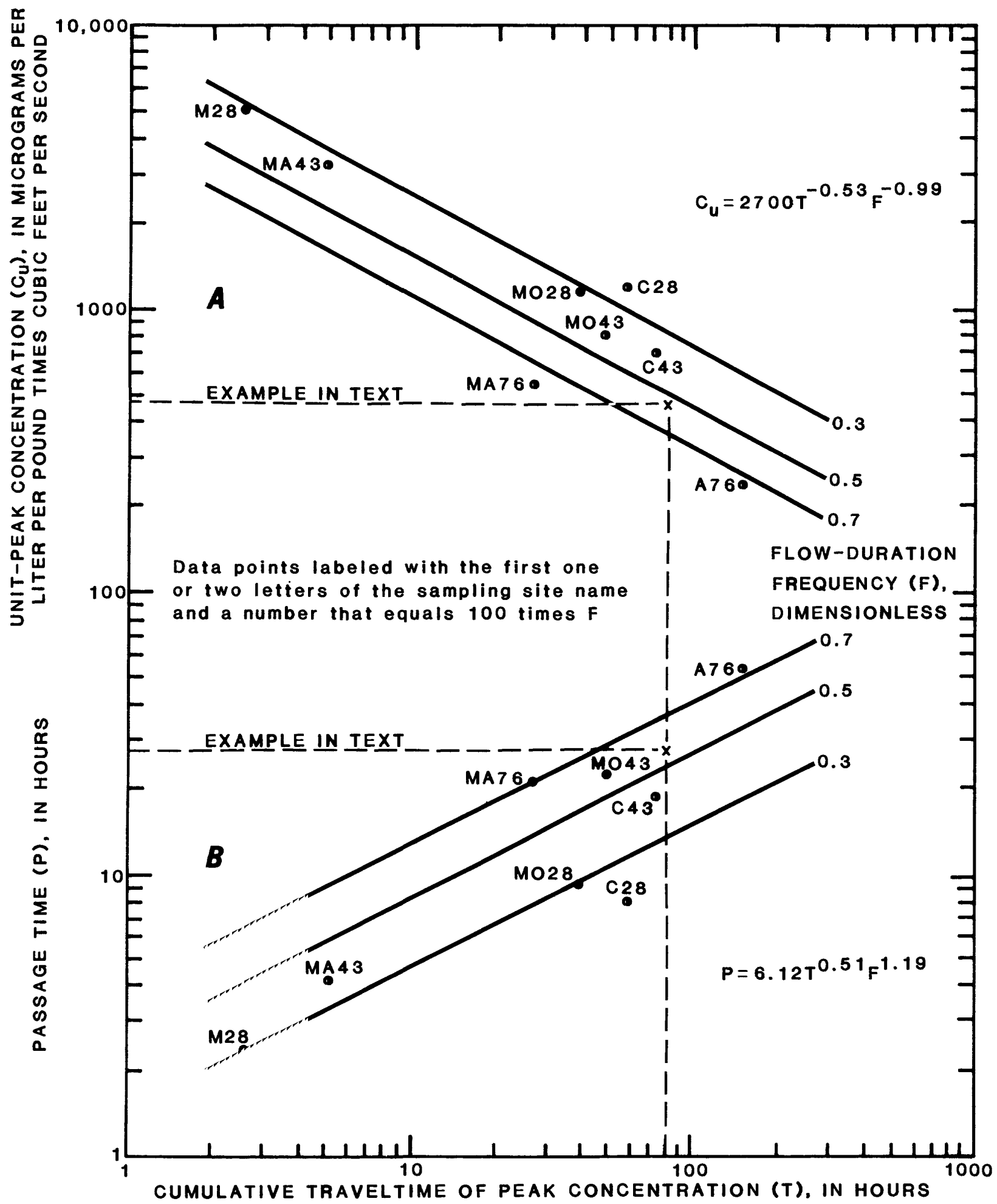

Figure 25. Relation of unit-peak concentration $(A)$ and passage time $(B)$ to traveltime of peak concentration and flow-duration frequency, Sangamon River.

$\longleftarrow$ Figure 24. Relation of traveltime of peak concentration to discharge, distance from injection, and flow-duration frequency, Sangamon River. 


\section{Shoal Creek}

Shoal Creek (figs. 1, 26) has a meandering channel with a sand bed. Gently rolling cropland surrounds the channel. Banks are moderately high and wooded. Channel slope, which averages $0.98 \mathrm{ft} / \mathrm{mi}$, decreases in the reach measured from about $1.9 \mathrm{ft} / \mathrm{mi}$ near Old Ripley to $0.76 \mathrm{ft} / \mathrm{mi}$ near

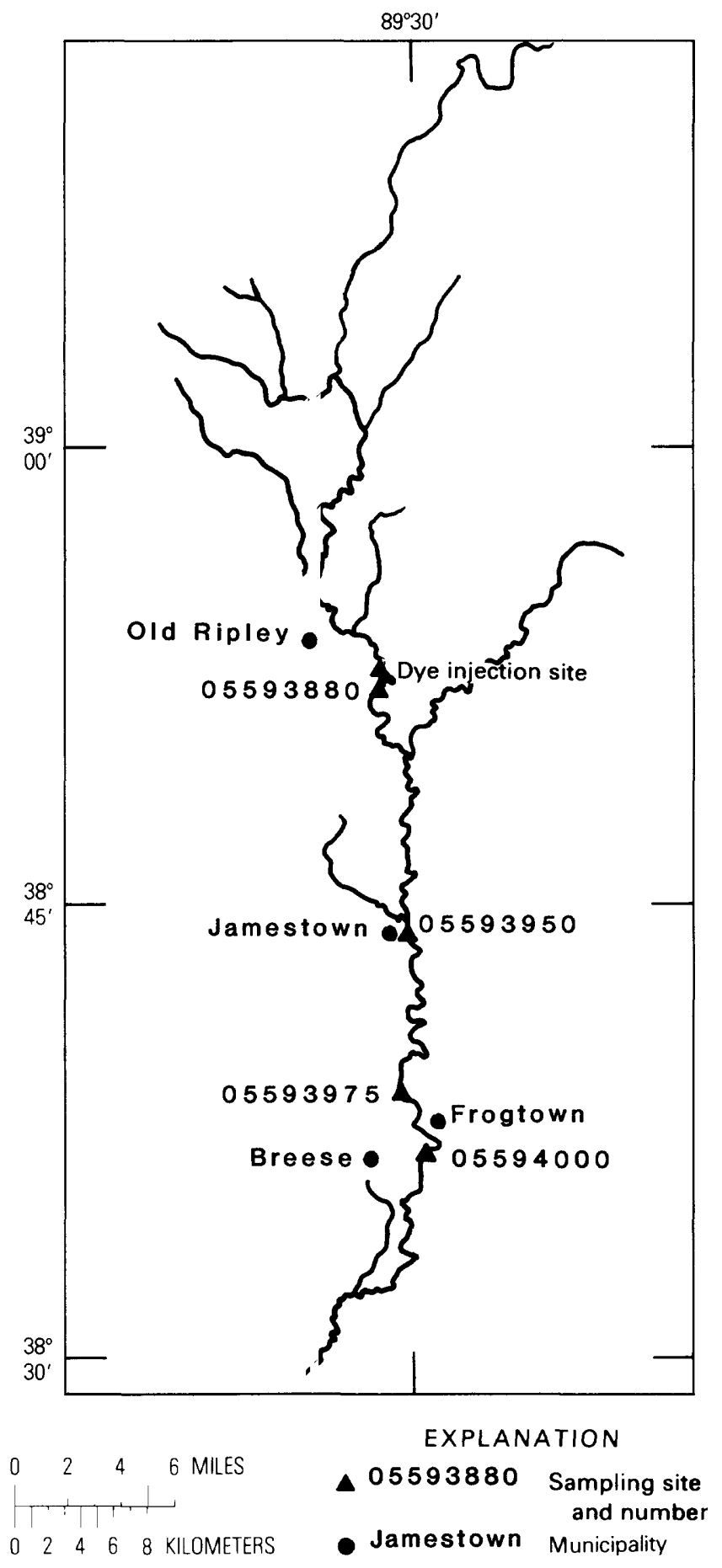

Figure 26. Location of injection and sampling sites, Shoal Creek.

42 Traveltime and Longitudinal Dispersion in Illinois Streams
Breese (fig. 26). The index gage at Breese is at the end of the measured reach.

Measurements were made on Shoal Creek at flow-duration frequencies of $0.33,0.58$, and 0.66 , corresponding to discharges at Breese of $257,72.0$, and $49.5 \mathrm{ft}^{3} / \mathrm{s}$, respectively (table 11). At the lowest flow, sand and gravel riffles were separated by pools, but depth and velocity differences between the two areas were not large. Large sand bars were exposed at that flow condition, and large areas of eddies or slow flow were observed on the downstream sides of bars, as well as below bends and logs in the channel. Pools and riffles were also observed during the highest discharge measurement, although the sand bars were largely submerged and flow velocity was more even across and along the channel than it was at the lowest flow. Conditions during the medium flow measurement were between those described above, with partially exposed sand bars exerting some influence on the flow. At low flow, a riffle below the gage site near Breese affects the flow locally. Flow velocity was much lower at the sampling site near Frogtown (fig. 26) than at other observation points at all measured flows.

Changes in discharge with time at the gage were observed during all three measurements. The measurement at the highest flow was begun after a discharge peak had passed the gage, and discharge there decreased by 79 percent during that measurement. During the measurement at $72.0 \mathrm{ft}^{3} / \mathrm{s}$, a small discharge peak passed through the reach. Peak discharge was $96.0 \mathrm{ft}^{3} / \mathrm{s}, 33$ percent above the timeweighted average discharge. A gradual increase of 20 percent in discharge was observed during the lowest flow measurement.

Estimated lengths for transverse mixing are less than the distance from injection to the first sampling site (table 2). For the measurements at the highest and lowest flows, dye was injected as two separate slugs. A single dye slug was injected at the $72.0 \mathrm{ft}^{3} / \mathrm{s}$ traveltime measurement.

Traveltime is defined by eight data points (fig. 27). These points show more scatter than those for most of the other streams discussed, and, therefore, the relation is less well defined (table 13). Regression techniques were used to define the relation for flow-duration frequencies from 0.30 to 0.70 and for distances up to $40 \mathrm{mi}$. Although the measurements at flow-duration frequencies of 0.33 and 0.58 were made during unsteady flow, as described above, the degree and type of unsteadiness differed. The deviation of the points representing samples collected at Frogtown and near Breese from the trends of points from upstream sites (fig. 27) may therefore be caused by real differences in the character of flow in those reaches and not by unsteady flow.

The equations for traveltime of the leading edge are

$$
T_{L}=8.11 X^{1.26} Q^{-0.47}
$$

and

$$
T_{L}=2.47 X^{1.20} F^{1.06} \text {. }
$$




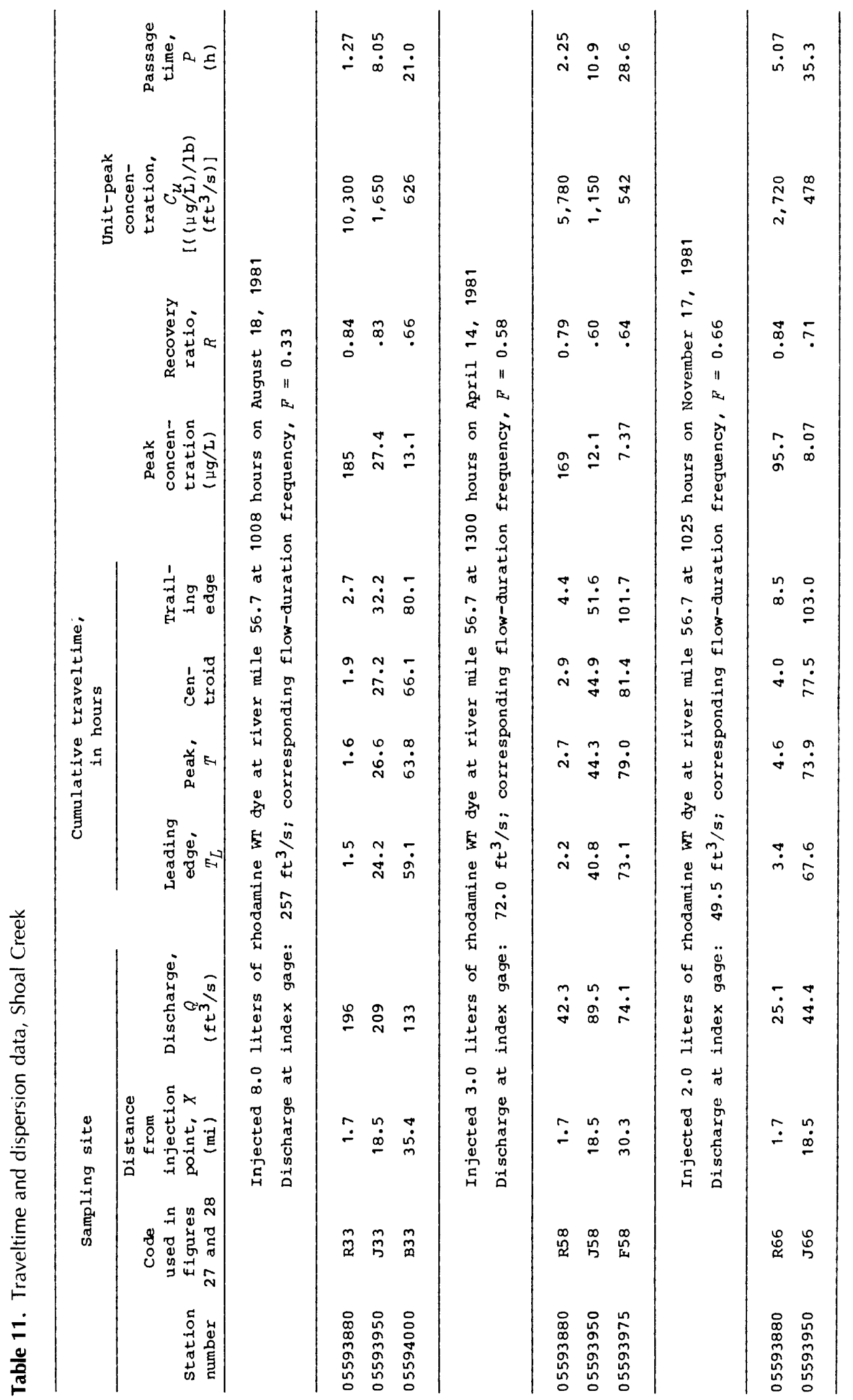


Standard errors of estimate for these two equations are equal and are very close to those of the equations for traveltime of the peak concentration (table 13).

Some indication that at low flow the relation of both unit-peak concentration and passage time to traveltime may be different than that for higher flows is given by the trend of data points in figure 28 . However, the dependence of those relations on flow-duration frequency is not great enough to justify the inclusion of that variable in an estimating equation, and an equation computed by simple linear regression is presented (fig. 28).

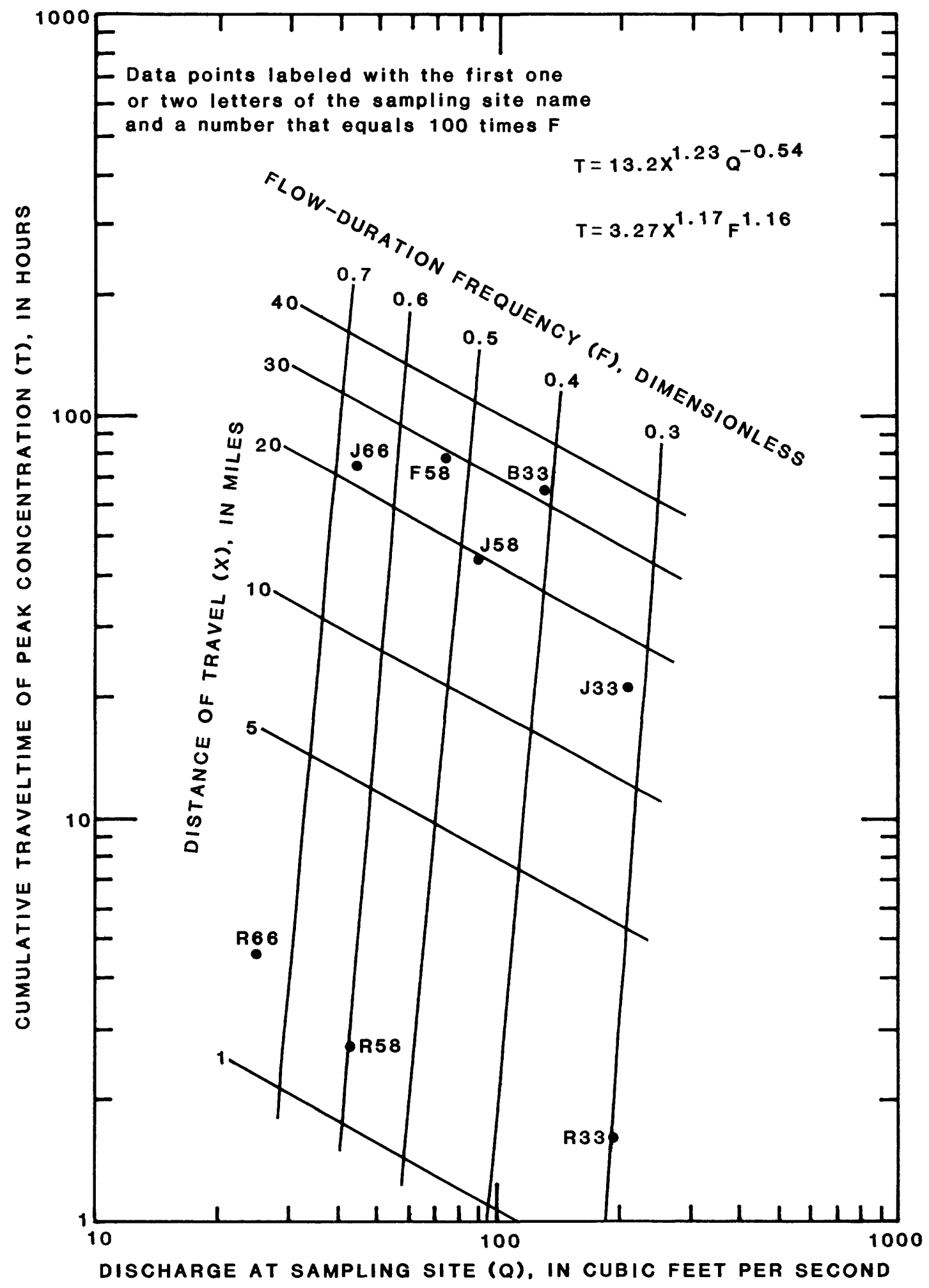




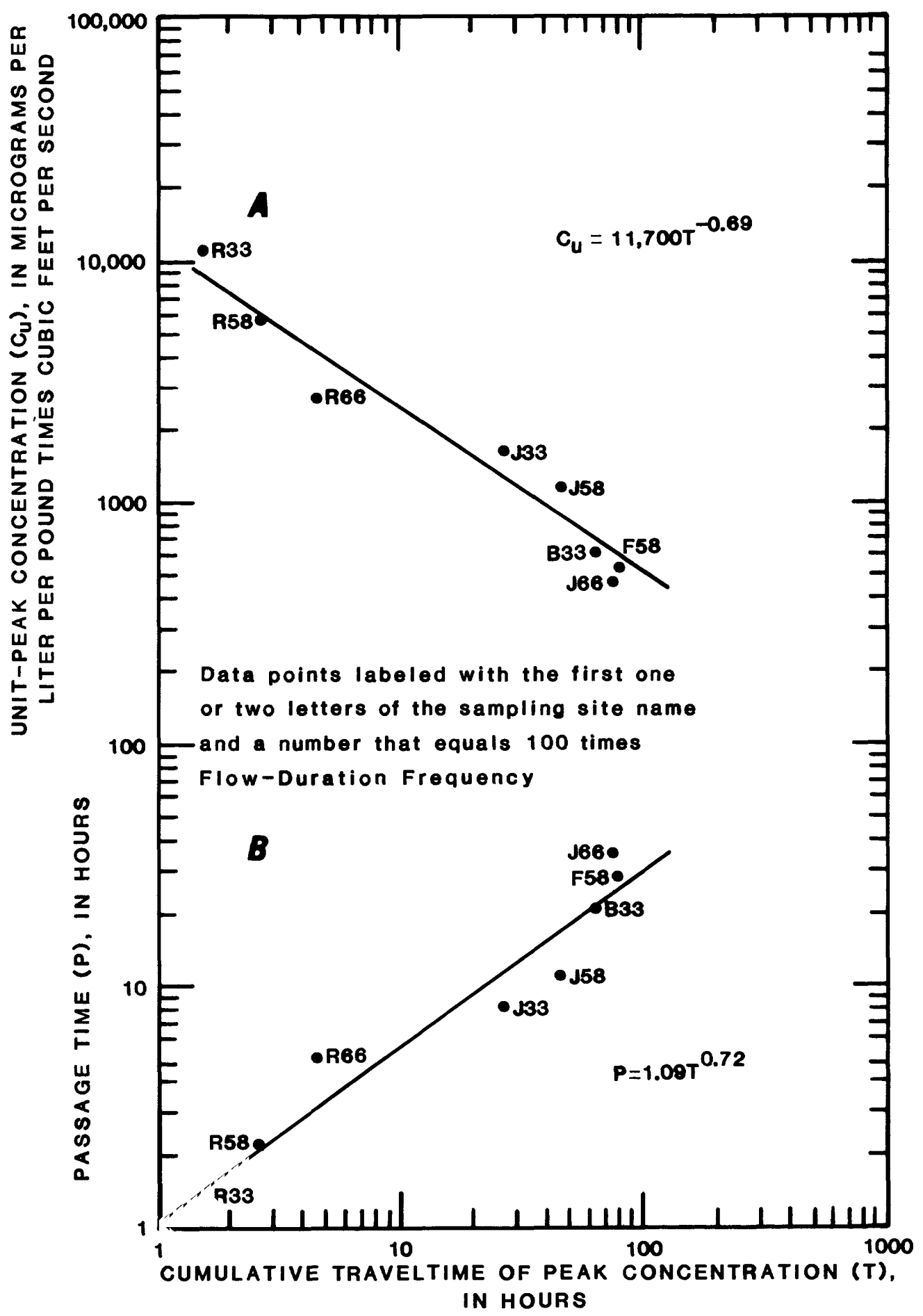

Figure 28. Relation of unit-peak concentration $(A)$ and passage time $(B)$ to traveltime of peak concentration, Shoal Creek.

$\leftarrow \quad$ Figure 27. Relation of traveltime of peak concentration to discharge, distance from injection, and flowduration frequency, Shoal Creek. 


\section{Vermilion River}

The Vermilion River (figs. 1, 29) meanders within steep, high banks that are formed of bedrock in many places in the measured reach. The streambed is composed of gravel and bedrock, with sand in pools. Channel slope is steep compared with most Illinois streams of this size and averages $5.72 \mathrm{ft} / \mathrm{mi}$ in the reach between the index gage near Leonore and the sampling site at Oglesby (fig. 29). Slope increases downstream in this reach, from $3.28 \mathrm{ft} / \mathrm{mi}$ at the gage site to about $11 \mathrm{ft} / \mathrm{mi}$ near the site at Oglesby. The gaging station near Leonore is at the upper end of the measured reach.

Measurements were made at flow-duration frequencies of $0.22,0.48$, and 0.76 , corresponding to discharges near Leonore of $1,540,495$, and $97.0 \mathrm{ft}^{3} / \mathrm{s}$, respectively (table 12). At the lowest flow condition, gravel and bedrock riffles were observed, and large gravel bars, formed at bends and obstructions, were exposed. Bars were partially submerged during the measurement at 0.48 flow-duration frequency, and flow velocities were more evenly distributed across the channel than they were at the lower flow. At the highest discharge, flow was turbulent and bars were submerged. The bridge at Oglesby was not accessible during this measurement, and a site at Lowell was used for sampling (table 1, fig. 29). The leading edge of the dye cloud

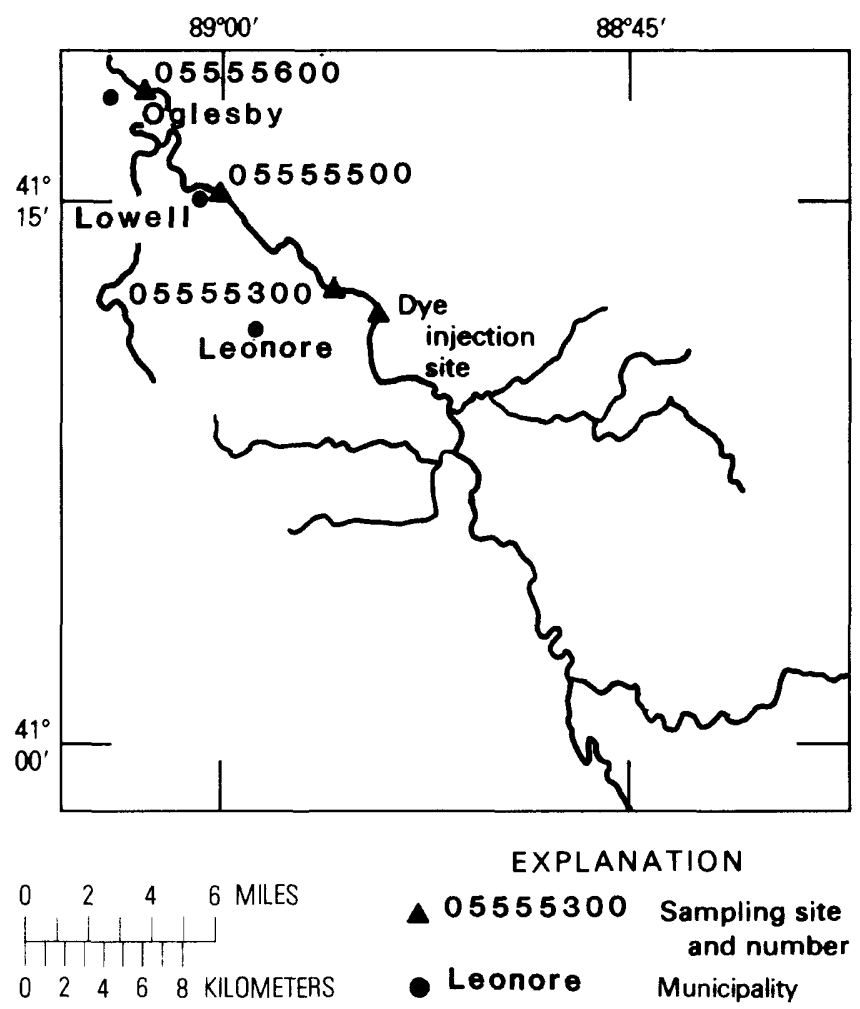

Figure 29. Location of injection and sampling siles, Vermilion River. was not sampled at Oglesby during the medium flow measurement and was determined by extrapolation from measured values.

Changes in discharge (in percent) during the measurements in the Vermilion River were smaller than those in most of the other streams. Little change in discharge occurred during either of the two highest flow measurements. Discharge gradually decreased 16 percent during the measurement at the lowest flow.

Estimated distances for transverse mixing are long compared with the distance between injection and the first sampling site (table 2). Analyses of samples collected at two locations across the channel at the first site of the highest flow measurement showed that mixing was not complete, and an average time-concentration curve was used.

Six data points from the three traveltime measurements define traveltime (fig. 30). The regression equations were used to compute equal flow-duration frequency and distance lines from flow-duration frequency of 0.20 to 0.80 and to distances of $20 \mathrm{mi}$. Fit of the equal flow-duration frequency lines to the data points is not as good as it is for other streams studied, but the regression equations developed estimate the distances well (table 13).

Equations for traveltime of the leading edge are

$$
T_{L}=28.7 X^{1.15} Q^{-0.59}
$$

and

$$
T_{L}=2.39 X^{1.15} F^{1.29} \text {. }
$$

The standard error of estimate for equation 22 is low, but that for equation 23 is relatively high (table 13).

Some dependence of unit-peak concentration on flow condition is shown in figure $31 \mathrm{~A}$. The dependence is shown even more clearly on the passage time-traveltime graph (fig. $31 B$ ). The variation of unit-peak concentration with flowduration frequency was judged to be insufficient to justify the use of a multiple regression relation for estimation of that variable, and a simple linear relation between the logarithms of the variables is presented (fig. $31 A$ ). For passage time, the dependence on flow-duration frequency was stronger and more consistent, and a multiple linear regression relation was developed from the logarithms of both flow-duration frequency and traveltime (fig. $31 B$ ). 


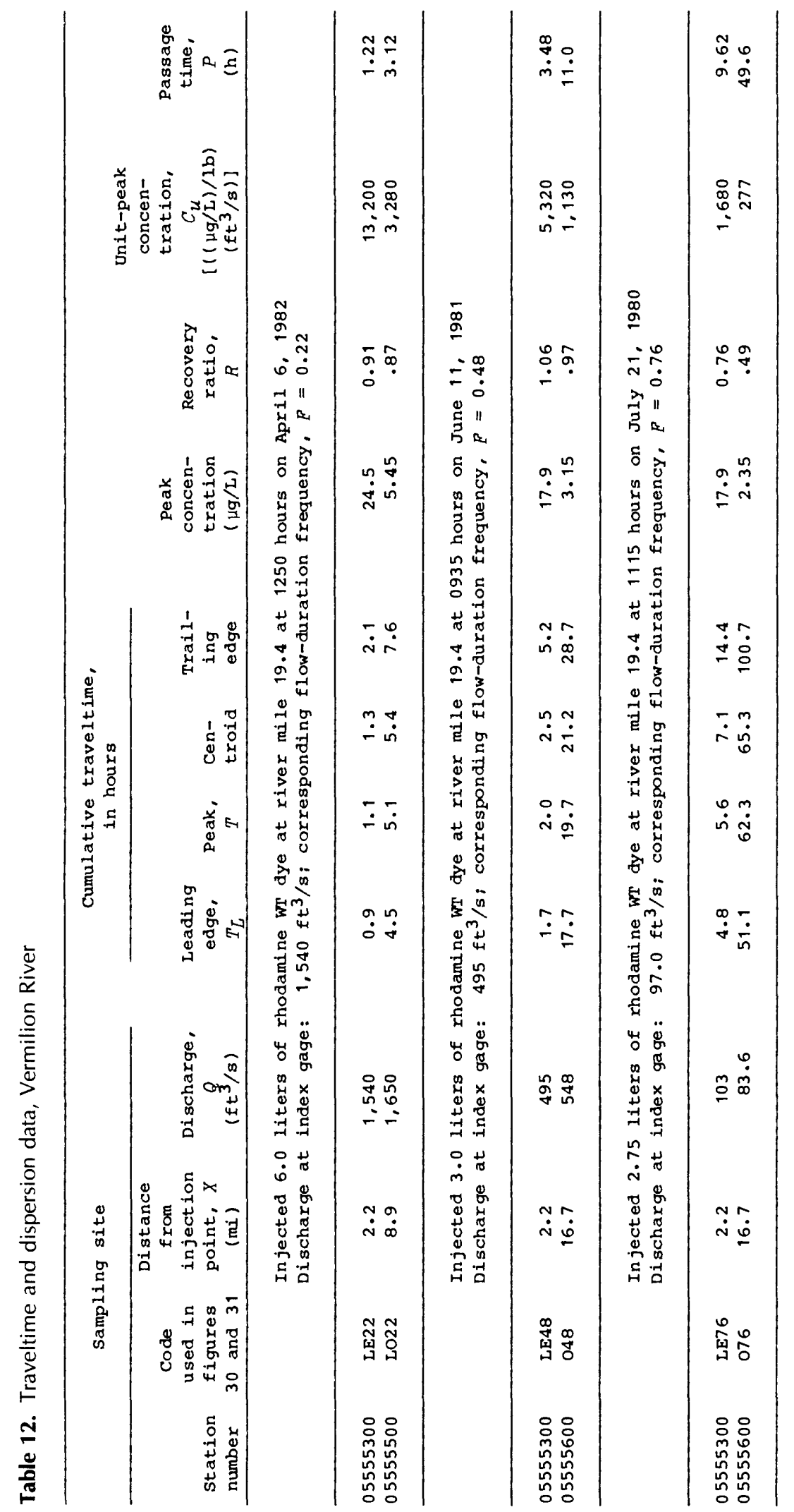




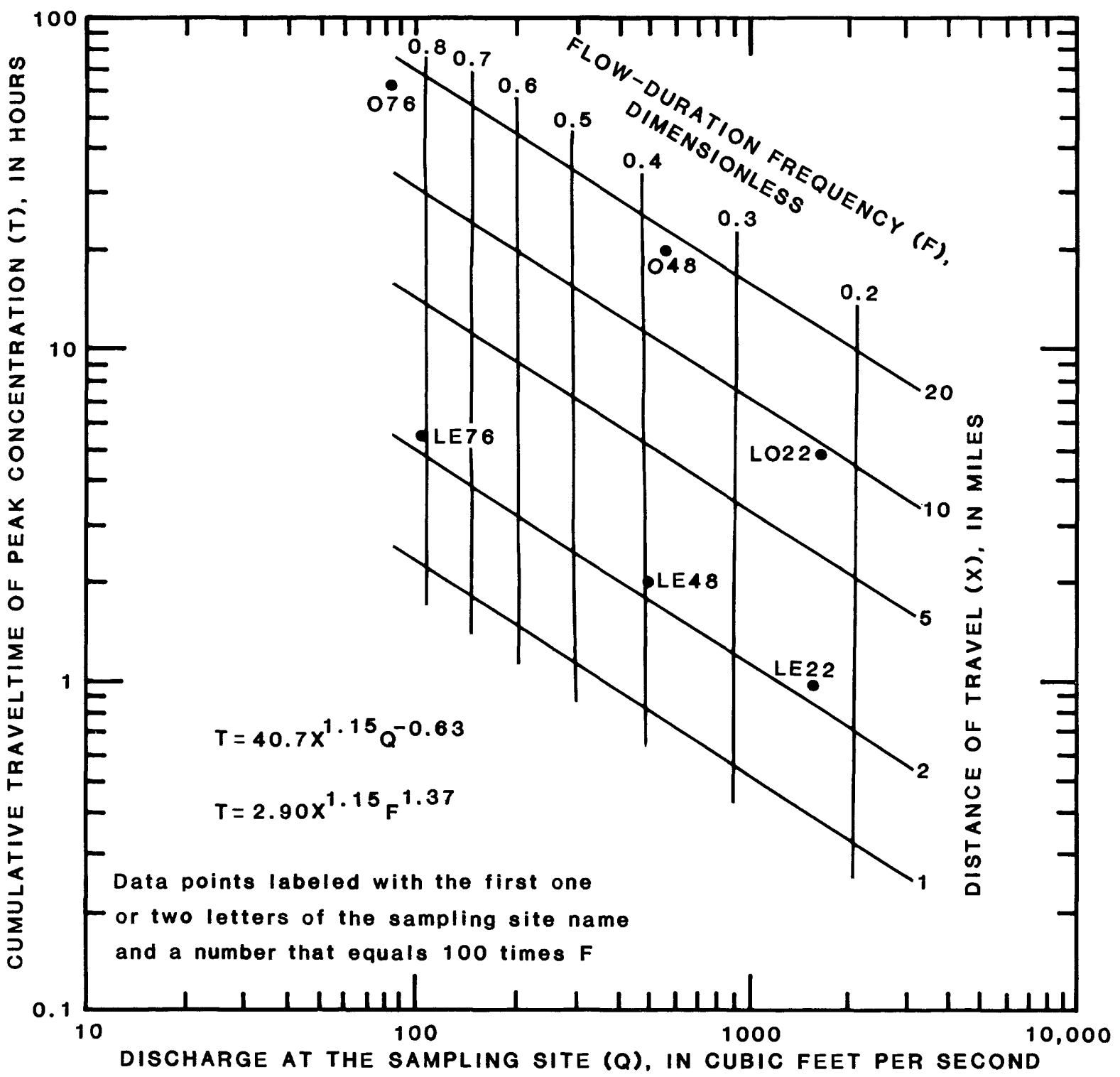

Figure 30. Relation of traveltime of peak concentration to discharge, distance from injection, and flow-duration frequency, Vermilion River. 


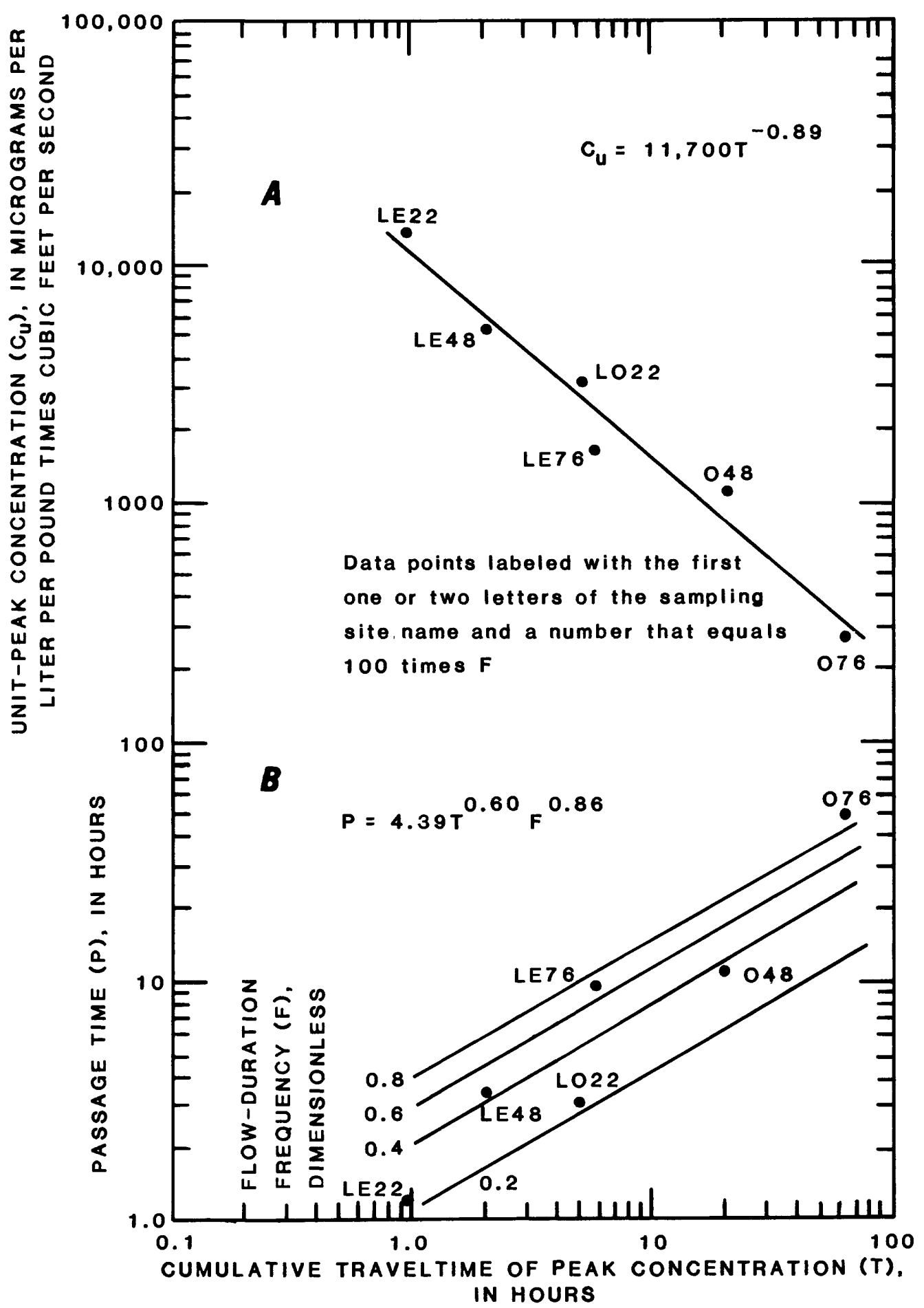

Figure 31. Relation of unit-peak concentration $(A)$ and passage time $(B)$ to traveltime of peak concentration and flow-duration frequency, Vermilion River. 


\section{EXTENSION OF RESULTS TO UNMEASURED STREAMS}

\section{Traveltime of Peak}

Flow-duration frequency, discharge at the end of the reach, and distance of travel were found to be the most significant variables in determining traveltime of peak when all measurements were pooled. Although flow-duration frequency was significant in the regression when tested at the 95-percent confidence level, it was not retained in the estimating equation. The difficulty and error incurred in estimating a value of $F$ for ungaged streams in Illinois outweighs the improvement in standard error gained (about 5 percent) by including that variable in the estimating equa- tion for traveltime of the peak concentration. The remaining variables, discharge and distance of travel, are related by the equation:

$$
T=7.85 Q^{-0.35} X^{1.09},
$$

where $T$ is in hours, $Q$ is in cubic feet per second, and $X$ is in miles. The correlation coefficient for this relation is 0.97 , and the standard error is $0.15 \log$ units or +41 and -29 percent. The relation between traveltime estimated with equation 24 and observed traveltime is shown in figure 32.

\section{Traveltime of Leading Edge}

An equation for estimating traveltime of the leading edge of the dye cloud was developed from discharge at the

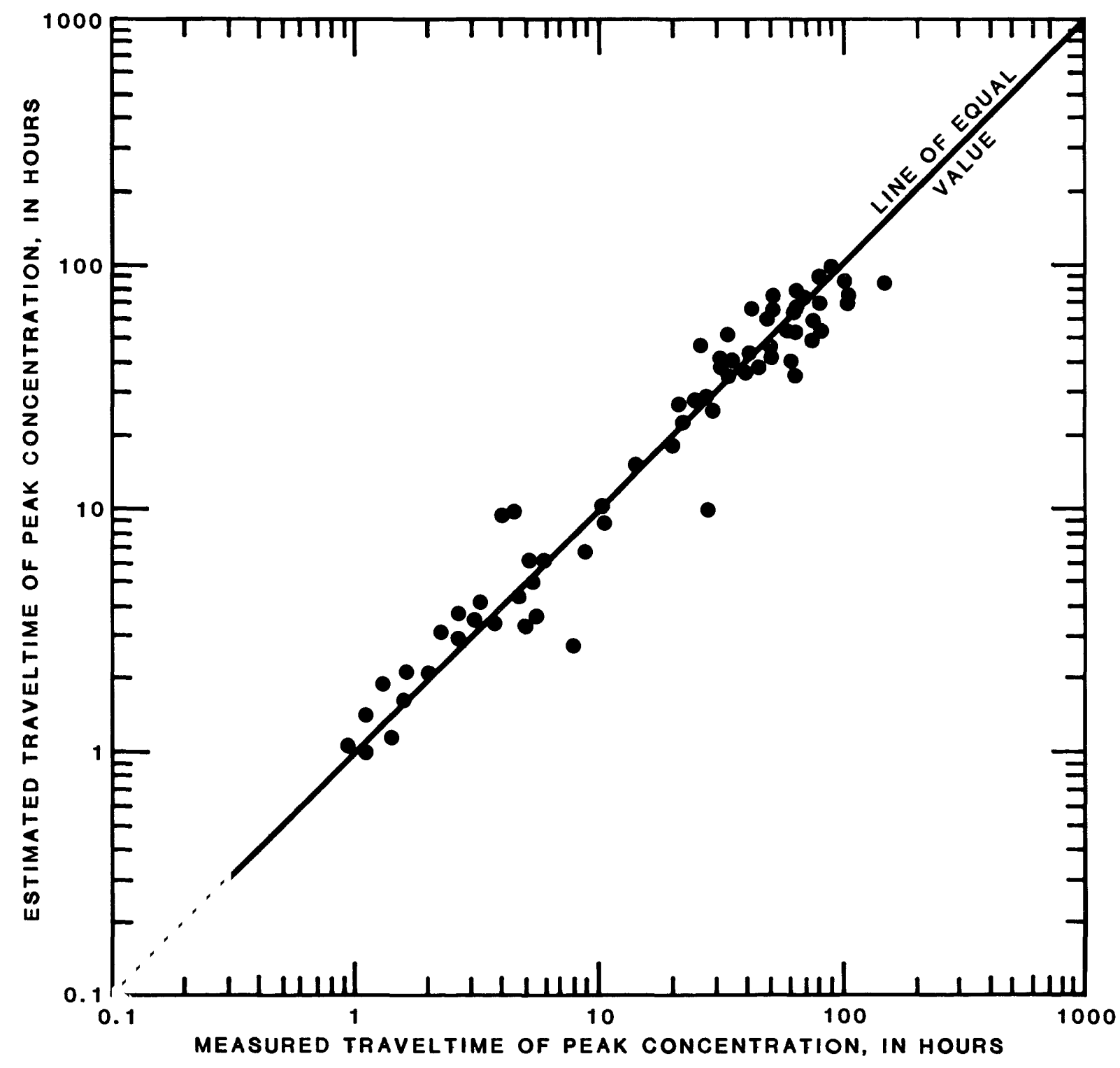

Figure 32. Relation between measured and estimated traveltime of peak concentration. 
sampling site and distance of travel for the pooled data. The relation obtained is

$$
T_{L}=5.88 Q^{-0.34} X^{1.13} .
$$

The correlation coefficient for the relation is 0.97 , and the standard error is $0.14 \log$ units or +38 and -27 percent. Flow-duration frequency was not included in this equation for the reasons given previously.

\section{Unit-Peak Concentration}

Unit-peak concentration is best determined from its relation to traveltime of peak based on flow-duration frequency of flow conditions. Although flow-duration frequency was found to be a significant factor in determining unit-peak concentration for 5 of the 10 streams described, it was not significant in the regression model developed from the pooled data. The equation for unit-peak concentration computed by linear regression from all data is

$$
C_{u}=10,200 T^{-0.69} \text {. }
$$

The correlation coefficient of the relation is 0.93 , and the standard error of estimate is $0.17 \log$ units or +48 and -32 percent.

A plot of all unit-peak concentration data versus traveltime of peak (fig. 33) illustrates the strong linear relation between the logarithms of the two variables, but also reveals that data points from most low-flow measurements (high flow-duration frequencies) are clustered to one side of the group. A flow-duration frequency of 0.6 was found by trial and error to best separate the two groups of points, and a separate regression equation was developed for each group (fig. 33A ). The two regression lines were found to be significantly different at the 95-percent confidence level using an F-test. Application of the F-test to the regression coefficients revealed that the slopes of the two lines were not significantly different, at that same confidence level. The equation developed for low flows ( $F$ greater than 0.6 ) is

$$
C_{u}=5,680 T^{-0.63} .
$$

The correlation coefficient of the equation is 0.90 , and the standard error is $0.16 \log$ units or +46 and -31 percent. For medium and high flows ( $F$ less than or equal to 0.6 ), the following equation best explained data:

$$
C_{u}=10,900 T^{-0.66} .
$$

The correlation coefficient of this relation is 0.96 , and the standard error is $0.12 \log$ units or +33 and -25 percent.

The standard errors given above do not include the error incurred when estimated traveltimes are used in equations 27 and 28 . To quantify that error, traveltime of the peak was estimated with equation 24 for all measured conditions and estimated traveltime was used to solve equations 27 and 28 for $C_{u}$. Unit-peak concentrations estimated in this way were then compared with observed unit-peak concentrations using regression analysis on untransformed values. The standard error of this regression is +44 and -44 percent.

\section{Passage Time}

Passage time shows a distribution similar to unit-peak concentration when plotted against traveltime of the peak (fig. 33B ). Estimating equations for passage time were developed in the same way as those for unit-peak concentration. The relation obtained from the entire data set is

$$
P=1.41 T^{0.72} \text {. }
$$

That relation has a correlation coefficient of 0.92 and a standard error of estimate of $0.20 \log$ units or +59 and -37 percent. For low flows ( $F$ greater than 0.6 ),

$$
P=2.93 T^{0.61}
$$

best describes the data. For medium and high flows ( $F$ less than or equal to 0.6 ), the equation computed is

$$
P=1.29 T^{0.70} \text {. }
$$

The correlation coefficients of the last two relations are 0.88 and 0.94 , respectively; the standard error for equation 30 is $0.18 \log$ units or +53 and -34 percent, and for equation 31 , the standard error is $0.16 \log$ units or +45 and -31 percent. For passage time, intercepts of the two regression lines also were found to be significantly different, whereas slopes were not (fig. 33B).

The standard error of estimate of passage time, using estimated traveltimes to solve equations 30 and 31 , was determined in the same way as the standard error for unitunit-peak concentration and is +40 and -40 percent.

Guidelines for use of these equations are given in the following section.

\section{APPLICATION OF ESTIMATING TECHNIQUES}

\section{Examples}

Application of the estimating techniques is illustrated below using hypothetical situations for both measured and unmeasured streams.

Example 1.- Suppose that approximately 100 pounds of toxic material are spilled into the Sangamon River. Estimates of traveltime to Monticello, a community 24.1 mi downstream of the spill (Healy, 1979b), and of peak 


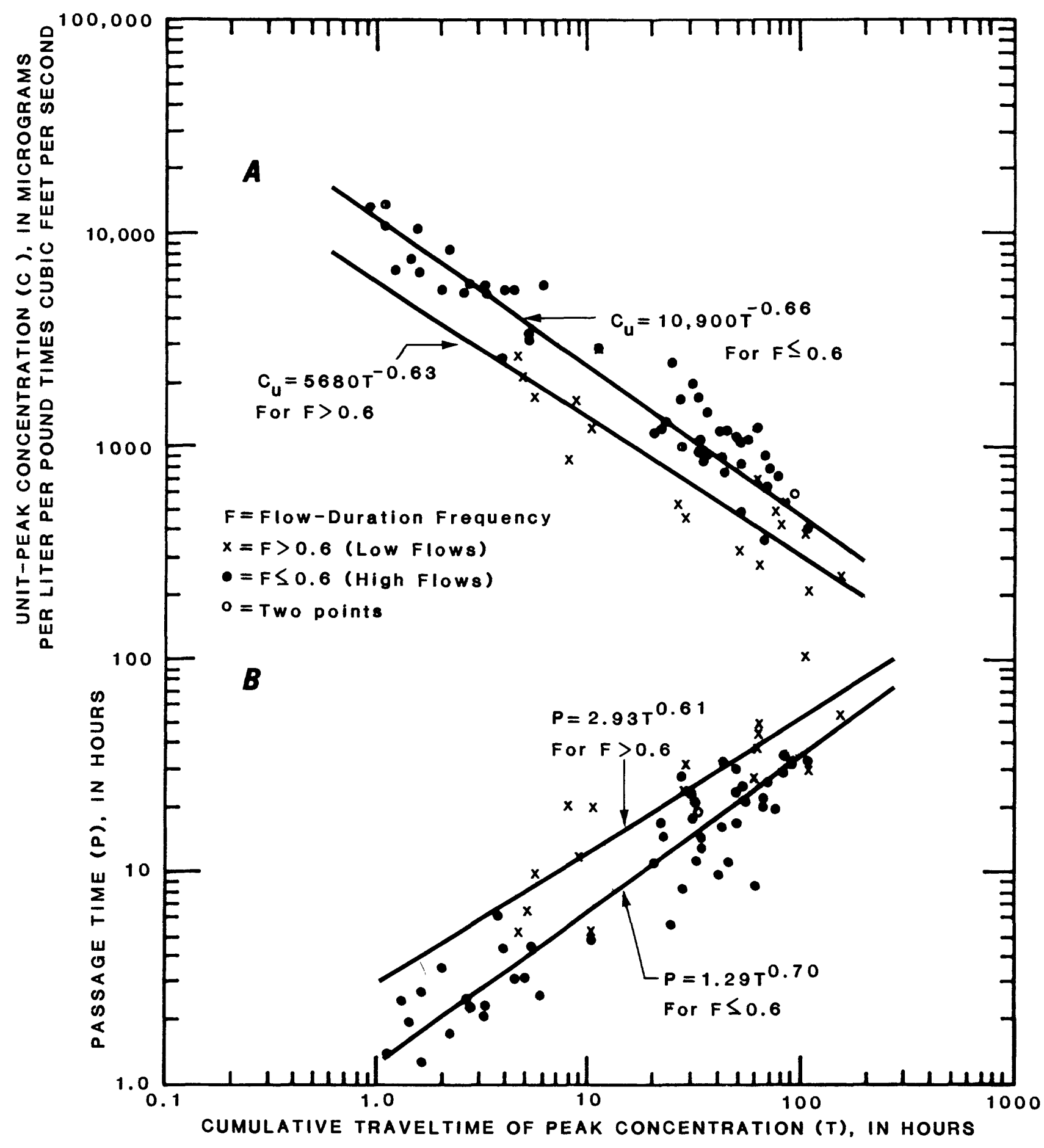

Figure 33. Relation of unit-peak concentration $(A)$ and passage time $(B)$ to traveltime of peak concentration and flowduration frequency, for all measured streams. 
concentration and passage time at that site are needed to plan response tactics. River stage at Monticello is found by reading the gage at Monticello, and discharge is found to be $90 \mathrm{ft}^{3} / \mathrm{s}$ from the existing stage-discharge relation at the gaging station. This discharge is equaled or exceeded 55 percent of the time $(F=0.55)$, as found from the flowduration curve developed for the gaging station. With figure 24 , traveltime is estimated graphically, for a discharge of 90 $\mathrm{ft}^{3} / \mathrm{s}$ and a travel distance of $24.1 \mathrm{mi}$, to be about 80 hours. The same value of traveltime is estimated graphically from figure 24 for a flow-duration frequency of 0.55 and a distance of $24.1 \mathrm{mi}$.

If traveltime is estimated using the regression equations presented in figure 24 , slightly different results will be obtained from the two equations. For example, the traveltime estimated in terms of travel distance and discharge is

$$
\begin{aligned}
T & =40.7 X^{1.19} Q^{-0.70} \\
& =40.7(24.1)^{1.19}(90)^{-0.70} \\
& =77 \text { hours, }
\end{aligned}
$$

and in terms of travel distance and flow-duration frequency is

$$
\begin{aligned}
T & =8.65 X^{0.98} F^{1.45} \\
& =8.65(24.1)^{0.98}(0.55)^{1.45} \\
& =82 \text { hours. }
\end{aligned}
$$

The difference is within the error of the estimate.

The equations for traveltime of the leading edge are used to estimate the time to first arrival of the contaminant at the site. Using equation 18 ,

$$
\begin{aligned}
T_{L} & =30.1 X^{1.24} Q^{-0.69} \\
& =30.1(24.1)^{1.24}(90)^{-0.69} \\
& =70 \text { hours, }
\end{aligned}
$$

and using equation 19 ,

$$
\begin{aligned}
T_{L} & =6.37 X^{1.03} F^{1.41} \\
& =6.37(24.1)^{1.03}(0.55)^{1.41} \\
& =73 \text { hours. }
\end{aligned}
$$

Unit-peak concentration estimated graphically from figure $25 A$ using a traveltime of 80 hours is about 480 $[(\mu \mathrm{g} / \mathrm{L}) / \mathrm{lb}]\left(\mathrm{ft}^{3} / \mathrm{s}\right)$. The equation on that figure gives an estimated unit-peak concentration of

$$
\begin{aligned}
C_{u} & =2,700 T^{-0.53} F^{-0.99} \\
& =2,700(80)^{-0.53}(0.55)^{-0.99} \\
& =478[(\mu \mathrm{g} / \mathrm{L}) / \mathrm{lb}]\left(\mathrm{ft}^{3} / \mathrm{s}\right) .
\end{aligned}
$$

The estimated peak concentration for a conservative solute is computed by multiplying the estimated unit-peak concen- tration by the pounds of substance spilled (100) and dividing by the discharge at the site of interest $\left(90 \mathrm{ft}^{3} / \mathrm{s}\right)$. In this case, using a $C_{u}$ of $478[(\mu \mathrm{g} / \mathrm{L}) / \mathrm{lb}]\left(\mathrm{ft}^{3} / \mathrm{s}\right)$, peak concentration is estimated to be about $530 \mu \mathrm{g} / \mathrm{L}$.

Passage time past the gage at Monticello is estimated graphically from figure $25 B$ to be 28 hours and from the equation given in the figure to be

$$
\begin{aligned}
P & =6.12 T^{0.51} F^{1.19} \\
& =6.12(80)^{0.51}(0.55)^{1.19} \\
& =28 \text { hours. }
\end{aligned}
$$

Example 2 .-For planning purposes, it is of interest to know the traveltime and mixing characteristics of a 30.5mile reach of upstream of a gaging station at both low and high flow conditions. At a flow-duration frequency of 0.75 , the discharge at the gage is $67 \mathrm{ft}^{3} / \mathrm{s}$, and at a flow-duration frequency of 0.25 is $720 \mathrm{ft}^{3} / \mathrm{s}$. Because no traveltime measurements have been made on this river, the equations developed for unmeasured streams must be used. For the lower flow condition, traveltime is estimated with equation 24 to be

$$
\begin{aligned}
T & =7.85 Q^{-0.35} X^{1.09} \\
& =7.85(67)^{-0.35}(30.5)^{1.09} \\
& =75 \text { hours, }
\end{aligned}
$$

and for the higher flow to be

$$
\begin{aligned}
T & =7.85 Q^{-0.35} X^{1.09} \\
& =7.85(720)^{-0.35}(30.5)^{1.09} \\
& =33 \text { hours. }
\end{aligned}
$$

Traveltime of the leading edge at the lower flow is estimated with equation 25 to be

$$
\begin{aligned}
T_{L} & =5.88 Q^{-0.34} X^{1.13} \\
& =5.88(67)^{-0.34}(30.5)^{1.13} \\
& =67 \text { hours, }
\end{aligned}
$$

and for the higher flow to be

$$
\begin{aligned}
T_{L} & =5.88 Q^{-0.34} X^{1.13} \\
& =5.88(720)^{-0.34}(30.5)^{1.13} \\
& =30 \text { hours. }
\end{aligned}
$$

Equation 27 is used to estimate unit-peak concentrations for the lower flow condition,

$$
\begin{aligned}
C_{u} & =5,680 T^{-0.63} \\
& =5,680(75)^{-0.63} \\
& =374[(\mu \mathrm{g} / \mathrm{L}) / \mathrm{lb}]\left(\mathrm{ft}^{3} / \mathrm{s}\right),
\end{aligned}
$$


and equation 28 is used for the higher flow condition,

$$
\begin{aligned}
C_{u} & =10,900 T^{-0.66} \\
& =10,900(33)^{-0.66} \\
& =1,180[(\mu \mathrm{g} / \mathrm{L}) / \mathrm{lb}]\left(\mathrm{ft}^{3} / \mathrm{s}\right) .
\end{aligned}
$$

For passage time, equation 30 is used for the lower flow condition,

$$
\begin{aligned}
P & =2.93 T^{0.61} \\
& =2.93(75)^{0.61} \\
& =41 \text { hours, }
\end{aligned}
$$

and equation 31 is used for the higher flow condition,

$$
\begin{aligned}
P & =1.29 T^{0.70} \\
& =1.29(33)^{0.70} \\
& =15 \text { hours. }
\end{aligned}
$$

\section{Limits of Application}

Traveltime and mixing relations presented in this report apply only to substances dissolved in stream water. The movement of a substance such as oil, which floats on the water surface, or a particulate substance, which may settle, cannot be estimated with these relations. Unit-peakconcentration relations give the change in concentration caused by mixing only. If other processes, such as chemical reactions or biological processes, are acting to change concentration, the relations presented in this report will not be sufficient to estimate concentration.

Data used to develop the estimating equations for unmeasured streams (eq. 24 through 31 ) were collected in reaches ranging from 5.2 to $40.3 \mathrm{mi}$ in length and from 0.7 to $11 \mathrm{ft} / \mathrm{mi}$ in slope. Flow-duration frequency ranged from 0.04 to 0.90 . Drainage area at sampling points ranged from 12.4 to $1,516 \mathrm{mi}^{2}$. Flow in all measured reaches was unregulated but represented a range in conditions from strongly developed riffles and pools to even, turbulent flow. Configurations ranged from nearly straight dredged channels to tightly meandering natural configurations. The equations presented, therefore, are applicable to a wide range of unregulated streams in Illinois having drainage areas less than about $1,500 \mathrm{mi}^{2}$.

The relations presented for measured streams are strictly applicable only to the reaches measured. They probably also can be used successfully for other reaches of the same stream that are similar in character to the measured reach. If the reach of interest is very different from the measured reach in channel geometry or other characteristics that control flow, the equations developed for unmeasured streams should be used for estimation of flow rate and dispersion. Relations for individual streams are applicable only to flows within the range of conditions measured.
All estimating equations developed in this study were computed using simple or multiple linear regression techniques. Equations derived from pooled data (eq. 24-31) were examined for violation of assumptions underlying the application of the regression technique, and all these equations do agree with the assumptions. For equations presented for individual streams (eq. 4-23 and those shown in figs. $3,4,6,7,9,10,12,13,15,16,18,19,21,22,24$, $25,27,28,30$, and 31 ), data points are too few to allow evaluation of the ability of the equations to meet the assumptions. Also, each data point used in the regressions exerts a strong influence on the result. Linear regression was used in these cases to provide a consistent, systematic method for interpolation between measured values, and the limitations of applying this technique to a very small number of data points should be recognized when the resulting equations are applied to a given situation.

Standard errors of estimate for each equation presented for the individual streams are given in table 13. Because these equations are computed from very few data points (four to nine) and most of them have two independent variables, the degrees of freedom are very small. The standard errors of estimate shown in table 13 should, therefore, be used only in conjunction with examination of the data presented in the figures as a guide to relative fit of the equations to the data.

For traveltime of the peak concentration and traveltime of the leading edge, standard errors for both equations using discharge at the sampling site and equations using flow-duration frequency are presented. For most streams, the standard error for equations with distance and discharge as independent variables is nearly equal to that for equations with distance and flow-duration frequency. However, for traveltime of the peak the equations using discharge would give better estimates for the Embarras, Sangamon, and Vermilion Rivers than the equations using flow-duration frequency, whereas the equations using flow-duration frequency yields better estimates for the Middle Fork Vermilion River. For traveltime of the leading edge, the equations using discharge give better estimates than those using flow-duration frequency for the Embarras, Sangamon, and Vermilion Rivers.

In development of the equations for passage time and unit-peak concentration for unmeasured streams, flowduration frequency was found not to be statistically significant in the relations. However, when the data set was split into two groups on the basis of flow-duration frequency, equations computed from the two groups were found to be significantly different. Flow-duration frequency is used in this analysis because it is one quantitative way of accounting for factors that vary with flow condition and that cannot be easily quantified directly. The fact that the passage timetraveltime and unit-peak concentration-traveltime relations are influenced by flow-duration frequency suggests that factors controlling longitudinal dispersion change with flow 
Table 13. Standard error of estimate for equations for traveltime of the peak concentration, traveltime of the leading edge of the dye cloud, unit-peak concentration, and passage time for individual streams

[ $X$ is distance of travel in miles, $Q$ is discharge at the sampling site in cubic feet per second, $F$ is flow-duration frequency, dimensionless, and $T$ is traveltime of the peak concentration in hours]

\begin{tabular}{|c|c|c|c|c|}
\hline \multirow[b]{2}{*}{ River } & \multirow[b]{2}{*}{ Equation } & \multicolumn{3}{|c|}{ Standard error of estimate } \\
\hline & & Log units & \multicolumn{2}{|c|}{ Percent } \\
\hline \multicolumn{5}{|c|}{ Traveltime of peak concentration } \\
\hline \multirow[t]{2}{*}{ Apple } & $T=17.4 X^{1.28} Q^{-0.61}$ & 0.06 & +15 & -13 \\
\hline & $T=4.81 X^{0.96} F^{0.45}$ & .06 & +15 & -13 \\
\hline \multirow[t]{2}{*}{ Cedar } & $T=12.3 X^{1.02} Q^{-0.46}$ & .04 & +10 & -8.8 \\
\hline & $T=5.61 X^{0.87} F^{0.48}$ & .03 & +7.2 & -6.7 \\
\hline \multirow[t]{2}{*}{ Elkhorn } & $T=6.85 X^{1.17} Q^{-0.43}$ & .03 & +7.2 & -6.7 \\
\hline & $T=4.35 X^{0.90} \quad F^{0.34}$ & .02 & +4.7 & -4.5 \\
\hline \multirow[t]{2}{*}{ Embarras } & $T=24.5 X^{1.10} Q^{-0.55}$ & .02 & +4.7 & -4.5 \\
\hline & $T=3.46 X^{1.07} F^{1.38}$ & .12 & +32 & -24 \\
\hline \multirow[t]{2}{*}{ Kaskaskia } & $T=4.37 X^{1.42} Q^{-0.52}$ & $\cdot 17$ & +48 & -32 \\
\hline & $T=8.49 X^{0.78} F^{1.16}$ & $\cdot 12$ & +32 & -24 \\
\hline \multirow[t]{2}{*}{ Mackinaw } & $T=56.2 X^{1.00} Q^{-0.64}$ & .08 & +20 & -17 \\
\hline & $T=10.0 \quad X^{0.94} F^{1.91}$ & .05 & +12 & -11 \\
\hline \multirow{2}{*}{$\begin{array}{l}\text { Middle Fork } \\
\text { Vermi lion }\end{array}$} & $T=35.5 X^{0.99} Q^{-0.63}$ & .09 & +23 & -19 \\
\hline & $T=5.85 X^{1.03} F^{1.66}$ & .02 & +4.7 & $-4 \cdot 5$ \\
\hline \multirow[t]{2}{*}{ Sangamon } & $T=40.7 X^{1.19} Q^{-0.70}$ & .09 & +23 & -19 \\
\hline & $T=8.65 X^{0.98} F^{1.45}$ & .14 & +38 & -28 \\
\hline \multirow[t]{2}{*}{ Shoal } & $T=13.2 X^{1.23} Q^{-0.54}$ & .07 & +17 & -15 \\
\hline & $T=3.27 X^{1.17} F^{1.16}$ & .08 & +20 & -17 \\
\hline \multirow[t]{2}{*}{ Vermilion } & $T=40.7 X^{1.15} Q^{-0.63}$ & .02 & +4.7 & -4.5 \\
\hline & $T=2.90 X^{1.15} F^{1.37}$ & .13 & +35 & -26 \\
\hline
\end{tabular}

Traveltime of leading edge

$\begin{array}{lllrrr}\text { Apple } & T_{L}=12.2 X^{1.33} Q^{-0.60} & 0.06 & +15 & -13 \\ T_{L} & =3.48 X^{1.02} F^{0.44} & .06 & +15 & -13 \\ \text { Cedar } & T_{L} & =9.97 X^{1.05} Q^{-0.44} & .04 & +9.6 & -8.8 \\ & T_{L} & =4.70 X^{0.89} F^{0.46} & .03 & +4.7 & -4.5\end{array}$


Table 13. Standard error of estimate for equations for traveltime of the peak concentration, traveltime of the leading edge of the dye cloud, unit-peak concentration, and passage time for individual streams-Continued

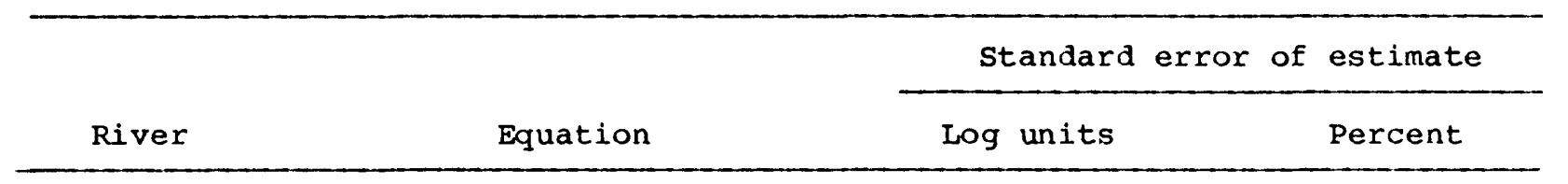

Traveltime of leading edge--Continued

\begin{tabular}{|c|c|c|c|c|}
\hline \multirow[t]{2}{*}{ Elkhorn } & $T_{L}=5.83 X^{1.20} Q^{-0.44}$ & .03 & +7.2 & -6.7 \\
\hline & $T_{L}=3.66 X^{0.93} F^{0.35}$ & .02 & +4.7 & $-4 \cdot 5$ \\
\hline \multirow[t]{2}{*}{ Embarras } & $T_{L}=17.8 X^{1.14} Q^{-0.53}$ & .03 & +7.2 & -6.7 \\
\hline & $T_{L}=2.62 X^{1.12} F^{1.34}$ & .13 & +35 & -26 \\
\hline \multirow[t]{2}{*}{ Kaskaskia } & $T_{L}=3.14 X^{1.38} Q^{-0.44}$ & .12 & +32 & -24 \\
\hline & $T_{L}=5.43 X^{0.84} F^{0.95}$ & .08 & +20 & -17 \\
\hline \multirow[t]{2}{*}{ Mackinaw } & $T_{L}=36.7 X^{1.06} Q^{-0.62}$ & .09 & +23 & -19 \\
\hline & $T_{L}=7.03 X^{1.00} F^{1.85}$ & .05 & +12 & -11 \\
\hline \multirow{2}{*}{$\begin{array}{l}\text { Middle Fork } \\
\text { Vermilion }\end{array}$} & $T_{L}=19.2 X^{0.96} Q^{-0.54}$ & .03 & +7.2 & -6.7 \\
\hline & $T_{L}=4.03 X^{1.00} E^{1.39}$ & .04 & +10 & -8.8 \\
\hline \multirow[t]{2}{*}{ Sangamon } & $T_{L}=30.1 X^{1.24} Q^{-0.69}$ & .08 & +20 & -17 \\
\hline & $T_{L}=6.37 X^{1.03} E^{1.41}$ & .15 & +41 & -29 \\
\hline \multirow[t]{2}{*}{ Shoal } & $T_{L}=8.11 X^{1.26} Q^{-0.47}$ & .08 & +20 & -17 \\
\hline & $T_{L}=2.47 X^{1.20} E^{1.06}$ & .08 & +20 & -17 \\
\hline \multirow[t]{2}{*}{ Vermilion } & $T_{L}=28.7 X^{1.15} Q^{-0.59}$ & .02 & +4.7 & -4.5 \\
\hline & $T_{L}=2.39 X^{1.15} F^{1.29}$ & .12 & +32 & -24 \\
\hline \multicolumn{5}{|c|}{ Unit-peak concentration } \\
\hline Apple & $c_{u}=7.040 T^{0.63}$ & 0.07 & +17 & -15 \\
\hline Cedar & $c_{u}=20,400 \mathrm{~T}^{-0.77}$ & .09 & +23 & -19 \\
\hline Elkhorn & $c_{u}=13,200 \mathrm{~T}-0.66$ & .05 & +12 & -11 \\
\hline Embarras & $C_{u}=5,660 T^{-0.60} F^{-0.56}$ & .05 & +12 & -11 \\
\hline Kaskaskia & $c_{u}=17,700 \mathrm{~T}^{-0.92}$ & .13 & +35 & -26 \\
\hline Mackinaw & $C_{u}=1,730 \mathrm{~T}^{0.54} \mathrm{~F}^{-1.50}$ & .08 & +20 & -17 \\
\hline $\begin{array}{l}\text { Middle Fork } \\
\text { Vermilion }\end{array}$ & $c_{u}=6,340 \mathrm{~T}^{0.80} \mathrm{~F}^{-0.71}$ & .05 & +12 & -11 \\
\hline
\end{tabular}


Table 13. Standard error of estimate for equations for traveltime of the peak concentration, traveltime of the leading edge of the dye cloud, unit-peak concentration, and passage time for individual streams-Continued

\begin{tabular}{|c|c|c|c|c|}
\hline \multirow[b]{2}{*}{ River } & \multirow[b]{2}{*}{ Equation } & \multicolumn{3}{|c|}{ Standard error of estimate } \\
\hline & & Log units & \multicolumn{2}{|c|}{ Percent } \\
\hline \multicolumn{5}{|c|}{ Unit-peak concentration--Continued } \\
\hline Sangamon & $c_{u}=2,700 T^{0.53} F^{-0.99}$ & .07 & +17 & -15 \\
\hline Shoal & $c_{u}=11,700 \mathrm{~T}-0.69$ & .12 & +32 & -24 \\
\hline Vermilion & $C_{u}=11,700 T^{0.89}$ & .13 & +35 & -26 \\
\hline \multicolumn{5}{|c|}{ Passage time } \\
\hline Apple & $P=2.22 T^{0.62}$ & 0.07 & +17 & -15 \\
\hline Cedar & $P=0.45 T^{1.02}$ & .06 & +15 & -13 \\
\hline Elkhorn & $P=0.91 T^{0.76}$ & .06 & +15 & -13 \\
\hline Embarras & $P=2.41 T^{0.61} F^{0.41}$ & .07 & +17 & -15 \\
\hline Kaskaskia & $P=1.29 T^{0.88}$ & .15 & +41 & -29 \\
\hline Mackinaw & $P=10.5 T^{0.51} F^{1.69}$ & .07 & +17 & -15 \\
\hline $\begin{array}{l}\text { Middle Fork } \\
\text { Vermilion }\end{array}$ & $P=2.60 T^{0.90} F^{1.10}$ & .03 & +7.2 & $-6 \cdot 7$ \\
\hline Sangamon & $P=6.12 T^{0.51} F^{1.19}$ & .09 & +23 & -19 \\
\hline Shoal & $P=1.09 T^{0.72}$ & .15 & +41 & -29 \\
\hline Vermilion & $P=4.39 T^{0.60} F^{0.86}$ & .08 & +20 & -17 \\
\hline
\end{tabular}

ondition. For the measured streams, the changes appear to Ke place over a narrow range of flow conditions near a 'ow-duration frequency of 0.6 . Changes could be the emersnce of bars that cause the thalweg to meander strongly and "at create eddies or stagnant zones, or they could be the ansition to nonuniform flow caused by riffles. The value J.6 found in this study probably depends strongly on the reams chosen for measurement and on the flows meatured.
Some knowledge of the character of the stream channel and flow conditions is required to successfully use the separate equations for low and high flows for an unmeasured stream. If the channel is characterized by strongly developed riffles and pools, if the thalweg meanders strongly around bars or obstructions, if there are large areas of eddies or water that appears stagnant, then the equations for low flows (eq. 27, 30) probably would give better estimates of unit-peak concentration and passage time than the equations 
computed from the entire pooled data set, even though the flow-duration frequency is less than 0.6 . If little or nothing is known about the stream for which estimates are needed, then the equations developed from the pooled data (eq. 26 for unit-peak concentration and eq. 29 for passage time) should be used, even though an estimate of flow-duration frequency is available.

\section{AVERAGE REACH VELOCITY}

Although traveltime is a useful variable for the type of application given in the examples, reach velocity is also of interest and may be needed for other applications, such as calibration of streamflow models. In a straight, uniform channel downstream of the transverse mixing distance, the velocity of the centroid, or center of mass, of the dye cloud through a reach is a measure of the average velocity of flow through that reach. Using centroid velocity measured in these streams, an estimating equation for average reach velocity was developed from the data for all measurements in the same way as the equation presented above for traveltime.

As expected from the results of the traveltime analysis, flow-duration frequency and discharge at the downstream end of the reach (discharge at the sampling site) were found to be the most significant variables for estimating reach velocity. However, in the case of reach velocity, untransformed values of the variables were found to be most suitable for the regression. Residuals from the regression on untransformed variables were found to be normally distributed about the regression line, as required for application of the linear regression model, whereas residuals from the regression on logarithms of values had a distinctly nonnormal distribution about the regression line. Because residuals of regression of logarithms of traveltime on logarithms of the independent variables were normally distributed, the transformation was used in that regression (eq. 24). Flowduration frequency was not retained in the equation for the reasons given in the section on traveltime of peak. The estimating equation obtained for reach velocity is

$$
V=0.38+0.000883 Q \text {, }
$$

where velocity is in miles per hour and discharge is in cubic feet per second. The correlation coefficient for this relation is 0.87 , and the standard error is \pm 29 percent. Figure 34 shows the relation between observed velocity and velocity estimated with equation 32 . The two points that lie above the main cluster of values represent measurements in the Apple River at the most downstream sites for the medium and high measurements. Velocities at one of these sites, near Whitton, could have been influenced by backwater from the Mississippi River during the measurement, whereas velocities at the site at Hanover may have been significantly affected by a pool upstream of the sampling site. Although these factors did not greatly influence the traveltime-discharge graphs for the Apple River (fig. 4), they appear to influence velocity significantly.

Equations for average velocity through stream reaches in 18 drainage basins in Illinois were developed from hydraulic-geometry relations by Stall and Fok (1968). They used records of discharge measurements at all gaging stations in each basin to develop a relation between discharge and velocity at a cross section. Flow-duration curves developed for each gaging station were used to express velocity $(V)$ in terms of flow-duration frequency $(F)$, rather than discharge. From data for all gages within a basin, Stall and Fok developed relations of the form $\ln V=a+b F+c U$, where $a, b$, and $c$ are constants for a basin and $U$ is stream order. Because drainage area is more easily obtained than stream order, Stall and Fok converted the equations to the form $\ln V=d+e F+f \ln D$ using the relation of stream order to drainage area $(D)$ developed for each basin. The coefficients represented by $d$, $e$, and $f$ are constants for a basin. Nine of the 10 streams for which velocity was measured as a part of the present study are within basins for which velocity equations were developed. The equations are given in table 14.

At the time of the development of these equations, no measured reach velocities were available for lllinois streams. Comparison of velocities measured in the White River in Indiana with those computed from equations, developed using the above method for that river, showed good agreement for flow-duration frequencies of 0.02 and 0.05 . At lower flows $(F=0.90)$, agreement was good in some reaches and poor in others. Later, the hydraulic-geometry relations (table 14) were used to estimate traveltime for 41 streams in Illinois (Stall and Hiestand, 1969). From comparison of estimated traveltime with traveltime measured in eight reaches. Stall and Hiestand concluded that velocities computed with the hydraulic-geometry equations would be maximum values and that computed values should be close to actual velocity at high flows.

The equations in table 14 were used to compute velocity in measured reaches of the nine streams listed for each flow-duration frequency measured. Figure 35 illustrates the relation between the computed and measured velocities. Most points on that graph lie above the equal line, supporting the conclusion that hydraulic-geometry equations yield velocities that are high relative to actual velocities. However, a plot of the difference between computed and measured velocities versus flow-duration frequency (fig. 36) does not support the suggestion that computed velocity will be closest to actual mean reach velocity for high flows.

Velocities computed with the hydraulic-geometry relations were compared with measured velocities with simple 


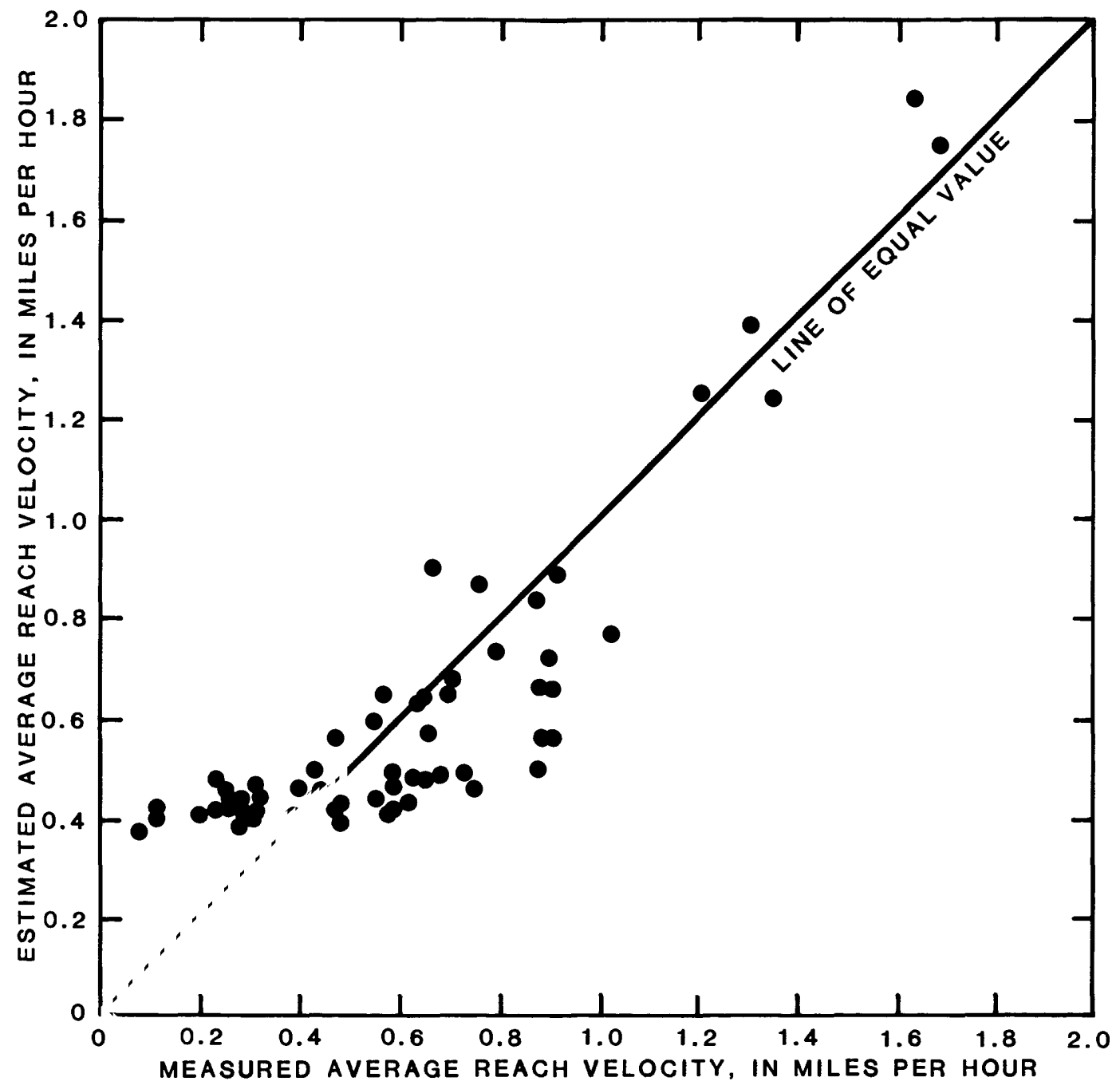

Figure 34. Relation between measured and estimated average reach velocity for measured streams.

linear regression to obtain a quantitative measure of the error incurred when using equations in table 14 to compute velocity. The regression relation computed with computed velocity as an independent variable has a standard error of \pm 40 percent. This is significantly larger than the \pm 29 percent standard error of the estimating equation based on measurements (eq. 32). Because equation 32 is a regression equation computed using least squares techniques, observed values are equally likely to be greater or less than estimated values, whereas values computed with the hydraulicgeometry relations are almost always greater than measured values.

\section{DISCUSSION OF DISPERSION CHARACTERISTICS IN MEASURED STREAMS}

Graphs that show the change in unit-peak concentration and passage time with traveltime for individual streams reveal that measured streams define two types of dispersion relations. One group of streams (Apple River, Cedar Creek, Elkhorn Creek, Kaskaskia River, and Shoal Creek) shows little or no systematic variation in dispersion with flowduration frequency. For these streams, the change in passage time and unit-peak concentration with traveltime can be adequately described by a simple linear regression model using logarithmically transformed data. In contrast, the relations between traveltime and dispersion in the Embarras, Mackinaw, Middle Fork Vermilion, Sangamon, and Vermilion Rivers vary systematically with flow-duration frequency.

Although no quantitative explanation for the presence of these two types of behavior can be presented, it should be noted that the Mackinaw and Sangamon Rivers, which show the greatest dependence of dispersion on flow-duration frequency, also underwent the greatest change in flow characteristics between the lower and higher flow measurements. Both of these streams develop long, deep pools at low flow 
Table 14. Hydraulic-geometry relations used to compute reach velocity for nine streams

[Equations, developed by Stall and Fok (1968), are of the form $\ln V=d+e F+f \ln D$, where $V$ is velocity in feet per second, $F$ is flow-duration frequency expressed as a decimal, and $D$ is drainage area in square miles]

\begin{tabular}{lccc}
\hline \multicolumn{1}{c}{ Stream } & $d$ & $e$ & $f$ \\
\hline Cedar Creek & 0.58 & -1.76 & 0.01 \\
Elkhorn Creek & .20 & -1.50 & .13 \\
Embarras River & -.92 & -1.62 & .26 \\
Kaskaskia River & -.26 & -1.28 & .14 \\
Mackinaw River & .38 & -2.26 & .09 \\
Middle Fork & -.81 & -2.20 & .29 \\
Vermilion River & & & .20 \\
Sangamon River & -1.01 & -.95 & .14 \\
Shoal Creek & -.26 & -1.28 & .17 \\
Vermilion River & -.20 & -2.19 & \\
\hline
\end{tabular}

that are largely drowned out at higher flows. Also, no measurements were made at low flow on the Apple River or on Elkhorn Creek, and a greater dependence of dispersion on flow condition might be revealed if low-flow data were included in the analysis.

For some of the streams in which unit-peak concentration and passage time vary with flow-duration frequency, data points corresponding to different flow conditions have different trends on the traveltime versus discharge graphs. However, different dispersion efficiencies at different flow conditions cannot be inferred from these trends. The number of data points is small (two to four), slope differences are not large in most cases, and unsteadiness of flows introduces an error that cannot be quantitatively evaluated. The multiple regression models developed for streams that show a dependence on flow-duration frequency smooth out these slope differences, yielding parallel flow-duration frequency lines. For the pooled data, the dependence of passage time and unit-peak concentration on flow condition was found to be best represented by forming two groups of data, using flows of 0.6 flow-duration frequency to separate the pooled data (fig. 33). Although the exponents in equations 27 and 30 and in equations 28 and 31 differ, the differences were not statistically significant. Therefore, although the magnitude of dispersion is greater at low flow, no difference in dispersion efficiency between low and high flows could be identified from these data.

Dispersion efficiency for the individual streams as described by the slopes of the traveltime of peak concentration (traveltime) component of the computed regression lines shown on figures $4,7,10,13,16,19,22,25,28$, and
31 are summarized in table 15 . The one-dimensional Fickian diffusion model predicts that unit-peak concentration will decrease as the square root of traveltime increases (that the slope of the traveltime-unit-peak-concentration relation will be -0.5) (Nordin and Sabol, 1974, p. 4-5). All measured streams have dispersion efficiencies greater than this theoretical value (table 15). The average exponent of traveltime of peak in equations developed in this study for estimating unit-peak concentration is -0.70 , which is very close to the slope of the traveltime-peak-concentration relation found by Nordin and Sabol $(1974$, p.56) in their analysis of 51 sets of dispersion data from streams nationwide. In the present study, the rate of increase of passage time with traveltime of peak concentration was found to be about the same as the rate of decrease in unit-peak concentration. The average exponent of traveltime in the passage time estimating equations is 0.71 .

The Mackinaw and Sangamon Rivers are closest to the theoretical dispersion efficiency, the Apple and Embarras Rivers and Elkhorn and Shoal Creeks disperse more efficiently, and Cedar Creek and the Kaskaskia, Middle Fork Vermilion, and Vermilion Rivers disperse the most efficiently. Although data are not available to quantitatively relate these dispersion efficiencies to channel and flow characteristics, some qualitative observations can be made. The Mackinaw and Sangamon Rivers are both large, deep streams that form very large pools at low flow. Water velocity through pools is extremely low and riffle sections are short. The streams exhibiting greater dispersion efficiencies tend to be shallower and to have coarser bed materials. Greater efficiencies also appear to be associated with large slack-water zones downstream of channel bars that are present over a range of flow conditions and with a thalweg that is sinuous within the channel because of development of bars. The relatively large dispersion efficiency of the Kaskaskia River is difficult to explain. The channel is quite straight, and the sand bed is flat and even over much of the measured reach. The stream does not undergo great changes in flow characteristics with changing flow condition.

\section{CONCLUSIONS}

Traveltime and longitudinal dispersion characteristics for many unregulated streams in Illinois can be estimated with the techniques presented in this report. The techniques were developed from an extensive set of data obtained by measurement of these characteristics on 10 streams over a range of flow conditions. Prior to this study, no measured data were available to estimate these characteristics for Illinois streams. The measured values, and the techniques developed for them, provide a means for estimating values that reflect the actual behavior of these streams better than those obtained from previously available techniques. 


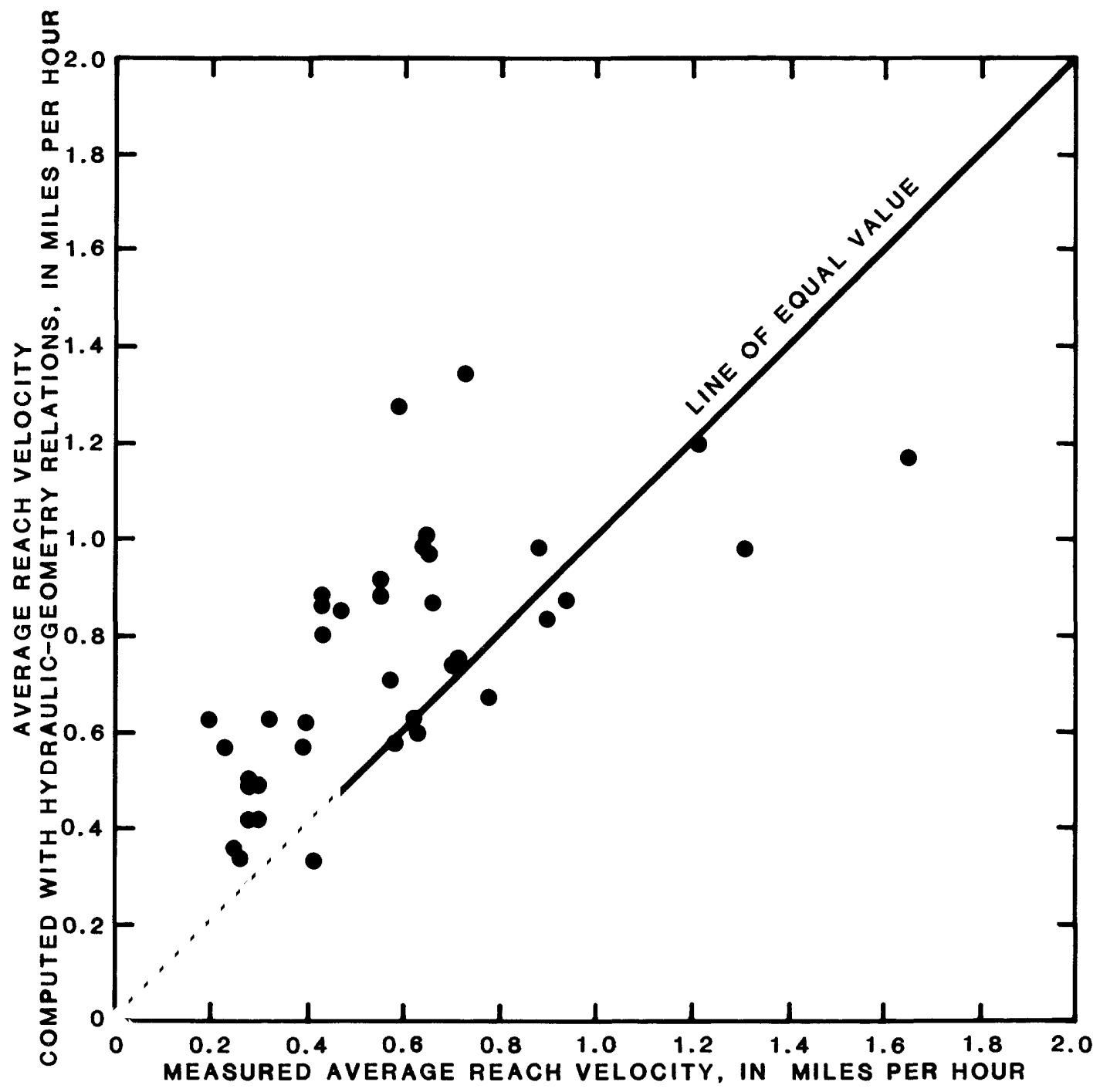

Figure 35. Relation between measured average reach velocity and reach velocity computed with hydraulic-geometry relations

For measured streams, traveltime of the peak concentration and the leading edge of the solute cloud are estimated from distance of travel and either flow-duration frequency or discharge at the site of interest. Estimating techniques based on both flow-duration frequency and discharge are presented in order to make the techniques more flexible. For unmeasured streams, although flow-duration frequency and discharge were found to explain a significant amount of the variation in the data, flow-duration frequency was not retained in the estimating equations because a sufficiently accurate value is not readily available for unmeasured streams.

Passage time and unit-peak concentration, measures of longitudinal dispersion, are estimated from traveltime of the peak concentration for both measured and unmeasured streams. For 5 of the 10 measured streams, the amount of longitudinal dispersion varies with flow-duration frequency.
To account for this variation, the technique presented for estimating passage time and unit-peak concentration consists of an equation for low flows and one for medium and high flows. The data suggest that the rate of change of longitudinal dispersion with traveltime (dispersion efficiency) does not vary significantly with flow condition. Dispersion efficiency determined from measurements is greater than predicted by the one-dimensional Fickian diffusion model.

Most of the measured average reach velocities are less than velocities estimated from the hydraulic-geometry equations developed by Stall and Fok (1968). An estimating equation developed from measured values relates average reach velocity to discharge.

Techniques of measurement and analysis used in this study are based on the assumption of steady or gradually varying flow. Discharge changed with time during almost 
Table 15. Dispersion efficiency of measured streams

\begin{tabular}{lcc}
\hline & $\begin{array}{r}\text { Rate of change of Indicated varlable } \\
\text { with traveltime } \\
\text { of peak concentration }\end{array}$ \\
\cline { 2 - 3 } \multicolumn{1}{c}{ Stream } & $\begin{array}{c}\text { Unit-peak } \\
\text { concentration, } \\
C_{\mu}\end{array}$ & $\begin{array}{c}\text { Passage } \\
\text { time, } \\
P\end{array}$ \\
\hline Apple River & -0.63 & 0.62 \\
Cedar Creek & -.77 & 1.02 \\
Elkhorn Creek & -.66 & .76 \\
Embarras River & -.60 & .61 \\
Kaskaskia River & -.92 & .88 \\
Mackinaw River & -.54 & .51 \\
Midale Fork Vermilion River & -.80 & .90 \\
Sangamon River & -.53 & .51 \\
Shoal Creek & -.69 & .72 \\
Vermilion River & -.89 & .60 \\
\hline
\end{tabular}

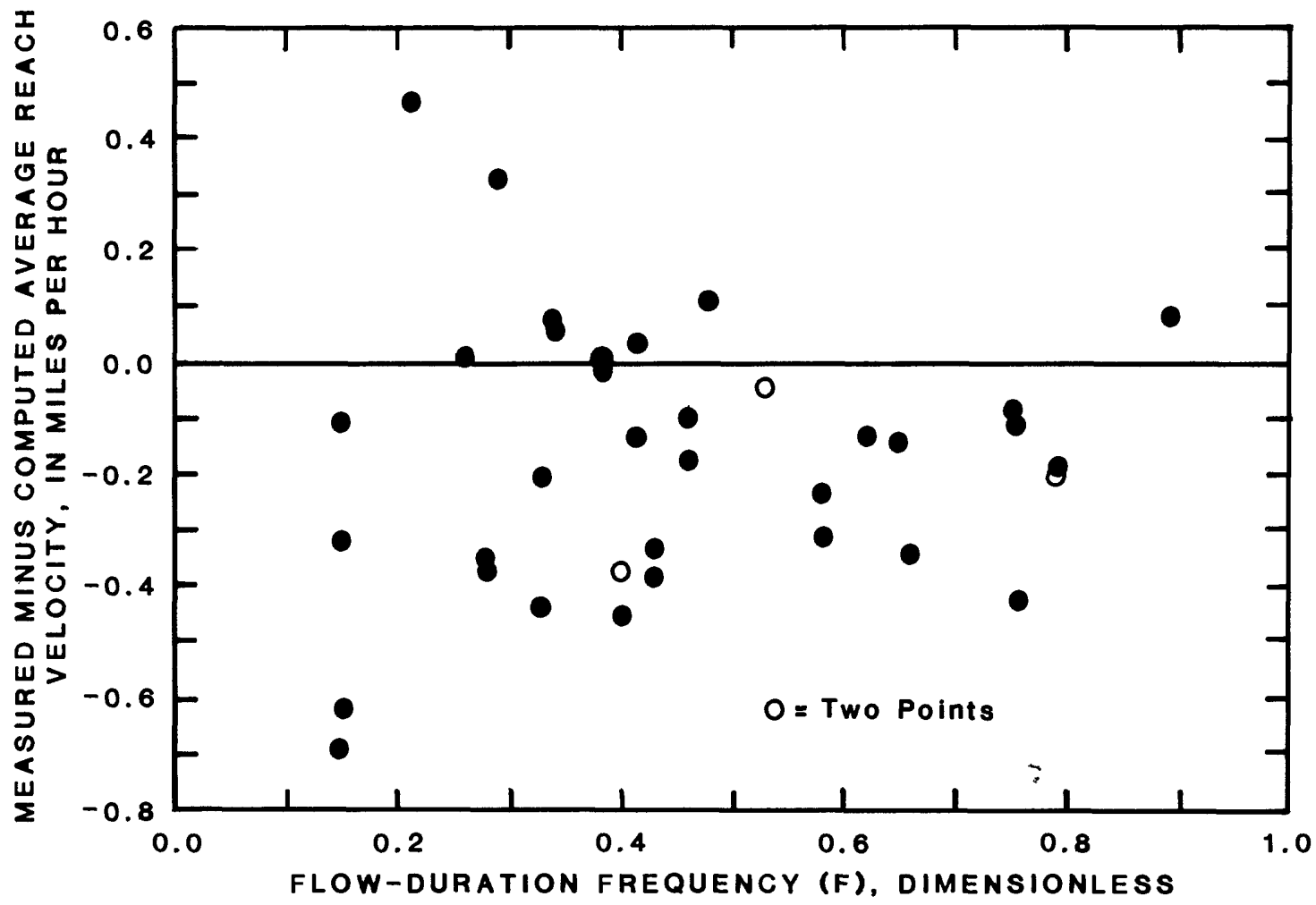

Figure 36. Relation between flow-duration frequency and the difference between measured and computed average reach velocity. 
all measurements, and changes at the index gage were greater than 20 percent for 11 of the 27 measurements. Discharge decreased during most measurements, either because the measurement was made during flow recession following storm runoff or because base-flow recession was taking place. Although the changes in discharge are larger than desirable for consideration as steady or gradually varying flow, they are probably representative of those that occur at the measured flows.

Channel slope was considered in the analysis but was found not to contribute significantly to the regression equations developed for traveltime or for average reach velocity (eq. 24 and 30). This differs from the results of both Boning (1974) and Eikenberry and Davis (1976), who found slope to be a significant variable even for pool-riffle reaches. The data suggest, however, that slope may be significant in determining traveltime in some streams (for example, in the Vermilion River) but that measurements in which slope is significant are too few to influence the regression.

\section{REFERENCES}

Boning, C. W., 1974, Generalization of stream travel rates and dispersion characteristics from time-of-travel measurements: U.S. Geological Survey Journal of Research, v. 2, p. $495-499$.

Day, T. J., 1975, Longitudinal dispersion in natural channels: Water Resources Research, v. 11, p. 909-918.

Eikenberry, S. E., and Davis, L.G., 1976, A technique for estimating the time of travel of water in Indiana streams: U.S. Geological Survey Water-Resources Investigations 76-9, $39 \mathrm{p}$.

Fischer, H. B., 1973, Longitudinal dispersion and turbulent mixing in open-channel flow: Annual Review of Fluid Mechanics, v. 5, p. 59-78.

Fischer, H. B., List, E. J., Koh, R. C. Y., Imberger, Jörg, and Brooks, N. H., 1979, Mixing in inland and coastal waters: New York, Academic Press, 483 p.
Godfrey, R. G., and Frederick, B. J., 1970, Stream dispersion at selected sites: U.S. Geological Survey Professional Paper 433K, $38 \mathrm{p}$.

Healy, R. W., 1979a, River mileages and drainage areas for Illinois streams: U.S. Geological Survey Water-Resources Investigations $79-110$, v. 1, $350 \mathrm{p}$.

1979b, River mileages and drainage areas for Illinois streams: U.S. Geological Survey Water-Resources Investigations 79-111, v. 2, 302 p.

Hubbard, E. F., Kilpatrick, F. A., Martens, L. A., Wilson, J. F., Jr., 1982, Measurement of time of travel and dispersion in streams by dye tracing: U.S. Geological Survey Techniques of Water-Resources Investigations, bk. 3, chap. A9, 44 p.

Kilpatrick, F. A., 1972, Automatic sampler for dye tracer studies: Water Resources Research, v. 8, p. 737-742.

Leopold, L. B., and Maddock, Thomas, 1953, The hydraulic geometry of stream channels and some physiographic implications: U.S. Geological Survey Professional Paper 252, $57 \mathrm{p}$.

Nordin, C. F., Jr., and Sabol, G. V., 1974, Empirical data on longitudinal dispersion in rivers: U.S. Geological Survey Water-Resources Investigations 20-74, 332 p.

Nordin, C. F., Jr., and Troutman, B. M., 1980, Longitudinal dispersion in rivers: the persistence of skewness in observed data: Water Resources Research, v. 16, p. 123-128.

Smart, P. L., and Laidlaw, I. M. S., 1977, An evaluation of some fluorescent dyes for water tracing: Water Resources Research, v. 13, p. 15-33.

Stall, J. B., and Fok, Yu-Si, 1968, Hydraulic geometry of Illinois streams: University of Illinois Water Resources Center, Research Report 5, 47 p.

Stall, J. B., and Hiestand, D. W., 1969, Provisional time of travel for Illinois streams: Illinois State Water Survey Report of Investigations $63,31 \mathrm{p}$

Wilson, J. F., 1968, Fluorometric procedures for dye tracing: U.S Geological Survey Techniques of Water-Resources Investigations, bk. 3, chap. A12, 31 p.

Yotsukura, Nobuhiro, and Cobb, E. D., 1972, Transverse diffusion of solutes in natural streams: U.S. Geological Survey Professional Paper 582-C, 19 p. 


\section{GLOSSARY}

Average reach velocity $(V)$. The mean rate of flow of water through a stream reach, in miles per hour.

Measured average reach velocity. The average reach velocity measured by the rate of movement of the center of mass of the dye cloud through a stream reach, in miles per hour.

Computed average reach velocity. The average reach velocity computed from hydraulic-geometry relations, in miles per hour.

Backwater. Water retarded in its course as compared with the normal or natural conditions of flow.

Daily mean discharge. The arithmetic mean of all instantaneous discharges available at a gaging station for a given day. At the gaging stations used in this study, gage height is recorded at 15-minute intervals and daily mean discharge is computed from the discharges that correspond to those 96 gage-height values.

Discharge. The volume of water that passes a given point in a given period of time, in cubic feet per second.

Time-weighted average discharge. The average discharge for a given period of time computed by multiplying discharge by the time interval during which that discharge prevailed, summing the resulting numbers for the entire period of time, and dividing the sum by the total number of time intervals in the period.

Dispersion. The mixing of water during flow by velocity gradients, by turbulent diffusion, and by molecular diffusion.

Dispersion efficiency. The rate of mixing of water during flow, measured in this study as the rate of decrease in unit-peak concentration of a solute with traveltime and the rate of increase in passage time of a solute past a site with traveltime.

Flow-duration curve. A curve that shows the cumulative frequency distribution of discharge at a particular site over a specified period of time.

Flow-duration frequency $(F)$. The fraction of time a given discharge at a gaging station is equaled or exceeded, determined from a flow-duration curve for that station, expressed in this report as a decimal fraction, dimensionless.
Gaging station. A particular site on a body of water where systematic observations of gage height and discharge are obtained.

Hydraulic geometry. The relation of hydraulic characteristics such as width, depth, channel slope, and roughness to discharge, expressed as a simple power function.

Index gage. A gaging station, in or near the reaches measured in this study, that provided flow-frequency data used in analysis of traveltime and dispersion data.

Injection. The introduction of the dye tracer into the stream water.

Passage time $(P)$. The time required for a solute to pass a site on a stream, measured as the time between the arrival of the solute at the site and the time corresponding to a solute concentration of 1 percent of the peak concentration on the receding limb of the time-concentration curve, in hours.

Sampling point. The location in a cross section at a sampling site where dye samples were collected.

Sampling site. A location along a stream where the cloud resulting from injection of dye was sampled.

Solute. A substance dissolved in a fluid.

Steady flow. A flow condition in which the discharge past a given point on a stream channel does not change with time.

Stream order $(U)$. A classification of streams in a drainage basin based on the pattern of confluences within the basin, dimensionless.

Transverse mixing. Mixing of water in a direction nrwinal to the mean direction of flow in a stream.

Traveltime of peak $(T)$. The time required for the peak concentration of a solute to move through a given reach of a stream, in hours.

Unit-peak concentration $\left(C_{u}\right)$. The peak concentration of a solute adjusted to remove the effects of discharge differences at sites along a stream and of different amounts of solute introduced into the stream, in micrograms per liter per pound times cubic feet per second.

Water year. A period beginning on October 1, ending on September 30 , and designated by the calendar year in which the period ends. 


\section{METRIC CONVERSION FACTORS}

For use of readers who prefer to use International System of Units (SI), conversion factors for terms used in this report are listed below:

\begin{tabular}{rll}
\hline Multiply inch-pound units & By & \multicolumn{1}{c}{ To obtain Sl units } \\
\hline mi (mile) & 1.609 & $\mathrm{~km}$ (kilometer) \\
$\mathrm{mi}^{2}$ (square mile) & 2.590 & $\mathrm{~km}^{2}$ (square kilometer) \\
$\mathrm{mi} / \mathrm{h}$ (mile per hour) & 1.609 & $\mathrm{~km} / \mathrm{h}$ (kilometer per hour) \\
$\mathrm{ft} / \mathrm{mi}$ (foot per mile) & 0.1894 & $\mathrm{~m} / \mathrm{km}$ (meter per kilometer) \\
$\mathrm{lb}$ (pound) & 0.4536 & $\mathrm{~kg}$ (kilogram) \\
$\mathrm{ft}^{3} / \mathrm{s}$ (cubic foot per second) & 0.02832 & $\mathrm{~m}^{3} / \mathrm{s} \mathrm{(cubic} \mathrm{meter} \mathrm{per} \mathrm{second)}$ \\
$\mathrm{ft}^{3}$ (cubic foot) & 28.32 & $\mathrm{~L}$ (liter) \\
\hline
\end{tabular}


